\title{
IMPACT OF LEADERS, TEAM BEHAVIORS, AND SENSE OF COMMUNITY ON INNOVATION IN CONVENTIONAL FASHION AND WEARABLE TECHNOLOGY PRODUCT DEVELOPMENT TEAMS
}

\author{
A Dissertation Presented to \\ The Faculty of the Graduate School \\ At the University of Missouri
}

\author{
In Partial Fulfillment \\ of the Requirements for the Degree \\ Doctor of Philosophy
}

by

DEEPIKA RAJ

Dr. Jung Ha-Brookshire, Dissertation Supervisor

July 2017 
(C) Copyright by Deepika Raj 2017 All Rights Reserved 


\title{
APPROVAL PAGE
}

The undersigned, appointed by the dean of the Graduate School, have examined the dissertation entitled

IMPACT OF LEADERS, TEAM BEHAVIORS, AND SENSE OF COMMUNITY ON INNOVATION IN CONVENTIONAL FASHION AND

WEARABLE TECHNOLOGY PRODUCT DEVELOPMENT TEAMS

\author{
Presented by \\ Deepika Raj \\ A candidate for the degree of \\ Doctor of Philosophy
}

And hereby certify that, in their opinion, it is worthy of acceptance.

Dr. Jung Ha-Brookshire

Dr. Pamela Norum

Dr. Kristen Morris

Dr. Hua Qin 


\section{ACKNOWLEDGMENTS}

I am thankful to my academic advisor, Dr. Jung Ha-Brookshire, for guiding me throughout the Ph.D. process. Your thoughtful remarks and constructive criticism have helped me shape this dissertation. Your confidence in me to choose and pursue an emerging topic has helped me in bringing new insights to the field of wearable technology as well as conventional fashion product development.

I would like to express my sincere thanks to Dr. Kristen Morris, Dr. Hua Qin, and Dr. Pamela Norum. Each of you has been a key source of inspiration and guidance throughout the dissertation process, as well as during my time as a doctoral student.

I am also thankful to the Center of Digital Globe for funding my dissertation. I am especially thankful to Dr. Antonie Stam for introducing many emerging topics from different disciplines such as Architecture, Journalism, and so on. The interdisciplinary mission of the program helped me in shaping this research.

I would like to thank my husband, Tarun, who was very patient with me. Three years of long distance was painful but strengthened our relationship and helped me to grow professionally. I sincerely appreciate your love and joy throughout this process. I would like to thank my mother, Indu Kumari, my father, Upendra Narayan Singh, and my brother, Ritu Raj who sacrificed a lot for my education, as well as my in-laws who supported me throughout this process.

Finally, I am grateful to all my friends at the University of Missouri. Especially, my sincere thanks and appreciation go to all graduate students of the Textile and Apparel Management department for encouraging and guiding me. 


\section{TABLE OF CONTENTS}

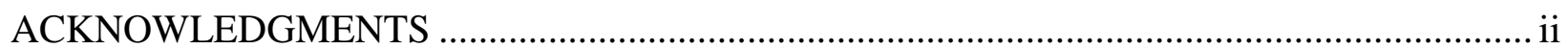

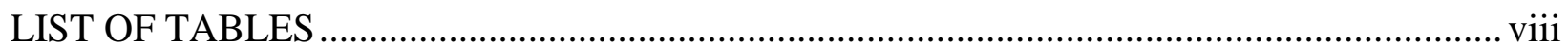

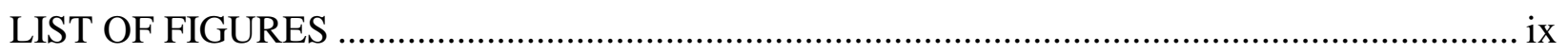

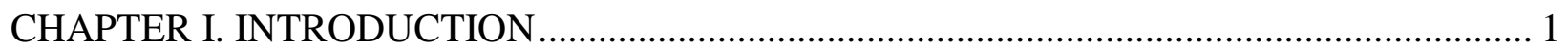

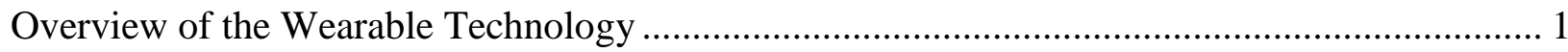

Wearable Technology and Fashion................................................................................ 2

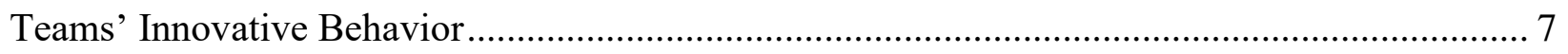

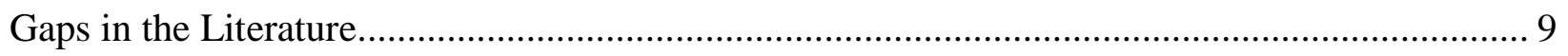

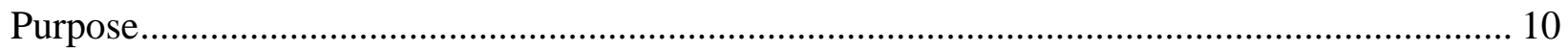

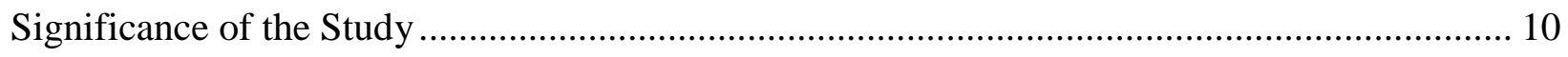

Guiding Principles and Assumptions........................................................................ 11

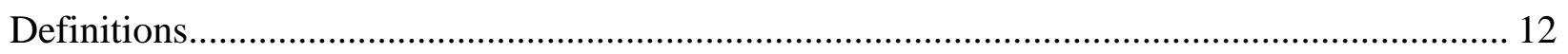

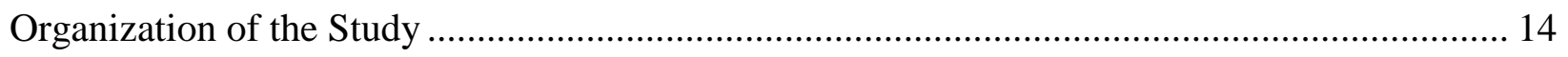

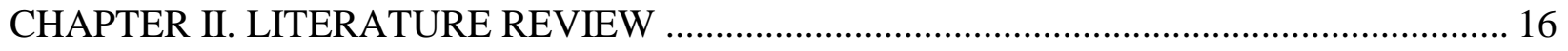

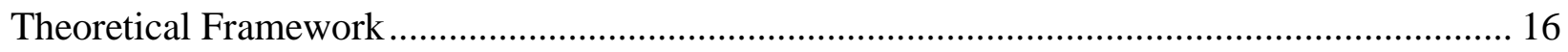

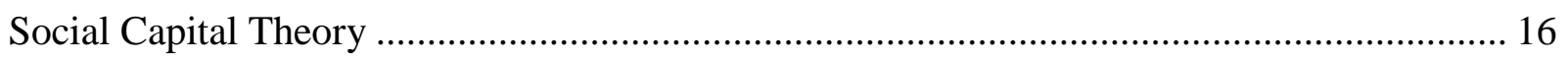

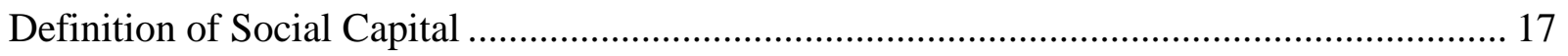

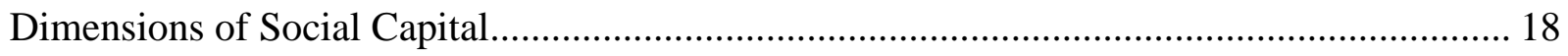




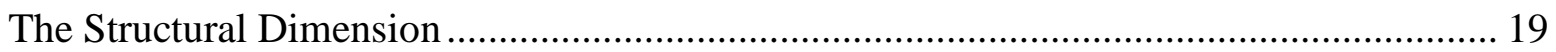

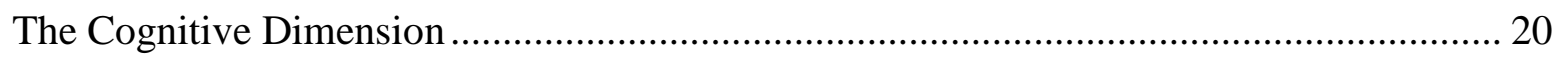

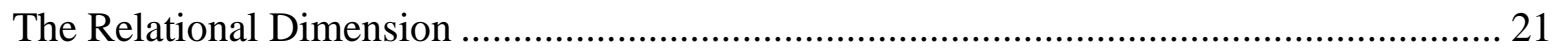

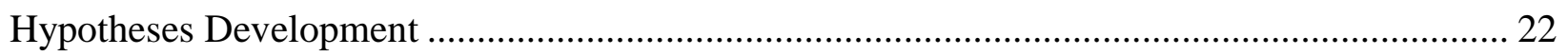

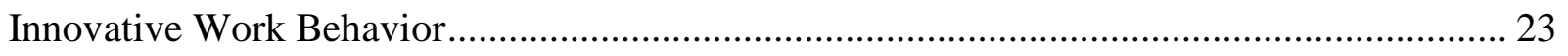

Definition of Innovative Work Behavior ......................................................................... 23

Components of Innovation Work Behavior .................................................................... 24

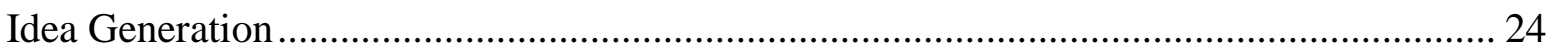

The Structural Dimension of SCT: Transformational Leadership........................................... 26

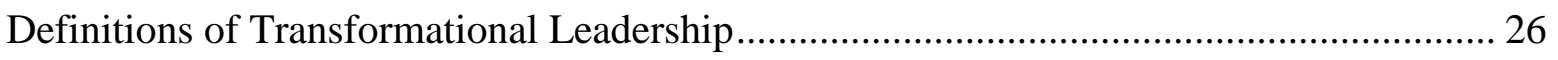

Components of Transformational Leadership .................................................................. 30

Transformational Leadership and Innovative Work Behavior ............................................. 31

Cognitive Dimension of Social Capital: Team Learning Behavior ......................................... 33

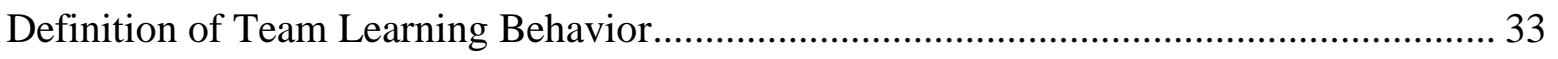

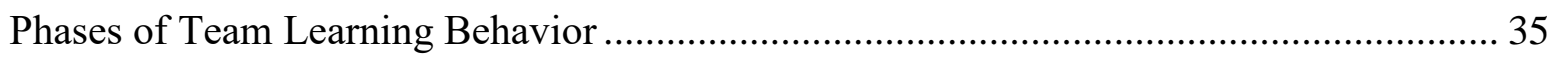

Application of Team Learning Behavior in Research ....................................................... 37

Transformational Leadership and Team Learning Behavior ................................................. 38

Relational Dimension of Social Capital: Sense of Community ……...................................... 40

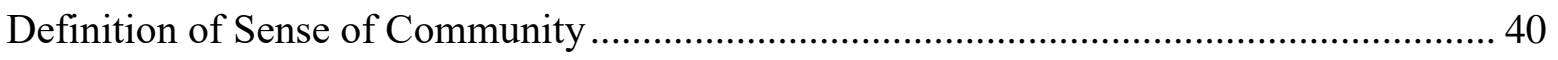

Components of Sense of Community ………………...................................................... 40 
Sense of Community and Team Learning Behavior

Team Learning Behavior and Innovative Work Behavior.......................................... 44

Difference in the Fashion and Wearable Technology Product Development Teams .............. 46

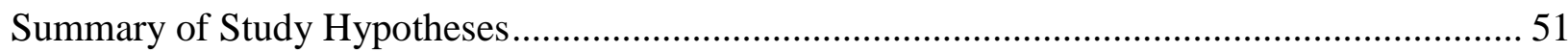

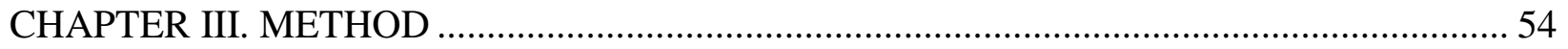

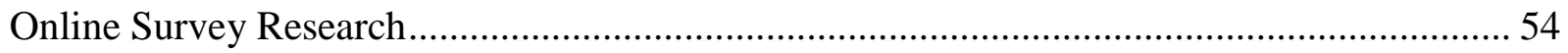

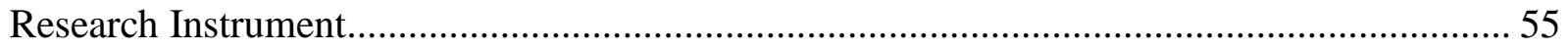

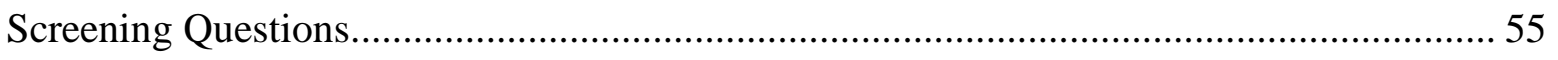

Transformational Leadership ............................................................................. 56

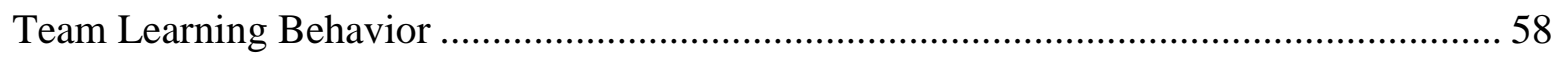

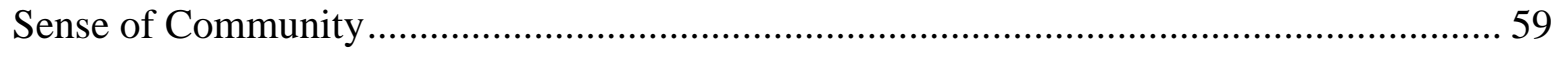

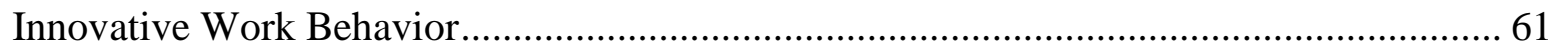

General Employment and Demographic Information............................................ 62

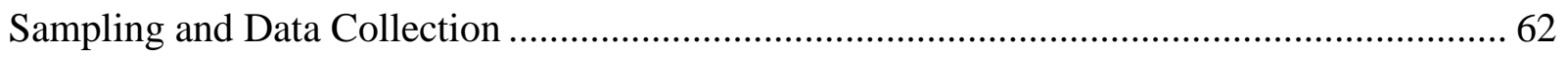

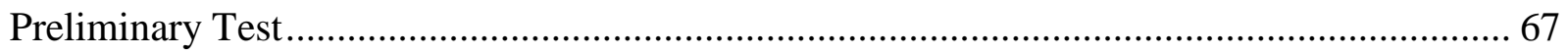

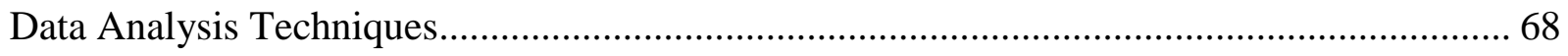

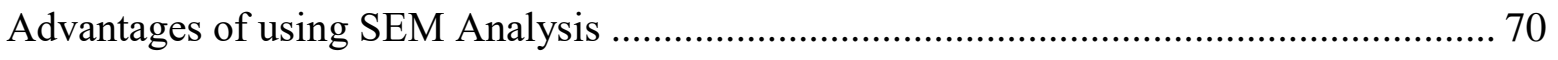

Assessing Measurement Model ...................................................................... 72

Assessing Structural Model ........................................................................... 74

CHAPTER IV. RESULT AND ANALYSIS ................................................................ 75 
Description of the Study Sample ................................................................................. 76

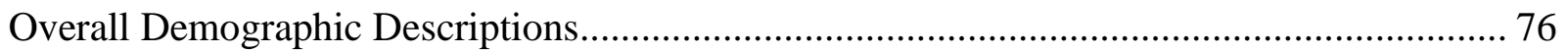

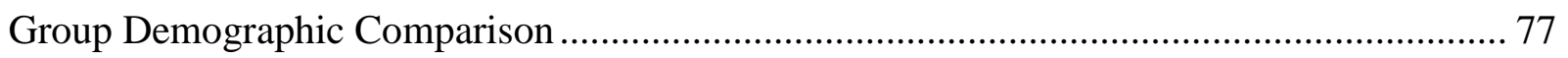

Result Analysis and Hypothesis Testing .................................................................... 81

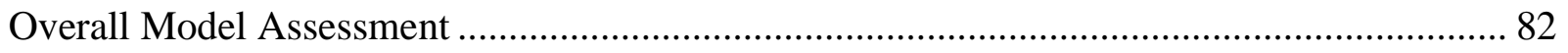

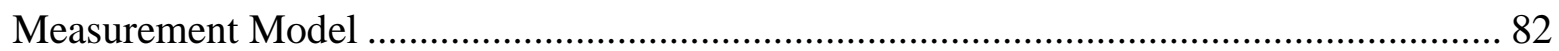

Structural Model and Hypothesis Testing...................................................................... 85

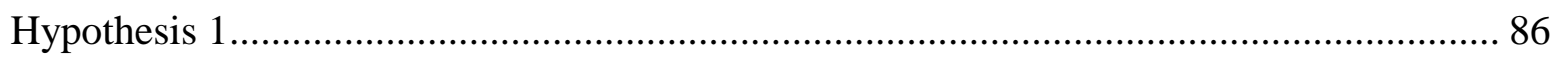

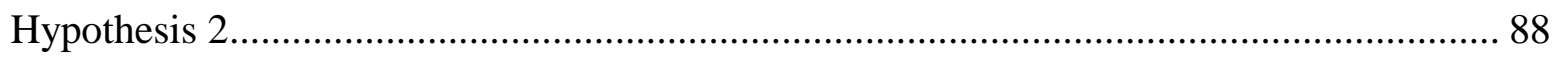

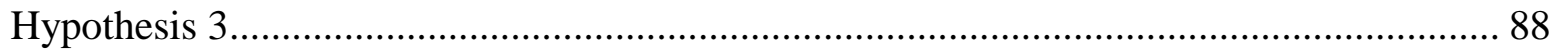

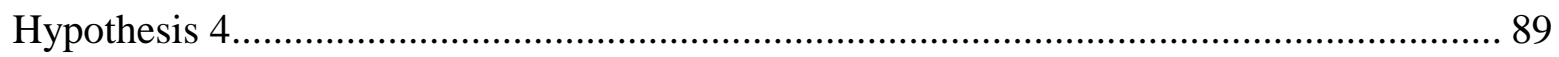

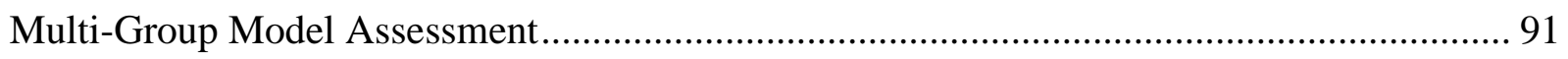

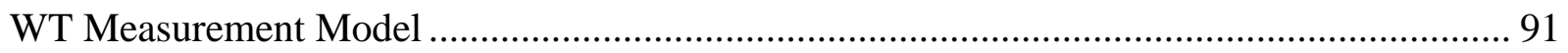

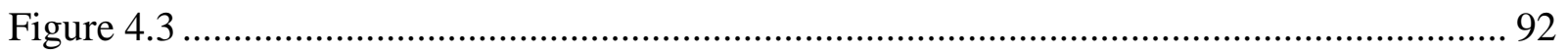

Fashion Product Development Group Measurement Model ............................................ 94

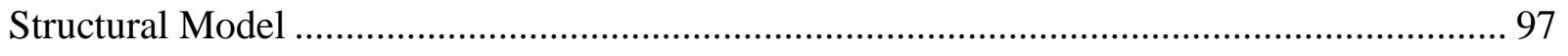

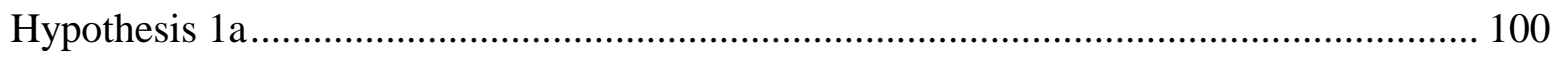

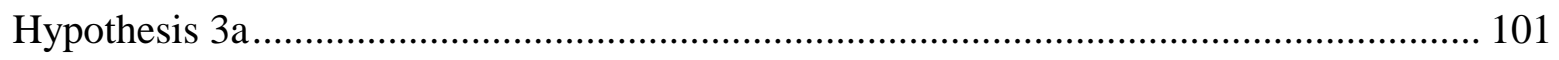

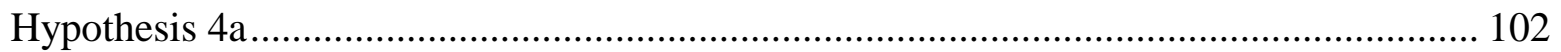




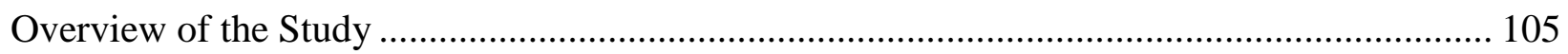

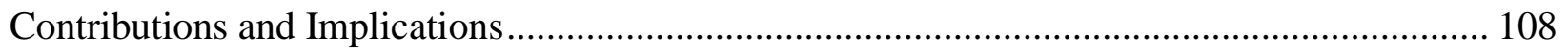

Theoretical Contribution and Implications ........................................................................ 109

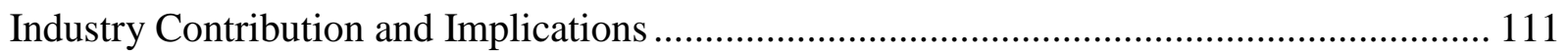

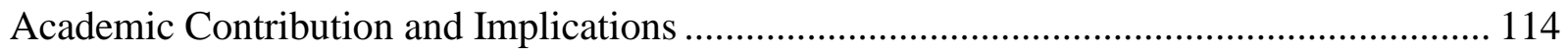

Study Limitations and Future Research Opportunities ........................................................... 117

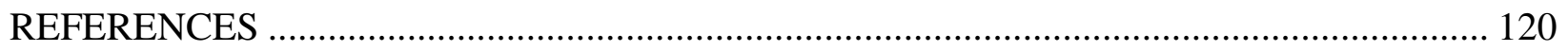

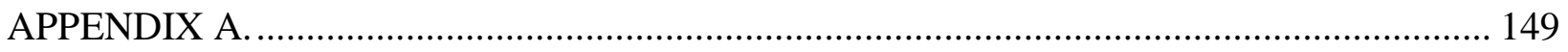

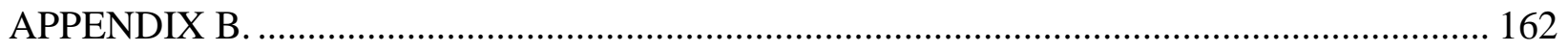

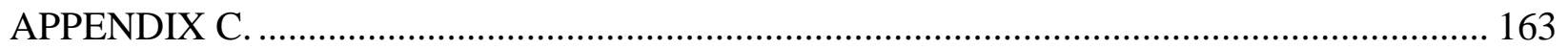

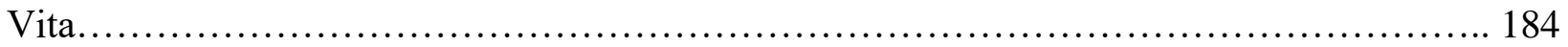




\section{LIST OF TABLES}

Table Page

Table 3.1 Survey Constructs, Measurement Item, Sources, and Cronbach’s alphas.... 64

Table 3.2 Changes in the Survey Constructs after Pilot Test and Cronbach's alphas..... 69

Table 4.1 Demographic Information of WTPD and CFPD Groups 80

Table 4.2 Group Demographic Characteristics of Participants and their Companies 81

Table 4.3 Measurements Model for Overall Wearable Product Development Group ............. 83

Table 4.4 Final Structural Model's Parameter Estimates, t-Values, and Significance Levels ..... 87

Table 4.5 Direct and Indirect Effects ............................................................................ 91

Table 4.6 Measurements Model for Wearable Technology Product Development Group ....... 93

Table 4.7 Measurements Model for Fashion Product Development Group .............................. 96

Table 4.8 Model Comparison to Determine Metric Invariance ................................................ 99

Table 4.9 Final Structural Model's Parameter Estimates, t-Values, and Significance Levels ..... 99

Table 4.10 Summary of Study Hypothesis 104 


\section{LIST OF FIGURES}

Figure Page

Figure 2.1 Conceptual Model with Hypothesis ............................................................ 23

Figure 4.1 Measurement Model (Confirmaotry Factor Analysis) .......................................... 85

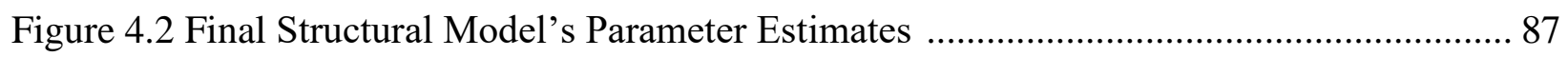

Figure 4.3 Measurements Model for Wearable Technology Product Development Group ......... 92

Figure 4.4 Measurement Model Fashion Group ..................................................................... 95

Figure 4.5 Final Structural Model's Parameter Estimate..................................................... 100 


\section{CHAPTER I. INTRODUCTION}

This chapter presents (a) an overview of wearable technology, (b) wearable technology and fashion, and (c) innovative behaviors in product development teams and discusses (d) gaps in the literature, (e) the purpose and (f) significance of the study, (g) its guiding principles and assumptions, and (h) definitions.

\section{Overview of Wearable Technology}

The invention of wearable technology such as smart wristwatches, glasses, and mobile cell phones was largely due to the people's needs and desires to access information when they are on move (Barfield \& Caudell, 2001). The literature is full of terms to describe products in the wearable technology domain, including wearables, wearable computer, wearable technology, smart clothing, and smart gadgets. According to Steve Mann (1998), a wearable computer is electronic equipment that is subsumed into the personal space of the user and has functions such as operational and interactional; it is always on and always accessible. Smart clothing, as defined by Ariyatum, Ray, and David (2005), are those garments or fashion accessories that are developed from intelligent textiles and electronic technology and have intelligent capabilities. In an exploratory study by Beloff (2010), the wearable computer was defined as an extension of the body that gives the wearer the power to perform some task previously impossible to perform. Ultimately, the term wearable technology (WT) encompasses all of these: simply by combining the definitions of the two words, it is clear that WT indicates an item which is capable of being worn, solves problems, and is made using science. Along these lines, Raj and Ha-Brookshire (2015a) defined WT in their qualitative research study as the items or accessories that not only 
are worn and have technical functions, "but also as those wearable items that makes one do more with less, gives super power, has some purposes and solves problems” (p. 2).

According to the market research company IDtechEx, the market size of the WT industry will grow from U.S. $\$ 30$ billion in 2016 at a $10 \%$ growth rate, reaching up to U.S. $\$ 40$ billion in 2018 and then accelerating by $23 \%$ annually to reach over U.S. $\$ 100$ billion by 2023 (Hayward, Chansin, \& Zervos 2016). This tremendous increase in the market size of WT is expected to create a huge impact on the lives of consumers in many ways, especially in health monitoring, work productivity, fashion trends, and fitness tracking. These innovations are bringing technology closer to the human body in the form of wearable devices, accessories, clothes, and even through in-skin implantation (Seymour, 2008). This balance of technology and wearability, with a seamless integration of functionality and aesthetics, is the key for successful WT products (Gepperth, 2012). The interests and investment in WT products from information technology companies such as Google, Apple, and Intel ${ }^{\circledR}$ are contributing to the accelerating rate of innovation in the WT domain. However, experts point out that, despite their important role, fashion companies are lagging in the WT domain compared to other industries in producing innovative WT products (Sultan, 2015). As a result, the success rate of new WT products can be improved by increased collaboration between fashion and technology companies (Gent, 2014).

\section{Wearable Technology and Fashion}

The origin of WT can be traced from multiple academic disciplines such as computer science, psychology, and design. The WT industry is unique in that it requires collaboration from professionals that have different educational and training backgrounds (Raj \& Ha-Brookshire, 2016). Particularly, WT businesses are dependent on collaborative groups with professionals 
from diverse fields such as fashion, information technology, health informatics, and even biotechnology. That is because when designing WT physical protection, ergonometrics, thermophysiological regulation, anthropometry, and human psychology is of considerable importance (McCann, 1999). This conjunction stresses that developers consider information like color, design, and clothing styles, as well as realizes the importance and implementation of its technological functionality (Marzano et al., 2000).

A lot of wearable technology products in the market today are geeky rather than fashionable items, which is hurting the sales and growth of this sector (Arthur, 2016). To overcome this, technology firms like Google, Microsoft, and Intel ${ }^{\circledR}$ are now collaborating with conventional fashion companies such as Levi's, Chromat, and Ralph Lauren. IT giant Google entered the field of WT with the invention of Google Glass. As the next step in WT, Google is working on Project Jacquard (Poupyrev et al., 2016). The project entails weaving fabric with conductive fibers that have the capability of communicating with digital devices. Additionally, the jacquard yarns woven into the fabric are touch sensitive and are able to collect information on the movement of the wearer. The fabrics are lightweight and the technology involved is small, with the circuit board connecting the fibers being small enough to be hidden inside a button. One of the apparel companies interested in the jacquard fiber is Levi Strauss, and they are collaborating with Google on this development (Sullivian, 2015). Their main aim in using such technology is to produce apparel that can transmit information and have emotional, aspirational, and functional attribute (Hill, 2015).

With many WT products—-such as Basis Peak ${ }^{\mathrm{TM}}$ (a fitness and sleep tracker), Biosport (a biometric ear bud), and MICA (a fashion forward smart bracelet)—entering the mainstream, 
Intel ${ }^{\circledR}$ is trying to fulfill the needs and wants of many demographic groups. Intel ${ }^{\circledR}$ is also collaborating with Chromat, a sportswear fashion label, to create a breathable and auto-adjusting sports bra and a 3-D-printed carbon fiber dress (Yetisen, \& Gibney, 2015). The sports bra has technology capable of sensing emotions based on perspiration, respiration, and body temperature. This information is then used to reshape or open some of the vents in the garment to make it more breathable. Somewhat differently, the carbon fiber dress is expressive and changes its shape based on the adrenaline levels of the person wearing the dress. When the wearer was excited, for example, the dress changed its form to an hourglass shape. These two products were first seen on the runways in the MADE fashion week (Budds, 2015).

Meanwhile, Ralph Lauren has developed one of the first WT integrated polo shirts in collaboration with the Canada-based tech innovation company Omsignal (Pau et al., 2015). With the help of silver fibers that are woven directly into the fabric, the innovative POLOTECH ${ }^{\mathrm{TM}}$ shirt collects data on the wearer's heart rate, breathing depth, calories burnt, steps taken, and activity level and records it on their iPhone ${ }^{\circledR}$ (Weinberg et al., 2015). Similarly, another fashion brand, Michael Kors, has announced its interest it WT. Per John Idol, the CEO of Kors, the company aims to create an ecosystem wherein its customers will not only have choices based on aesthetic attributes, but will also be helped in improving their lifestyle (Bhasin, 2015). And in an effort to keep up with this competition, Fitbit ${ }^{\mathrm{TM}}$, already an incredibly successful company producing smart wristbands, is collaborating with fashion designer Tory Burch to improve the aesthetics and design of their products.

Another challenge in WT is the product development process, which requires the convergence of two extremely different manufacturing processes: technology and apparel. The 
manufacturing of technology such as sensors, wires, and circuits requires cleaner environments and different processes than that of textiles and apparel (Arthur, 2016). Converging the two, which can enhance the mass manufacturing process of wearable technology, requires new product development techniques. This resonates with Paul Dillinger, the Vice President of global product innovation at Levi's:

So if we really want to make technology a part of every garment in the world, then we have to empower apparel makers such as Levi's or any other brand, to be able to manufacture smart garments. It means you have to work with their supply chain. (Arthur, 2016)

Such collaboration also creates challenges within the work environments. With conventional fashion product development teams, team members tend to have the knowledge of fashion forecasting, colors, design, arts, garment construction, fiber science, sourcing, or pattern making. In higher education, these subjects are taught in a department such as "Textile and Apparel Management," "Design and Merchandising," “Apparel Studies," or "Fashion Design and Retailing," belonging to the schools or colleges of design, arts, business, agriculture, human ecology, engineering, or human environmental sciences (Ha-Brookshire \& Hawley, 2012). On WT product development teams, however, team members tend to come from multiple disciplines that are not closely related, for example, computer science, electronics engineering, health informatics, and clothing/textile discipline (Raj \& Ha-Brookshire, 2016). On such product development teams, the professionals working together might have to bring tacit and explicit knowledge from their specific academic disciplines. Moreover, in such a diverse environment, professionals might use different jargons, symbols, and work language to generate ideas and 
information, and this can create communication breakdowns (Raj \& Ha-Brookshire, 2015b).

Therefore, throughout this study, the conventional fashion product development team is assumed to be more homogeneous or cognitively less diverse than the WT product development team in terms of academic and professional backgrounds. This assumption is consistent with industry professionals' statements that have been made in the recent past (Arthur, 2016).

Thus, for WT product development teams, even the work environment itself must be attended to. According to Raj and Ha-Brookshire (2016), the characteristics of the work environment within WT firms directly influence the knowledge conversion processes in their necessarily diverse teams. Specifically, Raj and Ha-Brookshire note that WT professionals expressed the need for an informal and flexible environment to improve the socialization process of the team members. Because communication is more difficult when the team lacks a sense of community, a nurturing and respectful environment was found to be crucial for bringing together the different kinds of knowledge from the diverse team members. In their observations, knowledge conversion was happening through socialization, experimentation, trial and error methods, and implementing ideas from many different media. This is important to note because one of the key factors for innovation and success within WT companies is balancing the focus of multidisciplinary team members in the product development process (Arthur, 2016).

Without an understanding of how new, innovative products are successfully being developed, any contribution to the understanding of overall WT company success would be limited. Despite this importance, our understanding of how innovation occurs during the wearable technology product development phase is very incomplete. There is a need for future research on innovation processes within WT teams that are much more diverse and heterogeneous in terms of team members' training and educational backgrounds than 
conventional fashion industry teams (Raj \& Ha-Brookshire, 2016). There is also a need to compare and examine the way product development occurs in WT teams and in conventional fashion teams to understand how they are related and what each can learn from the other.

\section{Teams' Innovative Behavior}

How, then, does successful innovation occur within WT product development teams? Are there are differences in innovative behaviors between WT and conventional fashion product development? Researchers interested in effective managerial approaches for innovation-aimed teams argue that the team leader's leadership style is one of the key factors. During the 2000s, globalization, high-paced information technology updates, and the increased rate of knowledge production affected the way knowledge is managed in organizations (Sher et al., 2004; Martin et al., 2005). Consequently, as Raj and Ha-Brookshire (2016) observe, for today's organizations to become innovative, they must take more risks and manage more heterogeneous team members than in the past. Transformational leadership is extremely important for their performance because it focuses on team members' inspiration, intellectual stimulation, and motivation (Boies, Fiset, \& Gill, 2015; Aga, Noorderhayen, \& Vallejo, 2016). In this light, many researchers examined teams' innovative behaviors and analyzed the effects of transformational leadership on team performance (Bai, Lin, \& Li, 2016; Kazmi, Naarananoja, \& Wartsila, 2016).

Organizational behavior literature also emphasizes the importance of team learning behavior among team members for such innovation-aimed teams. Researchers have shown that designing a complex product or solution requires the collective knowledge of more than one individual (Fischer, 2000; Langan-Fox et al., 2004), but the complexity of design processes increases when the product developers are from different educational backgrounds and possess 
different cultural identities (Snow, 1993). That is because these individuals possess different tacit knowledge and often communicate in different languages with distinct metaphors, symbols, norms, and representations (Snow, 1993). Language barriers, such as using the same labels for different terms, different labels for the same term, and discipline-specific jargon not used by people from other fields, can increase the difficulty in understanding each other's perspectives (Vreede, Briggs, \& Massey, 2009). Furthermore, communication researchers suggest that such language or cultural barriers can create clashes, mutual suspicion, hostility, or even disparity within the team (Irvine, 1985; Zwarenstein \& Bryant, 2000). These negative consequences may originate from the differences in people's outlooks when they see their own disciplines in comparison to others (Bernhofen \& Opie, 1997; Cott, 1997; Griffiths, 1997). People from the same academic background tend to form a community of their own, following specific norms of that discipline and valuing that discipline more than others (Snow, 1993). A sense of community, which adheres members to the organization, is therefore important for closing the communication or professional gap among team members. Team learning is the ability of team members to overcome these difficulties, that is, to coordinate their behaviors synchronously for the realization of common goals or objectives by having mutual knowledge, common beliefs, and assumptions (Mulder \& Swaak, 2002; Smart et al., 2009).

At the same time, diversity in a team is known to reduce team members' confirmatory thought processes that come from having similar tacit knowledge and which obstruct innovative, original, and complex work (Milliken \& Martins, 1996; Williams \& O’Reilly, 1998). Correspondingly, research has found that today's work teams are becoming more diverse (Bowers, Pharmer, \& Salas, 2000; Webber \& Donahue, 2001), and companies like Google are emphasizing the need to diversify their workforce and bring different perspectives to their teams 
(Lisa, 2016). Researchers therefore suggest that a sense of community amongst diverse team members who come from different professional and academic backgrounds is critical for the team's innovative behavior because it helps reduce confusion and increases team potency (Somech \& Drach-Zahavy, 2013). Especially in WT product development, team members belong to different academic backgrounds such as fashion design, computer science, electronics engineering, and health sciences (Raj and Ha-Brookshire, 2016), whereas product development for conventional fashion does not require the same kind of diversification among team members.

\section{Gaps in the Literature}

Given our limited understanding of how successful innovation occurs within WT and conventional product development teams, finding and examining key antecedents for teams' innovative behavior is critical. The literature analysis showed that transformational leadership is thought to be important for a team's innovative behavior. However, very little research has been done to examine its effect on cognitively diverse group interactions. Wearable technology has merged the boundaries of the conventional fashion industry and technology industries; thus, WT teams are becoming more and more diverse in terms of educational and professional backgrounds. Consequently, creating a sense of community becomes more difficult and team learning behavior - and therefore innovation—is much more difficult to achieve in diverse team settings than otherwise. Yet, little is known about how leadership, shared understanding, and senses of community are achieved, how such factors affect the product development teams' overall innovative work behavior, or how such dynamics function differently between WT and conventional fashion product development teams. 


\section{Purpose}

To address these gaps, this study is designed to examine the relationship between transformational leadership, team learning behavior, senses of community, and the team's innovative work behavior and to compare these relationships in (a) conventional fashion product development teams that tend to be much more homogeneous and (b) WT product development teams, which are thought to be much more diverse in terms of the members' educational and professional backgrounds.

\section{Significance of the Study}

The fashion industry always upgrades itself with the current improvements in technology and industrial setups (Tortora, 2015). The movement of the fashion discipline from a homebased industry to a global fragmented industry was triggered by globalization, industrial revolution, and advancements in technology (Ha-Brookshire \& Hawley, 2013; Tortora, 2015). Inventions such as the spinning jenny and sewing machine made changes in the way wearable products were mass-manufactured using technology and high work forces. Many researchers proclaim that we are currently going through another major industrial revolution triggered mainly by technological advancement and that it, similar to the last industrial revolution, may lead to disruptive innovation (Sun \& Lu, 2015; Raj \& Morris, 2016).

The impact of technology on fashion product development is growing, and collaboration between technology and fashion companies for such innovation is currently underway. If this

trend continues, the traditional fundamentals and processes of product development will be strongly affected due to the new innovation of small and smart sensors, circuit boards, and fibers. With these innovations happening in the industry right now, the examination of group dynamics 
within and between the fashion and technology workforces can help improve overall group performance, especially in terms of innovation. Therefore, first, this research is significant in developing knowledge on interdisciplinary collaboration, which will eventually help in generating strategies and improving business models for WT companies. Second, the result of this research also informs conventional fashion companies of the steps to take if they want to include technological elements in their products. Third, the research findings are significant for theoretical developments, especially in showing how social capital is built within the heterogeneous team toward group innovation. Moreover, the comparative findings on social capital building in cognitively diverse teams could offer pathways to success when managing heterogeneous workforces within an organization.

\section{Guiding Principles and Assumptions}

The guiding principles for this study were critical realism and structuralism. The world we live in is constantly changing with unique phenomena that are often uncomprehended and unreachable by our naked sensory tools. Reality changes every moment: there is always growth or degradation occurring, which makes the reality around us dynamic and every second unique. People experience reality as complex, dynamic, unique, and obscure, which together make it hard to understand (Jaccard \& Jacoby, 2010). In critical realism, reality is perceived through human conception, but the empirical world reacts to either support or reject the perceived human conceptions (Jaccard \& Jacoby, 2010). In light of this, the focus of this study was to examine the realities of WT and conventional fashion product development teams' behaviors in different settings and work environments through quantitative methods. Specifically, for this research, leadership behavior displayed by supervisors, as well as other social capital factors (such as 
senses of community and team learning behavior in homogenous and heterogeneous teams), was examined to identify the principles for highly innovative work behavior.

Structuralism, another paradigm upon which this study was based, emphasizes exploring how people think rather than what people think (Jaccard \& Jacoby, 2010). Under structuralism, it is believed that under the surface structure of society there lies another underlying structure, which connects actions through a finite set of principles that acts as a blueprint to understand human behavior (Jaccard \& Jacoby, 2010). A related theoretical framework used in this study is social capital theory, which asserts the importance of employees' structural, relational, and cognitive components for their organizations. This theory explains what people do in their personal and professional communities rather than what people think. These frameworks were especially relevant to this study, which specifically examines a deeper structure for innovation in homogenous and heterogeneous work environments.

\section{Definitions}

\section{Terms}

\section{Definitions}

Wearable Technology Industry that produces those items or accessories that are used for Industry wearing and also have some technical functions (Raj \& Ha-Brookshire, 2015).

Conventional Fashion For this research, the conventional fashion industry is defined as the Industry $\quad$ industry that produces those items or accessories that are used for wearing and have no technological functions.

Innovative Work For this research, innovative work behavior is defined as having three

Behavior traits displayed by individuals_-idea generation, promotion, and 
realization — to produce innovative products or solutions and enhance role performances within a group (Janssen, 2000).

Transformational Transformational leadership "involves inspiring followers to commit to Leadership a shared vision and goals for an organization or unit, challenging them to be innovative problem solvers, and developing followers' leadership capacity via coaching, mentoring, and provision of both challenge and support" (Bass \& Riggo, 2006, p. 4).

Sense of Community Sense of community is defined as "the perception of similarity to others, an acknowledged interdependence with others, a willingness to maintain this interdependence by giving to or doing for others what one expects from them, the feeling that one is part of a larger dependable and stable structure" (Sarason, 1974, p. 157).

Social Capital Theory Social capital theory categorizes human interactions and social relationships as those resources, which produce short- or long-term tangible and intangible benefits for individuals, organizations, or communities (Bourdieu, 1986; Coleman, 1988; N. Lin, 2001; Putnam 2000).

Team Learning Team learning behavior is defined as the readiness of team members to Behavior perform assigned tasks while respecting each members' work values, norms, philosophies, problem-solving approaches, and prior work experiences (Cannon-Bowers et al., 1993; Mathieu et al., 2000).

Diversity in team Diversity in team is defined as a team composition including 
professionals who belong to academic or professional backgrounds that are not closely related (Shin \& Zhou, 2007).

Product Development Product development is broadly defined as the processes or steps taken to convert a market opportunity into products available in stores for the target consumers (Krishnan \& Ulrich, 2001). For this study, product development involves series of steps for idea conceptualization, design, development, and marketing of new products or services. Some of the functions of product developers in this study's context were the forecasting of trends, product designing, product engineering, industrial engineering, pattern making, material science, branding, and marketing of the products.

\section{Organization of the Study}

This dissertation is divided into the following five chapters. Chapter I provides an overview of wearable technology, collaboration between the wearable technology and fashion industries, and team innovative behavior, as well as discusses the gaps in the literature, the purpose and significance of the study, its guiding principles, and definitions. Chapter II presents a literature review on social capital theory, transformational leadership, team learning behavior, sense of community, and innovative work behavior. The definitions and trends in all these major concepts are deeply explored and presented. The relationships between these variables are explicitly presented, leading to the development of each of the hypotheses. Chapter III explains the empirical relevance of the research model. It also explains the research instrument, the sampling frame, the reliability and validity of scales used, the research design, the data collection method, and the data analysis techniques. Chapter IV presents the research results and analysis, 
and Chapter $\mathrm{V}$ discusses contributions and implications of the results, the limitations of the study, and possible future research opportunities. 


\section{CHAPTER II. LITERATURE REVIEW}

This chapter discusses: (a) the theoretical framework, (a.i) social capital theory, (a.ii) dimensions of social capital theory, (b) hypothesis development, (c) innovative work behavior, (d) transformational leadership (the structural dimension of social capital theory), (e) team learning behavior (the cognitive dimension of social capital theory), (f) sense of community (the relational dimension of social capital theory), (g) difference in the fashion and wearable technology product development teams, and (h) a summary of study hypothesis.

\section{Theoretical Framework}

\section{Social Capital Theory}

Hanifan (1916) used the phrase 'social capital' for this first time to examine local school performances. He argued that a social unit was made up of individuals and families with tangible values such as "good will, fellowship, sympathy, and social intercourses" (p. 130). He further elaborated that social capital builds by the constant expansion of a network in a community. This network and the accumulation of social capital enhance the satisfaction level of social needs and improve the living conditions within a community substantially. According to Wallis, Killerby, and Dollery (2003), there are two key features of this explanation. First, the living conditions can be improved due to the focus of social capital on good will, fellowship, and sympathy. Second, social capital has benefits for private lives as well as influences externalities beyond private lives.

The social capital concept was subsequently explored from various viewpoints to explain societal phenomena from an individual level, including the exploration of inequalities (Bourdieu, 1986), the norms of society and social actions (Coleman, 1988), and the significance of civic 
engagement on the prosperity of a community (Putnam, 1995). The core principle of social capital theory is to recognize that the goodwill people have for one another is a valuable resource that generates unspecified obligations that ought to be returned later (Adler \& Kwon, 2002). Goodwill resources have the power to influence various interactions such as informational flow, trust, and the exploration of opportunities.

Social capital theory categorizes human interactions and social relationships as resources that produce either short- or long-term tangible and intangible benefits for individuals, organizations, or communities (Bourdieu, 1986; Coleman, 1988; N. Lin, 2001; Putnam, 2000). These usages of goodwill resources in various interaction systems have led to the development of social capital in many different areas and fields of study, including economics, political science, anthropology, community development, healthcare, and sociology. The development of social capital theory is largely based on the works of sociologists Pierre Bourdieu (1986), James Coleman (1988), and Robert Putnam (2000).

\section{Definition of Social Capital}

There is more than one definition of social capital theory. These definitions evolved with the development of the literature and the interests of scholars from different fields. One of the first researchers to define social capital theory was Pierre Bourdieu, who worked on this theory in 1970s and 1980s. He formulated his definition in the context of understanding human actions:

The aggregate of the actual or potential resources which are linked to possession of a durable network of more or less institutionalized relationships of mutual acquaintance and recognition — or in other words, to membership a group. (1986, p. 248) 
Similar to Bourdieu, Coleman (1988) defined social capital by investigating high school dropouts, specifically focusing on their relations among peers and comparing the concepts with financial, physical, and human capital:

Social capital is defined by its function. It is not a single entity but a variety of different entities having two characteristics in common: they all consist of some aspects of social structure, and they facilitate certain actions of individuals who are within the structure. (p. 98)

In 1993, Putnam published his first work on social capital in his book Making Democracy Work: Civic Traditions in Modern Italy. He examined institutional performance and levels of civic engagement in the northern and southern parts of Italy. Significantly, he emphasized and included a trust element in the theory. Putnam defined social capital:

By analogy with notions of physical capital and human capital - tools and training that enhance individual productivity - "social capital" refers to features of social organization such as networks, norms, and social trust that facilitate coordination and cooperation for mutual benefit. (1995, p. 136)

This definition formulated by Putnam (1995) fits well to the context of this study and was useful in further analysis.

\section{Dimensions of Social Capital}

Nahapiet and Ghoshal (1998) developed the most popular conceptualization of social capital. According to their study, there are three main dimensions of social capital: structural, relational, and cognitive. 


\section{The Structural Dimension}

The structural dimension of social capital explains the patterns of connections by which members are linked to each other (Nahapiet \& Ghoshal, 1998). The members utilize these connections to build and share their knowledge with each other and to improve their teamwork (Tsai \& Ghoshal, 1998). In addition to exploring the ties and network connections between team members, the structural dimension examines the strength of the ties (Chou et al., 2006). According to Xiang, Lu, and Gupta (2013), the structural component can be both formal and informal. The formal structures are those which are well defined and required by the organization, such as regular meeting times and detailed rules for tasks. The informal channels are the connections private to the members like, for example, going for informal lunch or meeting after work hours. The location of professionals in the network structure can give certain benefits to the individuals, such as favors in getting recommendations for jobs (Granovetter, 1992) or obtaining information from colleagues (Burt, 2000).

\section{Structural Dimension of SCT and Transformational Leadership}

The structural dimension of social capital explains the patterns of connections by which each member is linked to the others (Nahapiet \& Ghoshal, 1998). The leadership literature suggests that the structural patterns of member connections can be enhanced if the group has transformation leadership (Carter et al., 2015). According to SCT, there are two types of linkages within the organization. The first is called bonding, which involves internal collaboration, cooperation, and trust among the members of the organization. The second is calling bridging, which involves the development of external links between teams or organizations (Adler \& Kwon, 2002). The internal bonding and external bridging are enhanced through a well-defined 
team structure, which is facilitated by the presence of a transformational leader (Heavey et al., 2009). Having transformational role models encourages collaboration and coalitions and expands the network for reaching out to external members, which helps in the development of external and internal social capital (Den Hartog \& Belschak, 2012) and ultimately creates competitive advantages (Carter et al., 2015). In this light, transformational leadership is thought to help create the structural "bond" within the product development group and is critical for the group's innovative behavior, especially when the group is diverse.

\section{The Cognitive Dimension}

The cognitive dimension refers to the resources that are shared in the team, such as shared codes, languages, and narratives (Nahapiet \& Ghoshal, 1998). The cognitive resources are generated by individual team members through collective interactions in the team. Cognitive resources depend on the sharing of information, members' familiarity with procedures, and the working styles of the team. Shared vision and collective goals and mission help in formulating a holistic cognitive dimension for teams in organizations (Tsai \& Ghoshal, 1998).

\section{Cognitive Dimension of SCT and Team Learning Behavior}

Team learning behavior for shared understanding is an important process for developing social capital in today's knowledge-based economy (Liao, Fei, \& Chen, 2007). The cognitive dimension of social capital theory (SCT) refers to those elements within the team which help to develop a shared vision in the team, formulated through shared codes, languages, and narratives (Nahapiet \& Ghoshal, 1998). This cognitive dimension is similar to team learning behavior, which is also based on the construction, co-construction, and constructive conflict of knowledge within the team. In this light, it was also found that shared vision, shared objective, and shared 
understanding in a team leads to the development of a strong cognitive dimension (Isa, Abdullah, \& Senik, 2010). Davenport (1995) emphasized the nature of the interactions needed for coconstructing new knowledge. In his analysis, close personal interactions were found to help the successful transfer of knowledge and learning. Therefore, a strong relationship between the cognitive dimension of social capital and team learning is expected.

\section{The Relational Dimension}

Relational social capital defines the relationships among the members who are connected in organizations (Nahapiet \& Ghoshal, 1998). Some of the characteristics of theses relationships are trust, confirming to certain norms, identification, and obligations. Among these relationship characteristics, trust has been more explored in the literature due to its power to give encouragement and enable individuals to perform their duties in a free environment (Dirks \& Ferrin, 2002). Norms helps in formulating rules and standards for a job. The identification component makes team members more associated with the organization. Identification with the team can make them feel proud of their team's accomplishment, which would in turn inspire them to work harder towards achieving goals.

\section{Relational Dimension of Social Capital Theory and Sense of Community}

Researchers from the social sciences believe that social capital is related to political science, applied economics, and sociology in the same way that sense of community is to community psychology (Perkins \& Long, 2002). The relationship between the relational or behavior component of SC is especially related to sense of community (Perkins \& Long, 2002). The focus of the relational dimension of SC is on the relationships among the members of the organization and their sense of belonging (Nahapiet \& Ghoshal, 1998; Tennent et al., 2005). 
These relationships build on trust and confirming to certain norms (Dirks \& Ferrin, 2002). A sense of community is found to be a consistent indicator of the quality of community life. This quality of sense of community makes it a catalyst for relational dimensions of SC, occurring through organized participation as well as informal meetings (Beckman et al., 1998; Chavis \& Wandersman, 1990).

With the three key dimensions of social capital defined, the next section discusses key antecedents of the group's innovative work behavior and develops the study hypotheses.

\section{Hypotheses Development}

The conceptual and study hypotheses are presented in Figure 2.1. This model was grounded in social capital theory, specifically within the three dimensions of social capital. 
Figure 2.1

Conceptual Model with Hypothesis

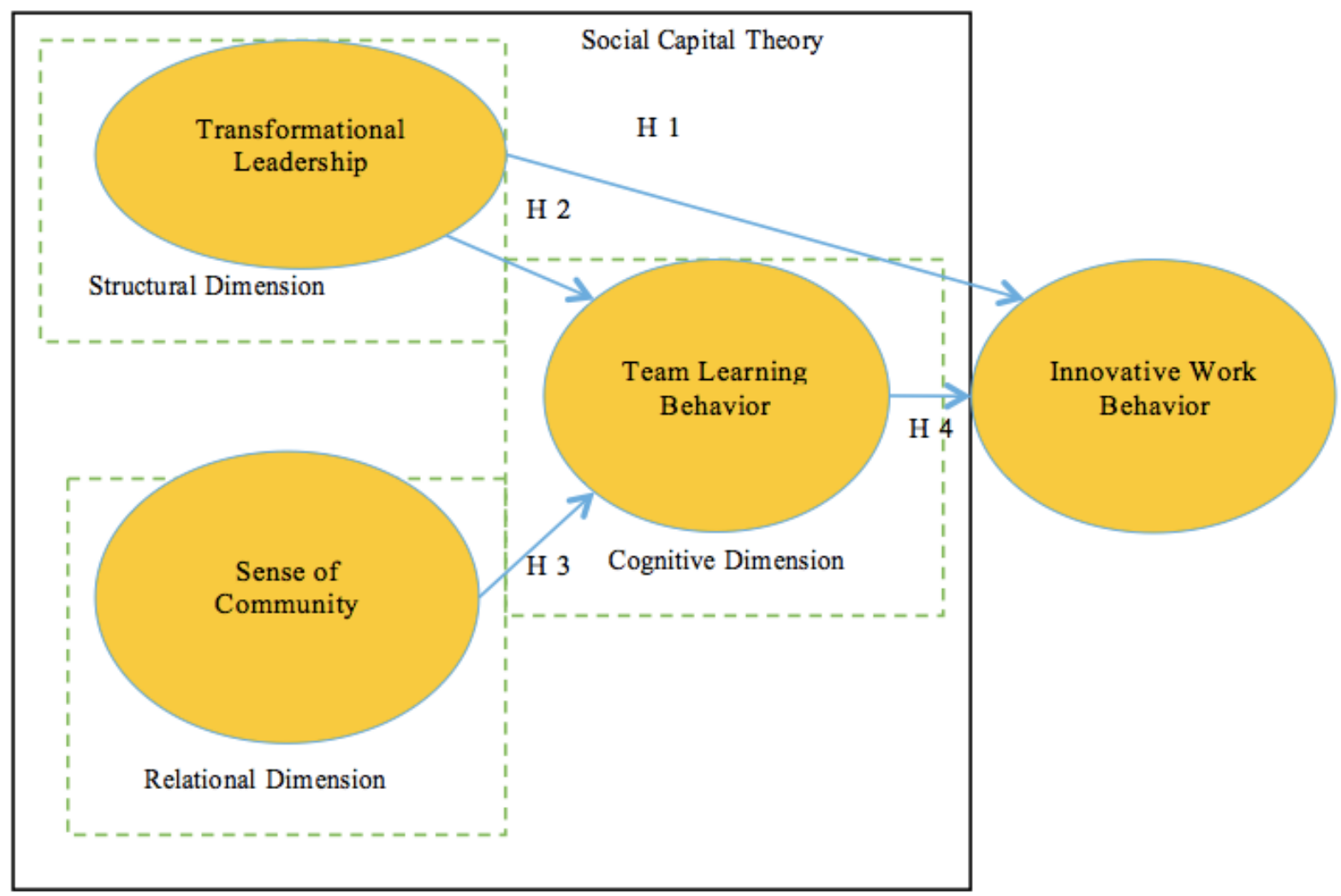

Innovative Work Behavior

The key dependent variable of this study is a team's innovative work behavior, as we are interested in why certain teams are better at innovation while others are not. For this question, the literature related to innovation and innovative work behavior is discussed.

\section{Definition of Innovative Work Behavior}

Scott and Bruce $(1994,1998)$ first used the term innovative behavior to analyze the role of individuals in producing innovative outcomes for organizations. Since then, this concept has been frequently used for both qualitative and quantitative research methods. The core foundation of innovation is the individual who can "develop, carry, react to, and modify ideas" (Van de Ven, 
1986, p. 592). Innovation is often viewed as having different stages, with each stage having peculiar behaviors associated with it (Scott \& Bruce, 1994). That is, innovation deals with the production and adoption of an idea, as well as its implementation process (Kanter, 1988; Van de Ven, 1986).

The definition of innovative work behavior has been refined and revised many time in the past couple decades. West et al. (1990) defined innovative work behavior as the intentions of people working in a team to introduce and apply ideas, processes, products, or procedures that are new to an area of adoption and which are designed to benefit the individuals, group, organization, or wider society. Janseen (2000) also used the component of "intentional creation" when defining innovative work behavior. He further explained that innovative work behavior is the intention of team members working in an organization to create, introduce, and apply new ideas that are formulated to improve their work performances and bring innovation in the area intended to. Similarly, Tuominen and Toivonen (2011) defined innovation as those "activities that aim at contributing to the creation and utilization of beneficial novelties in an organization" (p. 398). More recently Stan et al. (2014) defined innovative work behavior as employees' intentions for the generation, introduction, and application of idea processes or products that are new and intended to benefit the area of adoption.

\section{Components of Innovation Work Behavior}

\section{Idea Generation}

In this study, idea generation is defined as the first phase of innovation where brainstorming ideas happens among the team members and a few ideas are selected and passed onto the next phase. In this initial phase, based on their individual tacit knowledge, team 
members come up with as many ideas they can (Campbell, 1960; Mednick, 1962, Amabile et al., 1996; Kanter, 1996). By analyzing the merit of each idea based on its usefulness, value, and novelty, the team collectively decides which ones to select and which to reject (Amabile, 1983; Woodman et al., 1993). The generation of ideas happens in the individual's mind (Campbell, 1960) but it is further modified and refined through social interactions (Cronin \& Weingart, 2007; Mueller \& Kamdar, 2011). Work related problems, emerging trends, disruptions, and incongruities often lead to the generation of ideas (Drucker, 1985).

\section{Idea Promotion}

After shortlisting the ideas from the first phase, the next phase deals with promoting those ideas to stakeholders and potential allies (Janssen, 2000). For this phase to succeed, it is important that the idea be explicitly and implicitly explained and elaborated (Ford, 1996; Amabile, 1983, 1988; Torrance, 1988). The formation of the idea from a vague concept originating in an individual's mind to a clearly explicable format is very necessary for this stage. In championing the idea, the team tries to influence the gatekeepers by articulating a compelling vision and promising outcomes (Howell \& Higgins, 1990). At the end of this phase, the idea is either rejected or approved for further development and implementation (Fried \& Hisrich, 1994; Frost \& Egri, 1991; Markham, 2000).

\section{Idea Realization}

In this last phase of innovative work behavior, the idea is implemented to produce a tangible prototype, service, or process (Kanter, 1988). This development of a prototype or models is often executed by the team involved in the first two phases of innovative work behavior (Kanter, 1988). This phase begins with the development of a blueprint detailing the 
conversion of the idea into a final product (Perry-Smith \& Mannucci, 2017), and it concludes with a final evaluation of the innovative product or idea.

How, then, can a team have more intense innovative work behavior? Social capital theory predicts that social capital is one of the antecedent of innovation (Dakhli \& De Clercq, 2004; McFadyen \& Canella, 2004; Akcomak \& Weel, 2009). That is, the competitive advantage gained through social interactions, which is based on promoting trust and fostering collaboration, links innovation and social capital theory. Several studies have shown social capital to be one of the antecedents of innovation (Dakhli \& De Clercq, 2004; McFadyen \& Canella, 2004; Akcomak \& Weel, 2009). Social capital encourages cooperation among members, which helps in the development of new teams among organizations and thus facilitates innovation in organizations (Fukuyama, 1995; Jacobs, 1965; Putnam, 1993; cited in Nahapiet \& Ghoshal, 1998). In his research, Landry (2002) found that knowledge acquisition not only depends on the hierarchy and management of the organization, but also on the networks developed through interactions, which are facilitated by the social capital of the company. More specifically, all three key dimensions are critical for any teams to build and enhance social capital, which in turn help improve the team's innovative work behavior. The next section discusses three key conceptual components of social capital dimensions, which are built from transformational leadership, team learning behavior, and sense of community.

\section{The Structural Dimension of SCT: Transformational Leadership Definitions of Transformational Leadership}

The concept of leadership has evolved with changing social conditions. During the 1800 s, leadership was conceptualized as a trait especially related to one's charismatic aura and influence 
(House, 1976). In his book, A 1976 Theory of Charismatic Leadership, House conceptualized leaders as mystical, magnetic, and narcissistic. Moreover, leaders were said to have the power to mold the thoughts, behavior, and feelings of their followers by instilling self-confidence and thus creating radical changes beyond the established order (Weber, 1947). In this light, House hypothesized that charismatic leaders have the four key traits: dominance, self-confidence, influential capacity, and morally righteous convictions. Additionally, House (1977) defined the charismatic leader as one who has extraordinary personal abilities, capable of making a profound effect on their followers. For him, personal characteristics—-such as self-confidence, dominance, strong convictions, and a strong ethical sense — were the most important features of the leader.

Throughout the decades, the definition of leadership has evolved with the changing political and social climate. After House, Burns (1978) defined a leader as someone inducing followers to act for certain goals that represent the values and the motivationsthe wants and needs, the aspirations and expectations — of both leaders and followers. And the genius of leadership lies in the manner in which leaders see and act on their own and their followers' values and motivations. (p. 9)

Significantly, Burns (1978) argued leadership should be considered as a set of behaviors rather than traits. Researchers must therefore focus on leaders' behavioral styles, which he observed could be either transformational or transactional (Burns, 1978). Since then, transformational and transactional leadership have been heavily discussed within the literature of history, political science, and sociology (Bycio, Hackett, \& Allen, 1995; Bass \& Riggio, 2005).

Transformational leadership "involves inspiring followers to commit to a shared vision and goals for an organization or unit, challenging them to be innovative problem solvers, and 
developing followers' leadership capacity via coaching, mentoring, and provision of both challenge and support" (Bass \& Riggo, 2006, p. 4). Alternatively, transactional leadership refers to a leadership style focusing on the exchange of deeds with rewards and has been discussed within the psychology and economics literature (Bycio, Hackett, \& Allen, 1995; Bass \& Riggio, 2005). Yukl (1981) described transactional leadership in which both leaders and followers are influenced by one another and eventually get something of value at the end of the task. The relationship is of interdependence and is based on acknowledgement and rewards for both sides (Kellerman, 1984).

Researchers have also found that both leadership behaviors can be analyzed as a distinct variable to examine certain behaviors and interactions within organizations (Deinert et al., 2015). The effects of transformational leadership on individuals', teams', and organizations' performances in various aspects such as innovation have been studied (Sosik et al., 1998; Sosik et al., 1999). In several studies, the impact of transformational leadership on innovative behavior was found to be greater than that of transactional leadership (Jung, 2001; Sosik et al., 1998; Sosik et al., 1999).

Burns (1978) initially described that transformational and transactional leadership exist at the two ends of a continuum. However, Bass (1985) opposed the formulation, instead proposing that they were rather complimentary and that leaders can display both styles depending on the needs of the team members and the goals of the teams. In fact, Bass showed that transactional leadership focuses on marginal improvement, maintaining quantity and quality of performance, progressing with the attainment of goals, reducing resistance to actions by the employees, and implementing decisions. Meanwhile, transformational leadership aims at uplifting colleagues, 
subordinates, followers, and clients through a greater awareness of the consequences of tasks and by providing them with a shared vision, self-confidence, and inner strength "for what s/he sees is right or good, not for what is popular or is acceptable according to established wisdom of the times" (Bass, 1985, p.17)

Moreover, the different leadership styles within transformational leadership have been used separately depending on the outcome variables (Ashkanasy, 2015; Deinert et al., 2015; Fiset \& Gill, 2015). Deinert et al. (2015) investigated the subscale of transformational leadership from the lens of five main personality traits of leaders, namely neuroticism, extraversion, openness, agreeableness, and conscientiousness. Through Meta-Analytic Structural Equation Modeling analysis, they found that the five big traits directly linked to the transformational leadership subdimension. The study further emphasized that the sub-dimensions can be used separately to help reach a deeper understanding of transformational leadership behavior and its antecedents.

Kazmi, Naarananoja, and Wartsila (2016) conducted research to find the relationship between new product development and transformational leadership in work locations of a European multinational company. Using correlation and regression analysis to find the results, the study found that the support given on new product development by management had a significant relationship with transformational leadership. A leader's capacity to empower employees was observed to significantly affect the strategic thinking of the team members. It was also found that different components of transformational leadership could be used for generating different results for teams. Each of the components can be used separately to analyze the leadership behavior most suitable for the team (Deinert et al., 2015). Therefore, in this study 
transformational leadership is the focus for WT product development teams' innovative behavior.

\section{Components of Transformational Leadership}

Four components of transformational leadership are discussed next.

\section{Idealized Influence}

There are two types of idealized influence, one related to attributes and the other related to behavior. Idealized influence attributes are the characteristics recognized by followers that inspire them to listen to or model themselves on a leader, often discussed in terms of charisma. These perceptions can be formed when a leader talks about their most important values and beliefs, gives a strong sense of purpose to the team, or considers the moral and ethical consequences of decisions (Avolio \& Bass, 2004; Bass \& Riggio, 2005). Idealized influence behaviors are the action elements or steps taken by leaders that help in positive transformation of the team. Some of these include always being present for the group, instilling pride in team members, and going beyond self-interest for the good of the group (Avolio \& Bass, 2004; Bass \& Riggio, 2005).

\section{Inspirational Motivation}

Transformational leaders boost the morale of team through inspirational speaking, creating optimism, and motivating the members to achieve targets. They do so by providing meaning and challenges to their team member's work. It is also done by showing team members the brighter future that comes with success, formulating clear expectations, and creating a shared vision for the team (Avolio \& Bass, 2004; Bass \& Riggio, 2005). Shared vision is particularly 
essential for unifying team members and increasing their collective potential (Shamir et al., 1993).

\section{Intellectual Stimulation}

Innovative and creative thinking by the team members are the main goal for intellectual stimulation. By using methods such as "questioning assumptions, reframing problems, and approaching old problems in new ways," a transformational leader stimulates the thinking of the team members (Bass \& Riggio, 2005, p. 7). This is also encouraged when team members are given freedom to choose their own paths and are not criticized for deviating from the team leader's thoughts and ideas (Avolio \& Bass, 2004; Bass \& Riggio, 2005).

\section{Individualized Consideration}

Recognizing the uniqueness of team members and giving them learning opportunities in the work environment are the central elements of individualized consideration. These are accomplished by establishing strong two-way communication, personalizing interactions, and effective listening by both leaders and team members (Avolio \& Bass, 2004; Bass \& Riggio, 2005).

\section{Transformational Leadership and Innovative Work Behavior}

A number of previous studies have found a relationship between transformational leadership and innovation. Boies, Fiset, and Gill (2015), for example, investigated the relationship between two sub-components of transformational leadership (intellectual stimulation and inspirational motivation) and task/creative performance. In their experiment, a third of 44 student groups was exposed to intellectual simulation-focused transformational leadership, another third was exposed to inspirational motivation-focused transformation leadership, and the 
last third was a control group exposed to very limited leadership. It was found that overall team communication and team trust sequentially mediated the relationship between inspirational motivation-focused transformational leadership and students' creative performance. At the same time, intellectual stimulation-focused transformational leadership had a positive impact on students' task performance.

Similarly, Jaiswal and Dhar (2015) found a positive relationship between transformational leadership and employee creativity. A study by Noruzy (2013) also found the relationship between transformational leadership and organizational innovation to be positive. And in a theoretical review on the effect of team- and individual-focused transformational leadership's effects on personal, interpersonal, and group level creativity, Lo, Tse, and Ashkanasy (2015) proposed that group members working on a collective cause and sharing an affective activating state collectively would increase group creativity if they experience high team-focused transformational leadership. Their group creativity would decrease if they experience low team-focused transformational leadership. The study also proposed that individuals who experience high individualized transformational leadership would show high creativity as compared to individuals who experience less individualized transformational leadership.

Recalling that transactional leadership focuses on marginal improvement, maintaining quantity, and quality of performance — whereas transformational leadership aims at uplifting colleagues, subordinates, followers, and clients through greater awareness of consequences of tasks and by providing them with shared vision, self-confidence, and inner strength (Bass, 1985) - transformational leadership is thus thought to be a very important antecedent for a 
group's innovative behavior. This relationship was also not tested in the fashion or WT PD sector. Therefore, the following hypothesis was developed:

H1: Transformational leadership positively impacts innovative work behavior in wearable product development teams.

\section{Cognitive Dimension of Social Capital: Team Learning Behavior Definition of Team Learning Behavior}

Team learning behavior is defined as the readiness of team members to perform assigned tasks by respecting each members' work values, norms, philosophies, problem-solving approaches, and prior work experiences (Cannon-Bowers et al., 1993; Mathieu et al., 2000). Team learning is an active state attained through interactive processes between team members by maintaining and constructing common grounds (Deshpande et al., 2005). Some of the other terms used in describing team learning behavior are shared understanding, shared mental models, team mental models, group cognition, and sense making (Bittner \& Leimeister, 2014)

The origin of team learning is traced from the works of Vygotsky $(1978,1981,1986$, $1987,1997)$ on shared meaning making. Vygotsky found that before the conception of any idea in the minds of individuals, its existence is external and thus social in nature (1981). These social understandings are achieved in two dimensions: the social and psychological levels. Using extant child life psychology literature, he further explained that when a child makes any gestures, he or she does not connect with the gesture until there is a reaction from the parents. After getting these social reactions to the gesture, he or she develops psychological meanings of that gesture. Vygotsky also expanded the literature by formulating the zone of proximal development theory. 
This theory states that the connection and interaction between self and environment is needed for the internalization of any social learning.

Continuing with the interaction of self and environment, Bandura (1986) explained that the concept of self has two distinct elements: personal factors and behavioral factors. In this conceptual framework, which he named social cognitive theory, he went on to define three main elements for social interactions: personal factors (cognition, knowledge, attitude), environmental factors (social norms, access to the community), and behavioral factors (nature, self-efficacy, skills). Bandura's theory was frequently used in analyzing the effects of environments, personalities, and cognitions on various subject matters such as innovation, learning, organization outcomes, and performance. The results of this research suggested that through such social interactions, humans try to achieve shared understanding, in turn facilitating team-learning behavior with their external environments.

On a lightly different note, the group innovation literature suggests that effective group members' collaboration is the key to team learning readiness. Particularly, Mihaly Csikszentmihalyi (1990) coined the term flow to describe a state of heightened consciousness during group members' social interactions. According to his research, group members experience a different sensation when they are at highest level of creativity during social interactions, and they experience a continued unifying sense that makes them move from one moment to another, strictly in control of their actions, "and in which there is little distinction between stimulus and response, self and environment or between past, present, or future." Taking inspiration from Csikszentmihalyi's work, Sawyer (2006) formulated principles that would facilitate this concept of flow during group interactions. Sawyer (2007) used the phrase 
"group genius" to recognize the fact that group innovation requires collaboration, which he identified as the secret of group innovation. Per his research, innovation is not always the product of a lone genius whose mystical moment of enlightenment revolutionizes the world. Rather, through collaboration, small sparks emerge in a team. And with continued team effort and though critical analysis of the idea, the sparks can turn into incredible innovations, if only after a lot of improvisation and failures. Throughout this process, team learning readiness must be established within the group members so that the small sparks can materialize as innovations (Sawyer, 2007).

\section{Phases of Team Learning Behavior}

According to the literature on team learning behavior, there are three phases in which shared understanding between team members occurs: construction, co-construction, and constructive-conflict (Beers et al., 2007; Van den Bossche et al., 2006).

\section{Construction.}

When a team is faced with a task or a problem, team members first start to think about various ways of solving it individually by articulating their own interpretations and meanings of that problem based on their personal experiences and social contexts (Beers et al., 2007; Van den Bossche et al., 2006). The team members then explain the problem to their peers using their common language, and the other members listen and give them feedback (Webb \& Palincsar, 1996). Because construction entails the process of understanding, which includes explaining as well as listening, elaboration and thought-process sharing are especially important in this phase (Visschers-Pleijerrs et al., 2004). 


\section{Co-construction.}

According to Baker (1994), "co-construction is the mutual process of developing shared knowledge and building shared meaning by refining, building on, or modifying an original offer in some way" (p. 116). During this step, carefully listening to the team members, mutually building on the information, critiquing the information, and modifying the original proposition proposed by other team members take place (Baker, 1994). Additionally, in this phase the social contexts of each member's understanding of the problem collide, ideally resulting in mutual learning of each other's point of view. This is important because new knowledge is created through interpreting, questioning, and paraphrasing by the team members (Visschers-Pleijers et al., 2004). The co-construction phase is an important collaborative effort by the whole team as it generates new knowledge that was not developed before and could not have been possible without the help of the collective cognition of all the team members (Decuyper et al., 2010).

\section{Constructive-conflict.}

During co-construction, there can come a point when team members do not agree with each other on certain points. This conflict can be both positive and negative for the team, hence it is very important to resolve the conflict without ignoring any of the involved parties (De Dreu \& Weingart, 2003). It can be a negative when team members feel disrespect, rejection, or other emotional turmoil in such a situation. In this case, the conflict can affect the morale of the team members and thus negatively impact the team's productivity (De Dreu \& Weingart, 2003). On the other hand, the conflict can generate more opportunities for communication among the team members to clear the concepts and help in understanding each other's point of view (Dillenbourg et al., 1996). This means that more knowledge transfer is possible during the constructive conflict phase than the other two phases. However, the conflict would have a positive effect only 
when it produces a deeper level of analysis and helps in the collective growth of the team (van Knippenberg et al., 2004; Homan et al., 2007).

\section{Application of Team Learning Behavior in Research}

Boujut (2003) researched the usage of annotations for team learning behavior in an ethnographic study of the product development stage within automobile manufacturing companies. The annotations, which were made on CAD programs, had to be addressed at three different levels: the physical level (related to specific elements or physical properties of the product), the knowledge level, and the symbolic level (the local language without which information could not be transferred). In the research, it was hypothesized that co-designers had to develop local language to co-create and jointly produce their artifacts. Moreover, the analysis found that cross learning processes were initiated when annotations were written for people from different expertise. They further found that annotations could be manipulated and transformed into a new language system with updated meanings and representations in symbols for people from different background to understand. It was also found that an annotation system can be used as artifacts, which ease the contextual learning process, and that an annotation system can be a convention, which has language-like power to boost shared understanding among team members.

Mulder et al. (2004) formulated a conceptual framework of team learning behavior. For this framework, conceptual learning, feedback, expression of affect, and questioning were found to be factors for generating shared understanding from prior knowledge and backgrounds.

Qualitative research via video-based communication was used to conduct the study. It was found that questioning and feedback were most essential elements for conversion of prior knowledge 
into shared understanding among the team members. The study also indicated suboptimal reflective behavior by the team members.

\section{Transformational Leadership and Team Learning Behavior}

Transformational leadership has been discussed as one of the key antecedents of a group's team learning behavior, especially in a heterogeneous group setting. This section elaborates on the relationship between team learning behavior and transformation leadership, which can be understood as a part of the relational dimension of Social Capital Theory.

Transformational leadership makes a positive impact on a team's learning because it provides collaborative and ideal role models (Mumford et al., 2003). In their examination of health workers' team learning behavior, Raes et al. (2012) found that transformational leadership was a key factor in team learning behavior because transformational leaders facilitate deeper communication among team members. Liu and Philips (2011) also examined the relationship between transformational leadership and knowledge sharing among team members for the facilitation of team innovativeness. They recruited 301 employees from research and development departments of 84 Taiwanese companies in their study and found that transformational leadership positively impacted the team's knowledge sharing intentions. Further, the authors found transformational leadership to be important for the team's learning behavior, especially for those teams that collaborate on complex and interdependent tasks such as research and development work. Likewise, Noruzi also found a positive relationship between transformational leadership and organizational learning and knowledge management.

More recently, Aga, Noorderhayen, and Vallejo (2016) researched the relationship between transformational leadership and team learning to better understand the critical success 
factors for project management in the context of Ethiopian Non-Government Organizations. Based on input from 200 project managers, the researchers found that transformational leadership positively impacted team building and the achievement of shared understanding. The study also suggested that a holistic set of team building strategies that includes goal-setting, roleclarification, interpersonal relations, and problem-solving help to create a committed and empowered team with a common shared understanding. Aga, Noorderhayen, and Vallejo (2016) described role-clarification as a particularly useful strategy to facilitate the co-construction and constructive conflict phases, two key components of team learning behavior.

Similarly, after investigating knowledge management practices in a textile auxiliaries and dye manufacturing company in Middle East, Gelard, Boroumand, and Mohammadi (2014) showed that transformational leadership positively impacted the team learning behavior of knowledge creation amongst team members. The correlation analysis showed that there was a relationship between transformational leadership and all of the components of knowledge management, including knowledge creation, sharing, utilization, and retention, with each helping to increase shared understanding among the team members. This relationship between transformational leadership and team learning behavior is also expected in the wearable technology product development team because the product developers have to come up with new product ideas, innovative designs, and solutions based on the changing needs and wants of the consumers. All three components of team learning behavior — construction, co-construction, and constructive conflict—are expected to help in team building and knowledge creation on complex and interdependent tasks, and transformational leadership is a key to achieve shared understanding. It is important to examine this relationship in the context of WTPD and CFPD which has not yet been done. Therefore, the study hypothesized: 
H2: Transformational leadership positively impacts team learning behavior in wearable product development teams.

\section{Relational Dimension of Social Capital: Sense of Community Definition of Sense of Community}

Sense of community is defined as "the perception of similarity to others, an acknowledged interdependence with others, a willingness to maintain this interdependence by giving to or doing for others what one expects from them, the feeling that one is part of a larger dependable and stable structure" (Sarason, 1974, p. 157). Sense of community directly relates to the self-identity of employees in relation with their organization (Levett-Jones \& Lathlean, 2008; Rupp et al., 2006). The more the employees relate with the organization's mission and principles, the more likely they will identify themselves with the organization (Kim, Lee, Lee, \& Kim, 2010; Masterson \& Stamper, 2003; Rupp et al., 2006). Organizational members often have similar needs, priorities, and objectives, which further facilitates the sense of community among them (Burroughs \& Eby, 1998; Chavis, Lee, \& Acosta, 2008). Further, the emotional quotient is high among the members of organizations that have strong senses of community, which in turn makes members comfortable with other members and with helping them and increases the longevity of their connection with the organization (Chavis et al., 2008; McMillan \& Chavis, 1986).

\section{Components of Sense of Community}

Currently, organizational behavior researchers identify four components of sense of community: membership, influence, the reinforcement of needs, and a shared emotional connection (Chavis et al., 2008; McMillan \& Chavis, 1986). 


\section{Membership}

There are five main sub-components of membership: boundaries, emotional safety, a sense of belonging and identification, personal investment, and a common symbol system (McMillon \& Chavis, 1986). The boundary around the community helps in differentiating between community members and non-members. It also helps in providing members with emotional safety and allows them to expose their needs and desires in the confined boundary (Bean, 1971; Ehrlich \& Graeven, 1971). The sense of belonging and identification explains the feelings of acceptance in the group and the belief that the members are a part of larger whole that, if necessary, will be willing to sacrifice for the group. Personal investment in terms of

physical, mental, psychological, or monetary efforts can help in building the bonds between the group members (McMillon \& Chavis, 1986). Due to the personal investments, membership within a community will be more meaningful and valuable to the members who have strong senses of community (McMillian, 1976).

\section{Influence}

The influence component works both ways, for the community as well as for the individuals in the community. The individual members need to influence the collective ideologies of the community (Peterson \& Martens, 1972; Solomon, 1960), and the ideologies and missions of the community should resonate well with the individuals (Kelley \& Volkart, 1952). The two-way influences must happen concurrently and simultaneously in a tightly knit community (McMillon \& Chavis, 1986). According to consensual validation research, a group vision cannot be forced on the members of a community; rather, it is transactional, coming from the individual and the group. Therefore, conforming behavior of the members is necessary to consensually validate the membership and formulate the group norms. 


\section{Reinforcement of Needs}

The fulfillment of needs by participating in the works of the community is necessary for members' continued devotion towards the community (McMillon \& Chavis, 1986). There can be many types of reinforcements that bind individuals to the community. Some of them are: the status of being members of the community (Kelley, 1951; Zander \& Cohen, 1955), the success of the community (Peterson \& Martens, 1972), and the competence of its members (Hester, Roback, Weitz, Anchor, \& McKee, 1976; Zander \& Havelin, 1960). Members attract other members of the community if their skills or competencies are needed by them or benefit them in some capacity. Shared values that bring in similar needs, common goals, and ideologies among the members can help to reinforce the appropriate expectations from the community (Cohen, 1976; Doolittle \& MacDonald, 1978).

\section{Shared Emotional Connection}

One of the important components of a sense of community is members' sharing or identifying with events or histories together to build an emotional connection (McMillon \& Chavis, 1986). Increasing the number and quality of interactions between the members also facilitates the emotional connection (Allan \& Allan, 1971; Cook, 1970; Festinger, 1950). Unresolved tasks and ambiguous interactions lead to a decline in the shared emotional connection. Conversely, sharing important events related to success or crisis reinforces the connections. Celebrating an accomplishment or chastising the members for failure in front of other members has consequences on the attractiveness of the community, whether positively or negatively (Festinger, 1953; James \& Lott, 1964).

\section{Sense of Community and Team Learning Behavior}


Team learning through knowledge creation, co-creation, and constructive conflict is related to altruism and is considered voluntary social behavior (Nonaka \& Takeuchi, 1995), and the literature on sense of community shows that it shares the same characteristics (Bolino, 1999). Aruştei and Leon (2013) further elaborated that although tacit knowledge sharing and sense of community in organizations lead to personal and professional development, there is a lack of scholarship addressing these two factors together. To fill in this gap, the researcher conducted a study on hospitality management in Romania. Their analysis revealed that sense of community in organizations positively impacted tacit knowledge sharing among the hotel employees. Tacit knowledge sharing occurred by improving team activities through socializing and sharing their experiences with one another.

Using a laboratory experimental method on 46 distributed teams, Windler (2015) found that sharing the e-profiles of team members who are apart from each other at the beginning of team projects, a moment which creates a sense of community, can enhance their readiness to learn together and thereby reduce conflict and increase collaboration. Sharing e-profiles was expected to increase the emotional connections among geographically distant team members and thus help in boosting collective sentiments within the teams and positively affect their readiness to learn among the distant members. In the data analysis, it was found that exposure to e-profiles of distant team members reduced task conflict among them. In similar research done on Turkish online students, the sense of classroom community positively impacted the team learning behavior (Erdem \& Gumus, 2016). Similarly, many other study have shown a positive relationship between sense of community and team learning behaviors such as information sharing and the creation of shared commitment to achieving collective goals (Bruffe, 1993; Ded, 
1996; Wellman, 1999). This positive relationship between sense of community and team learning increases satisfaction through increased cooperation and teamwork.

In addition, Hill et al. (2014) explored the impact of a sense of community and team learning behavior on innovation. It was argued that giving voice to all the members of the company is important for innovation. This was achieved by generating a sense of respect, trust, and influence among the members of the companies irrespective of their hierarchy and diversity. This empowerment, which happens through the generation of sense of community, was stated to be effective for developing a shared vision among the team members and, in turn, their readiness to learn together. This relationship was not tested in the fashion or WTPD sector. Therefore, the following hypothesis was developed:

H3: Sense of community positively impacts team learning behavior in wearable product development teams.

\section{Team Learning Behavior and Innovative Work Behavior}

Finally, many researchers have examined the impact of social capital on a group's innovative behavior (Dakhli \& De Clercq, 2004; McFadyen \& Canella, 2004; Akcomak \& Weel, 2009). Team learning relates to the cognitive dimension of social capital theory, and therefore the researchers suggest that shared understanding, as a dimension of social capital, can positively affect the team's innovative behavior. This section further elaborates this idea to explain team learning as one of the antecedents of innovative behavior.

With the importance of team learning behavior having already been established by the 1990s, researchers during the 2000s and 2010s were interested in how to achieve shared understanding within a group. Fruchter (2001) argued that there are four stages of achieving 
cross-disciplinary learning within a group or an organization. The first stage is when the group members are on restricted islands of knowledge specific to their disciplines. In the second, group members become aware of different disciplines. Thirdly, group members start appreciating each other's disciplines to understand different points of the view. In the fourth and final stage, group members start to merge knowledge from different disciplines and are capable of understanding each other's languages and goals. Fruchter therefore argued that these team learning behaviors help in achieving shared understanding at the fourth level and thus help the team to engage in successful group innovation. Since then, team learning behavior has been used in various contexts such as community development and manufacturing to help foster innovation, performance, and collaboration in team contexts.

Aube et al. (2015) researched the relationship between team learning and team performance for 101 teams working in a Canadian public safety organization. It was found that group potency (the team-members' belief in their collective capability) and team effort had a mediating role between team learning and team performance. The results showed a positive effect of collective cognition on group efficacy, which in turn contributes to team performance. It also reaffirmed the fact that a common understanding of the work energizes the team by activating two motivational mechanisms, group potency and team effort (Hoeft et al., 2005; Johnson et al., 2007; Klimoski \& Mohammed, 1994; Auebe et al., 2015).

Bagher et al. (2016) also studied the effect of transformational leadership, knowledge management and organizational innovation capacity on a large university in Iran. In their study, they used five components of knowledge management—acquisition, registration, creation, transfer, and application. These five components are similar to the three dimensions of team 
learning, that is, construction, co-construction, constructive conflict. In their quantitative analysis, it was found that transformational leadership positively affected knowledge management and organizational innovation. Additionally knowledge management and team learning behavior had positive impacts on organizational innovation.

Similarly, Dingler and Enkel (2015) studied the effect of socialization on the knowledge transfer that results in collaborative innovation. It was found that the sharing of knowledge through personal interactions and the development of a common language and norms triggered innovation across industry boundaries. In a parallel vein, a study done by Choi et al. (2016) found transformational leadership and team learning to have a positive impact on the innovative behavior of workers employed in the Korean manufacturing industry. In addition, Chang et al. (2015) found that knowledge sharing positively impacts altruistic behavior in the context of Taiwanese semiconductor industry, which ultimately leads to better performance from the team members.

Therefore, as the relationship was not tested in the WTPD or CFPD in past, this study hypothesized that shared understanding positively impacted innovative work behavior for wearable product development teams.

H4: Team learning behavior positively impacts innovative work behavior in wearable product development teams.

\section{Difference in the Fashion and Wearable Technology Product Development Teams}

Transformational leadership has been analyzed in different settings within a team, such as the individual level, dual level, and team level. There is a strong and positive effect of transformational leadership on the performances of diverse team members in terms of different 
cognitive and demographic background (Kearney \& Diether, 2009). In research by Wang et al. (2016), for instance, it was found that transformational leadership was important with teams comprised of diverse members. Similarly, in another study by Shen (2012), it was found that in the presence of transformational leadership, a team's diversity positively affects individual team member's creativity. In another study on the United States federal government, transformational leadership was found to positively influence diverse team members (in terms of biodemographics and, again, functionally diverse teams) to perform beyond their job responsibilities more than in teams with homogenous members (Moon, 2017). It is thus important for team members to bring their tacit knowledge and share it with their team, which could be facilitated by transformational leaders. When a team consists of professionals from multiple backgrounds such as engineering and fashion, the impact of individualized consideration on each team member, which occurs through transformational leadership, can be crucial for team's success. This relationship has not been examined for WTPD and CFPD teams. Consequently, the study hypothesized:

H1a: Transformational leadership has a greater impact on innovative work behavior with heterogeneous WT product development teams than with conventional homogeneous fashion product development teams.

Furthermore, research suggests that the diversity among team members impacts the relationship between transformational leadership and team learning behavior. Wang, Kim, and Lee (2016) researched the impact of cognitive diversity amongst team members on team creativity. They used team intrinsic motivation as a mediator and transformational leadership as a moderator variable in hierarchical regression modeling. Their work found that when 
transformational leadership was high, the cognitive diversity effect on team's intrinsic motivation to share knowledge was positive, and when transformational leadership was low, the effect was negative. These results suggested that transformational leadership is especially important for a team's learning behavior when the team has cognitively diverse members.

Similarly, within wearable product teams, it is expected that when the product development teams consists of diverse team members in terms of academic background and professional experience, transformation leadership was more important for achieving shared understanding with increased team learning behavior than with teams consisting of homogenous members belonging to same academic discipline. Consequently, the study hypothesized:

H2a: Transformational leadership has a greater impact on team learning behavior within heterogeneous WT product development teams than on conventional homogeneous fashion product development teams.

Knowing and learning are the results of social dynamics (Jaccard \& Jacoby, 2010; McMurtry, 2016). In the communities of practice literature, the act of knowing is a result of relationships among team members, and the rate of knowledge increases as the individual team members move from being newcomers to mature members of the team (Bunniss \& Kelly, 2013). This importance of interactions and the sense of community for team learning increase with an increase in the diversity of the team members (Collin et al., 2010). Through ethnographic study of surgical operating teams, Collin et al. (2010) further validated the point that collegial support, inclusive work environments, a willingness to cross interdisciplinary boundaries, and wellformulated task divisions—all of which are components of a sense of community—are important for inter-professional team based learning. 
Moreover, Gratton (2007) found that the diversity of team members can be handled properly by upper management through human resources initiatives such as sponsoring events that give opportunities for colleagues to meet each other beyond their expected work schedules. The study showed that through such events, a sense of community develops among the diverse team members, which subsequently facilitates team-learning behavior. Additionally, Bunniss and Kelly (2013) found that shared understanding and learning in team activities were highly relational. In other words, team members who knew each other well could anticipate each other's thought processes. On the other hand, the team members who did not share professional history faced problem in articulating the next steps. The diverse team members needed extra bonding time, which comes through the development of a sense of community in order to enhance team learning. Those team members who belong to same academic background and share professional history together have less of a problem understanding each other and articulating their thought processes (Bunniss \& Kelly, 2013).

Most recently, in research on WT professionals by Raj and Ha-Brookshire (2016), it was found that knowledge creation among diverse team members was happening through socialization and in informal work environments. Socialization gave the diverse team members more opportunities to meet frequently and thus understand each other's perspectives, and an informal atmosphere gave them a free and productive environment for brainstorming. It was also found that risk-taking and nurturing environments were needed for bringing multi-disciplinary workforces together. Therefore, a sense of community in the diverse team was found to have greater effects on team learning behavior. In this light, the study hypothesizes that it is more important for diverse team members to have a sense of community for developing positive team learning behavior than is the case for a homogenous team. The diverse team members of a 
WTPD team needed to develop a sense of community to come out of their distinct academic backgrounds. This development of a sense of community led to more construction and coconstruction of knowledge. If team members considered each other as belonging to the same community with the same goals and visions for team, they would also be able to positively handle constructive conflict, which is one of the components of team based learning. Therefore, the study hypothesized:

H3a: Sense of community has a greater impact on team learning behavior within heterogeneous wearable technology product development teams than in conventional homogeneous fashion product development teams.

Furthermore, according to Leonard and Sensiper (1998), "intellectually heterogeneous groups are more innovative than homogeneous ones"' (p. 118). Team diversity in terms of members' technical backgrounds, ages, and other characteristics creates tension among them. This tension is thought to challenge them to perform better, thus increasing the team's performance and learning behavior through the increased effort toward shared understanding in the team (Roberts, 1987). Leonard and Sensiper (1998) further argued that collaboration among diverse team members often results in "creative abrasion," which produces new ideas and helps drive innovation.

More recently, Nissen et al. (2014) studied heterogeneous team members' knowledge sharing through collaboration and cooperation for innovation in public-private partnership projects. They found that teams that continuously use different methods for bringing out the knowledge of diverse team members succeed in the innovation process. They also found that continuously re-establishing shared knowledge bases after conflict or challenges in the team 
helps progress towards innovation in organizations. Similarly, Akturan and Çekmecelioğlu (2016) researched team learning and creative behavior in organizations in the context of educational institutions in Turkey. It was found that the more team learning behavior was displayed within the institution, the more team members showed their creative behavior.

Heterogeneous team members bring diverse tacit knowledge, different vocabularies, and unique cognitive patterns (Drach-Zahavy \& Somech, 2001). The management of knowledge in heterogeneous teams is therefore especially important for making any progress towards innovative development. The type of knowledge sharing method is also important because if a wrong style of method is chosen, it can reduce the innovative capabilities of the team (Sapsed et al., 2002). In a homogenous team, however, there is similarity in the tacit knowledge of the team members, thus requiring less effort to explain or demonstrate something to the team (MarinGarcia \& Zarate-Martinez, 2007; Sapsed et al., 2002). This relationship between team learning and innovative behavior is yet to be examined from the context of fashion and WTPD teams. Therefore, the study hypothesized:

H4a: Team learning behavior has a greater impact on the group's innovative behavior in heterogeneous wearable technology product development teams than in conventional homogeneous fashion product development teams.

\section{Summary of Study Hypotheses}

This study is built upon Social Capital Theory (Bourdieu, 1986; Putnam, 2000; Wallis, Killerby, \& Dollery, 2000) and utilizes literature from but not limited to leadership (Burns, 1978; Bass, 1985; Bycio, Hackett, \& Allen, 1995; Bass \& Riggio, 2005), community (Perkins \& Long, 2002; Chavis et al., 2008; McMillan \& Chavis, 1986), team learning behavior and innovation 
(Cannon-Bowers et al., 1993; Mathieu et al., 2000), and innovation (Kanter, 1988; Scott \& Bruce, 1994; Van de Ven, 1986). Based on the findings of various studies from these different fields, the study formulated the following hypotheses to further expand and fill in the gaps in the literature.

Hypothesis 1: Transformational leadership positively impacts innovative work behavior in wearable product development teams.

Hypothesis 2: Transformational leadership positively impacts team learning behavior in wearable product development teams.

Hypothesis 3: Sense of community positively impacts team learning behavior in wearable product development teams.

Hypothesis 4: Team learning behavior positively impacts innovative work behavior in wearable product development teams.

Hypothesis 1a: Transformational leadership has a greater impact on innovative work behavior on heterogeneous WT product development teams than on conventional homogeneous fashion product development teams.

Hypothesis 2a: Transformational leadership has a greater impact on team learning behavior within heterogeneous WT product development teams than in conventional homogeneous fashion product development teams.

Hypothesis 3a: Sense of community has a greater impact on team learning behavior within heterogeneous wearable technology teams than in conventional homogeneous fashion product development teams. 
Hypothesis 4a: Team learning behavior has a greater impact on the group's innovative work behavior within heterogeneous wearable technology product development teams than in conventional homogeneous fashion product development teams. 


\section{CHAPTER III. METHOD}

The following sections are discussed in detail in Chapter III: (a) online survey research, (b) the research instrument, (c) data collection and sampling, (d) the preliminary test, and (e) data analysis.

\section{Online Survey Research}

An online survey technique was used to collect the data to test the hypotheses of this study. In comparison to other techniques such as phone interviews, the online survey technique is helpful in giving the research participants the opportunity to be in their natural setting with the least influence and interference from the researcher during their participation (Dillman, 2009). Survey aids in capturing the current conditions and attitudes of the research participants. An increase in the amount of people's connectivity to the internet allows online surveys to have a greater reach in various types of research studies related to governments, businesses, academics, politicians, and numerous other organizational behavior studies (Gaddis, 1998). This technique is also useful in targeting participants without any restriction of geographical boundaries, which is helpful in establishing the external validity (Wimmer \& Dominick, 2006). The easy transferability of online links helps in quicker data collection and also facilitates any follow up actions (Dillman, 2009). Further, the use of online survey format also allows respondents to review and verify their answers conveniently and anonymously (Christian, Dillman, \& Smyth, 2007; Lewis, Watson, \& White, 2009).

However, there are a few limitations of the online survey technique as well, such as lower response rates due to email filtering and technological problems. To deal with the issue of email filtering, a data collection agency, Qualtrics, was used. A representative of Qualtrics informed 
the PI about the recruitment process utilized for this study. In the communication with the representative, it was found that Qualtrics verifies the panel members for each industry (Nathan, personal communication, January 28, 2017). Qualtrics has been used in similar kinds of organizational behavior research for the fashion industry in the past (Lee, 2016).

\section{Research Instrument}

The research instrument used for online survey was adapted from the literature. The online survey instrument consisted of seven sections: (a) screening questions, (b) transformational leadership, (c) team learning behavior, (d) sense of community, (e) innovative work behavior, (f) general employment, and (g) demographic information.

\section{Screening Questions}

For the study samples, a few screening questions were formulated to determine the eligibility of the research participants. A list of the screening question is shown in Appendix A.

In the beginning of the online survey, the first question was asked to ensure the participants belonged to either CFPD or WTPD teams. If they were not qualified for either option, then they were stopped from further participating in the study. For this purpose, a definition of product development was displayed to help them in choosing the correct option.

A second question was asked to understand their product development roles. The participants were asked to write in a word or two about their work function in their team. This helped in further determining the nature of the work functions of the research participants and to ensure that they belonged to the product development teams. 
Third, to assess the cognitive diversity of the team, additional screening questions were asked. First, two word maps depicting a set of cognitively/academically diverse team members were shown. The first figure showed more academically diverse team members compared to second one (Appendix A). The participants who choose option B were classified as belonging to cognitively diverse team. Questions three and eleven were compared to check if the conventional fashion product development is indeed more cognitively homogenous than the WT product development team.

\section{Transformational Leadership}

In 1980s, by examining the leadership behaviors of senior executives (Bass, 1985a) and examining the leadership behavior of 104 army officers (Bass, 1985b), Bass operationalized the concept of transformational leadership and created Multifactor Leadership Questionnaire (MLQ). MLQ contained the three components of transformational leadership - charismatic leadership, individualized consideration, and intellectual stimulation. Later, Avolio, Waldman, and Yammarino (1991) added the components of 'inspirational motivation' to MLQ, and charismatic leadership was changed to 'idealize influence.' Since then, Avolio, Waldman, and Yammarino's (1991) scale was largely used in organizational behavior, mostly to predict management performance, team satisfaction, organizations' performance outcomes, and management team building stimulation (Avolio, Waldman, \& Einstein, 1988; Hater \& Bass, 1988; Keller, 1992). Consequently, the scales were refined in 1990 by Bass and Avolio and again in 2002.

However, the scale developed by Carless, Wearing, and Mann (2000), which is called Global Transformational Leadership (GTL), is more robust. It was called the Global Transformational Leadership (GTL) scale because it is a single construct of transformational 
leadership that captures all the elements of transformational leader in a short scale. The scale was tested on a sample of 1,440 subordinates who were asked to rate the behavior of their leaders. This study was done from sampling based on a large Australian financial organization. The scale was tested through convergent and divergent validity. The factor loadings of GTL scale ranged from .78 to .88 .

For assessing the convergent and divergent reliabilities the two other scales for measuring leadership, Leadership Practices Inventory (LPI) (Kouzes \& Posner, 1990) and the Multifactor Leadership Questionnaire (MLQ) (Avolio, Bass, \& Jung, 1995), were also measured. The LPI and MLQ are the other two most common measures of transformational leadership. The correlation between items of GTL and corresponding items of LPI and MLQ were high, ranging from .76 to .88 , proving strong convergent validity (Carless et al., 2000). The Cronbach's alpha was .93, proving GTL as a reliable source for measuring transformational leadership (Carless et al., 2000). To date, the GTL components are supported as the most robust measurement items to capture transformational leadership.

Seven items were used in this research to capture transformational leadership. The first, "communicates a clear and positive vision of the future," correlated with LPI's inspiring a shared vision. The second was "treats staff as individuals, supports and encourages their development," which correlated with MLQ's individual consideration. The third was "gives encouragement and recognition to staff," which correlated with LPI's encouraging the heart. The fourth was "fosters trust, involvement, and co-operation among team members," which correlated with LPI's enabling others. The fifth, "encourages thinking about problems in new ways and questions assumptions," correlated with LPI's challenging the process and MLQ's intellectual stimulation. 
The sixth, "is clear about his/her values and practices what he/she preaches," correlated with LPI's modeling the way. Finally, the seventh was "instills pride and respect in others and inspires me by being highly competent," which correlated with MLQ's charisma.

To measure these items, a five point Likert scale was used, from 1 being "Rarely or never" to 5 being "Very frequently, if not always." The participants were asked to rate their leaders "in terms of how frequently he or she engages in the behavior described" (Carless et al., 2000, p. 395). All the items used to measure TL are listed in Table 3.1. Minor modifications of the items were done to improve the language and help present the items to the research participants according to the context of this study. For example, "My team leader" was added before every item to help understand the context. All the modifications, which are minor, are italicized and presented in Table 3.

\section{Team Learning Behavior}

Visschers-Pleijers, Dolmans, Wolfhagen, and Van der Vleuten (2003) measured collaborative learning processes through exploratory questions having four items, such as "What group members said was checked by asking each other critical questions." The scale was tested on students from a large university in Europe,who had experience in problem-based learning. Van den Bossche et al. (2006), taking inspiration from Visschers-Pleijers et al. (2003), developed and validated the scale for measuring team learning behavior.

The three phases inspired from Visschers-Pleijers et al. (2003) that led to team learning behavior were termed construction, co-construction, and constructive conflict and were measured separately. To measure the construction phase, three items were used. One such item was "If something is unclear, we ask each other questions." Co-construction was measured using three 
items, one being "Information from team members is complemented with information from other team members." Three items also measured constructive conflict, one of which was "This team tends to handle differences of opinions by addressing them directly." Through factor analysis, it was concluded that all the selected items had a high loading with a minimum of .66 and high internal consistency (Cronbach's alpha of .88) (Van den Bossche et al., 2006). A seven point Likert scale adopted from Boon and Raes (2013) was used for this study, with 1 being "strongly disagree," 4 being "neutral," and 7 being "strongly agree." No modifications were done to the items or the Likert scale, as they were well suited to the context of this study. All the items are listed in Table 3.1.

\section{Sense of Community}

McMillan first conceptualized the theory of community in 1976. This theory was used by Chavis et al. (1986) to develop a scale for sense of community. The scale developed was used in conducting research primarily for neighborhoods but expanded to other communities as well. For example, the scale was used to examine adults in their workplace (Brodsky \& Marx, 2001; Pretty \& McCarthy, 1991), religious communities (Miers \& Fisher, 2002), immigrants (Sonn, 2002), residential neighborhoods (Brodsky \& Marx, 2001; Brodsky, 1999), students in universities (McCarthy, Pretty, \& Catano, 1990; Pretty, 1990), adolescents in residential neighborhoods (Pretty, Andrewes, \& Collett, 1994; Pretty, Conroy, Dugay, Fowler, \& Williams, 1996), retention of seasonal employees (McCole et al., 2012), and job satisfaction (McCole, 2013).

This scale originally had twelve items. After a period of popularity and application in various studies, it was highly criticized during 2000s. In research conducted to re-test the scale, the following four main problems came up: (1) dimensions varied in terms of place and time, (2) 
measurement did not reflect McMillan and Chavis's objectives, (3) the true and false response option restricted the measure's sensitivity, and (4) construct validation was not properly donefor example, items such as place attachment and length of stay did not properly match with the original construct (Long \& Perkins, 2003). In 2008, Chavis, Lee, and Acosta revisited the old scale and upgraded it to address the criticisms of it. In the study, they confirmed that the twelveitem scale was reliable, but their four sub-components had low reliability and were inconsistent. The usage of the scale in cross-cultural research was prominent, but its reliability in measuring cultural difference was questionable (Chavis, Lee, \& Acosta, 2008).

Hence, Chavis, Lee, and Acosta redeveloped the scale in a 2008 study on immigrant integration in a western U.S. state. The new scale consisted of 24 items covering all the aspects of sense of community developed in the original theory. A Likert scale was used instead of true and false responses. After the pilot study, a higher reliability was found and minor changes were recommended, such as changing the description of the items. The scale was then tested on 1,800 people and showed high reliability with a Cronbach's alpha of .94. The subscales also had Cronbach's alphas ranging from .79 to .86 .

This new version of sense of community, as developed by Chavis, Lee, and Acosta (2008), was therefore used in this study. It has four sub-dimensions. The first is the reinforcement of need, which has five items, such as "My team members get important needs met because they are part of this organization." The second is membership and it has five items, including "Most of my team members know each other." The third is influence and it has six items, including "My team members have influence over what this organization is like." The fourth is shared emotional connection and it has six items, including "Our team members spend 
time together and enjoy being with each other." All the items were measured on a four point Likert scale, with 1 being "not at all", 2 "somewhat", 3 "mostly", and 4 "completely." The language of some of the items was modified slightly to suit the respondents for this study. The modification was also done to change the items to be representative of team behavior rather than individual behavior. For example, "I" was changed to "My team members," and the grammar of the sentences was changed accordingly. All the items are measured on the team rather than individual level. The details of each item and modification are reported in Table 3.1.

\section{Innovative Work Behavior}

To measure innovative work behavior, the scale developed by Janssen (2000) was used in this study. Janssen (2000) formulated the scale based on the works of Scott and Bruce (1994) and Kanter (1988). Scott and Bruce (1994) first formulated the scale with six items measuring one concept called innovative behavior. Janseen (2000) used these components and combined it with Kanter's (1988) three stages of innovative work behavior — idea generation, idea realization, and idea promotion. The scale was tested on a Dutch industrial organization in the food sector. The scale has since been used by researchers to measure innovation in organizations across various sectors, such as financial services (Vegt \& Janssen, 2003), educational institutions (Janssen, 2003), information technology service, furniture design manufacturing, and other types of manufacturing (Ramamoorthy et al., 2005; Yuan \& Woodman, 2010)

Three items measured each of the three components. For example, idea generation was measured using "searching out new working methods, techniques, or instruments," idea promotion was measured using "acquiring approval for innovative ideas," and idea realization was measured using "'transforming innovative ideas into useful applications." Reported inter- 
correlations between idea generation and idea realization was .76 and between idea promotion and idea realization was .85 .

Due to these high correlations, the three phases combined effectively to create an overall scale of innovative work behavior. A seven point Likert scale was used to measure the items, from (1) "never" to (7) "always." The reported reliability of the scale was high with a Cronbach's alpha of .95 (Janssen, 2000). Similarly, for this study the three phases were used to measure innovative work behavior. The language of some of the items was modified slightly to match the context of this study. For example, "As a team," was added before each item to help in creating appropriate context for the research participants. The details of each item and modification are reported in Table 3.1.

\section{General Employment and Demographic Information}

Other general questions were asked to the research participants. First, they were asked information about their companies, such as the number of employees, gross sales figures, and the performance of the company (Ha-Brookshire, 2007; Lee, 2015). Second, they were asked about the product categories they work on, the geographic location of their company, how long the company has existed. This information helped in determining the nature of the companies the research participants worked for. Third, demographic information such as age, gender, and ethnicity were asked in the survey to understand the characteristics of the research participants. Detailed information about demographic questions can be found in Appendix A.

\section{Sampling and Data Collection}

The population of product developers in the conventional fashion industry is relatively larger than in the wearable technology industry. The conventional fashion industry is a well- 
established industry. The wearable technology industry, in comparison to the conventional fashion industry, is still in an introductory stage. To gain participation from both of these industries, a data collection agency was used to target participants from each industry.

In this study, the intended sample size was 300 , based on the rule of thumb of having 5 or 10 observations for each estimated parameter (Bentler \& Chou, 1987) and 10 cases per variable (Nunnally, Bernstein, \& Berge, 1967). In this study, there is a total of 48 parameters and four variables. From that, the minimum number of observations required would be 240 . Therefore, targeting 275 samples, which is more than the minimum required, was acceptable for this study. Additionally, power analysis was conducted, from which it was found that for $d f$ of 1200 , alternate RMSEA of .08, Null RMSEA of .05, and alpha of .05, a power of .98 could be achieved from the sample size of 275 (Preacher \& Coffman, 2006). 


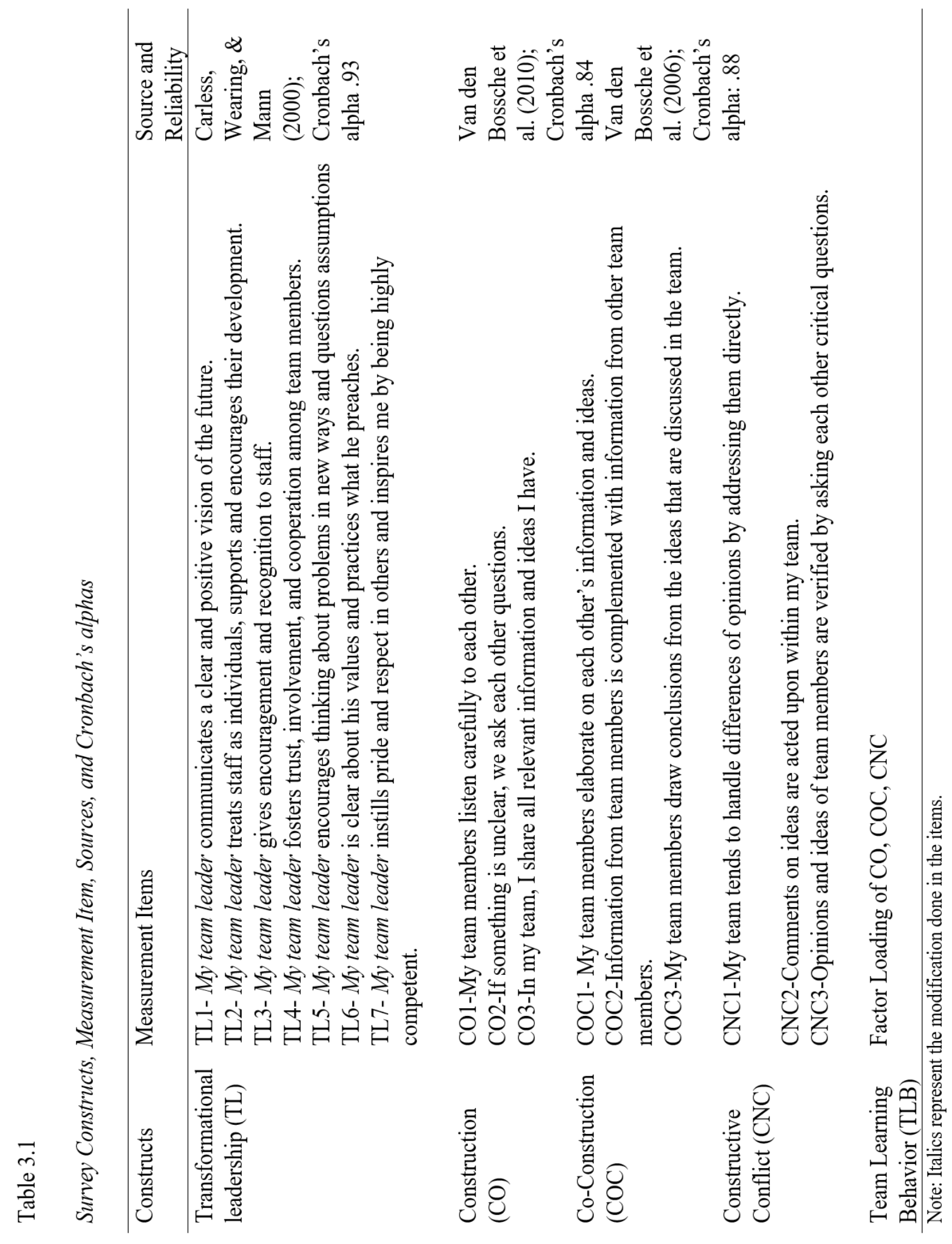




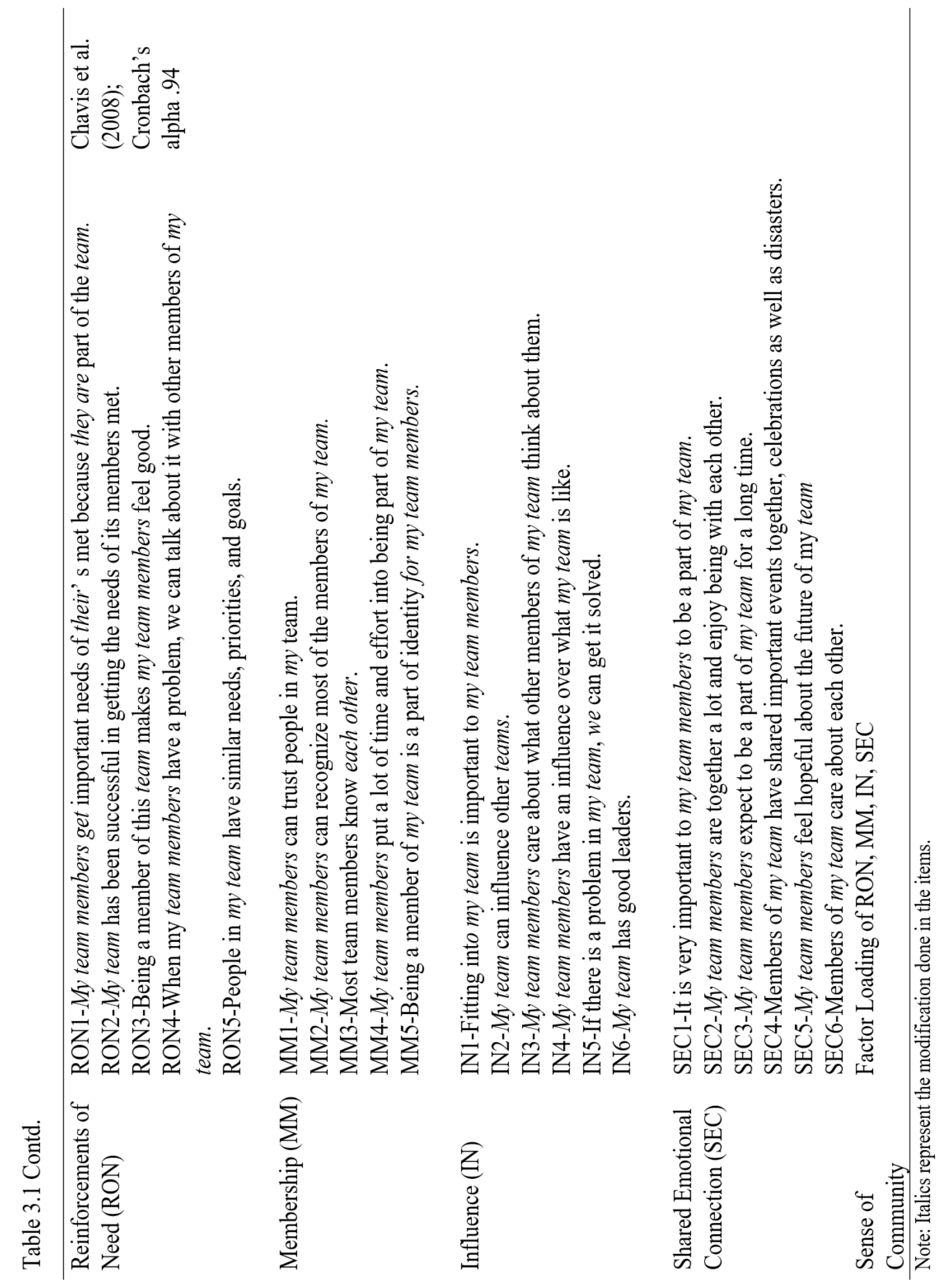




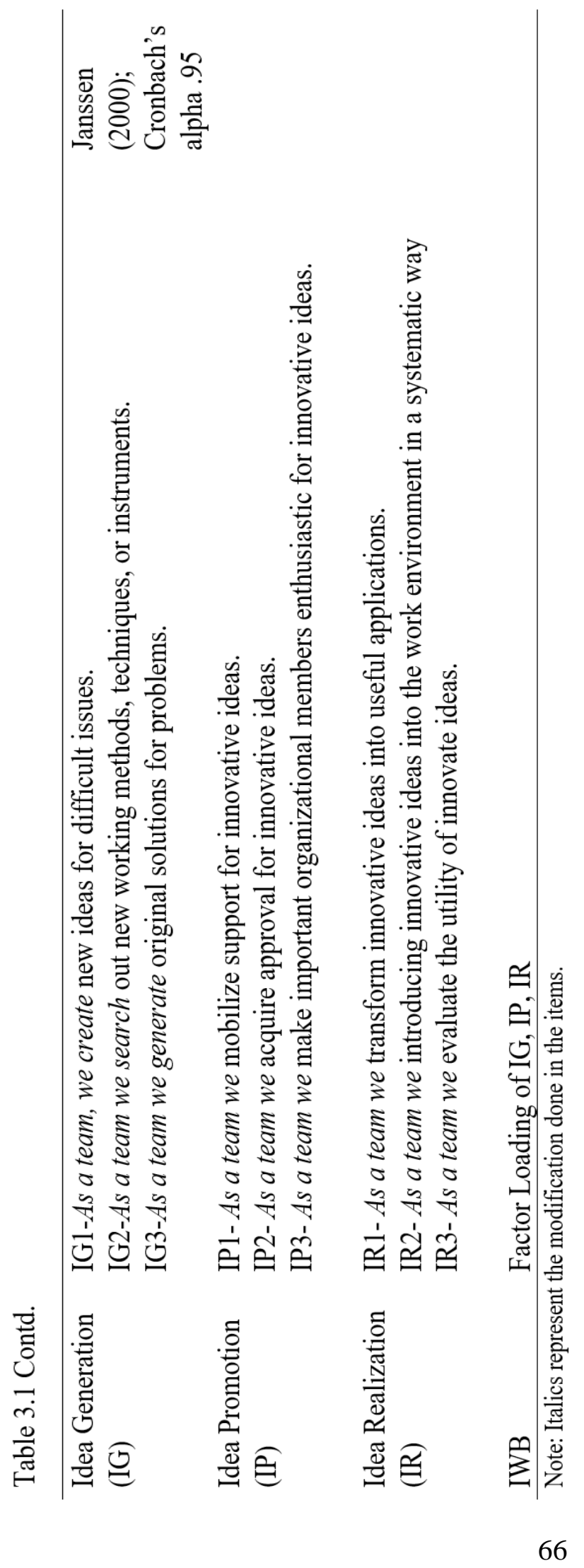


Recruiting research participants who not only work in an emerging and niche sector, Wearable Technology, but also more specifically work in the product development activities was challenging. An established data collection agency, Qualtrics, promised to recruit only 100 participants for the WT group because it was difficult to recruit product developers from such a niche area. Qualtrics had panel members who worked for the apparel industry in various product development roles and collected 150 responses from product developers in the conventional fashion industry. At the end of the data collection process, Qualtrics recruited 125 product developers from the WT industry. The total cost of collecting 275 research participants from Qualtrics was $\$ 3,850$.

The designed survey was formulated using principles of tailored design format, as developed by Dillman, Smyth, and Christian (2014). The survey was kept simple and to the point. After receiving the approval for conducting this research from the University of Missouri Institutional Review Board, the survey was sent to the data collection agency. The survey also had an informed consent form on its first page.

\section{Preliminary Test}

Preliminary testing is recommended with a group similar to the intended sample or with professionals with special knowledge or experience of data collection in a similar setting (Dillman, 2009). Therefore, the survey was first tested through four faculty members in Textiles and Apparel Management to improve the language, clarity, and flow of the questions. Follow-up interviews were conducted with the professors who completed the pretest survey to identify any issues and any navigation problems, as suggested by Dillman (2009). The faculty members suggested minor changes in regard to the wording of the questions. Pictures showing key 
wearable technology products and fashion products were added to aid better understanding for the research participants, as reported in Appendix A.

Second, after the approval of Institution Review Board, the data collection agency was asked to collect the first 50 data from the target sample pool. The collected data were analyzed to examine the factor loading, and Cronbach's alphas were calculated. After analyzing the data, the final questionnaire was slightly modified by adding one more screening question at the beginning of the survey that asked if the participant's work was involved with product development. Only those participants who said yes were allowed to proceed with the survey. Apart from this, the questionnaire remained the same, as the factor loading and Cronbach's alpha value were in range for the pilot test data as shown in Table 3.2.

\section{Data Analysis Techniques}

The data from the online survey was downloaded from Qualtrics in CSV format. The data was then cleaned and coded for the analysis. The cleaned data was then analyzed in MPLUS software, which is used for analyzing Structural Equation Modeling (SEM) applications. In the section below, the advantages of using SEM analysis, a measurement model, and structural models are explained. The two-step approach of a measurement model and structural model has been widely used in many studies (Hair et al., 1998). 


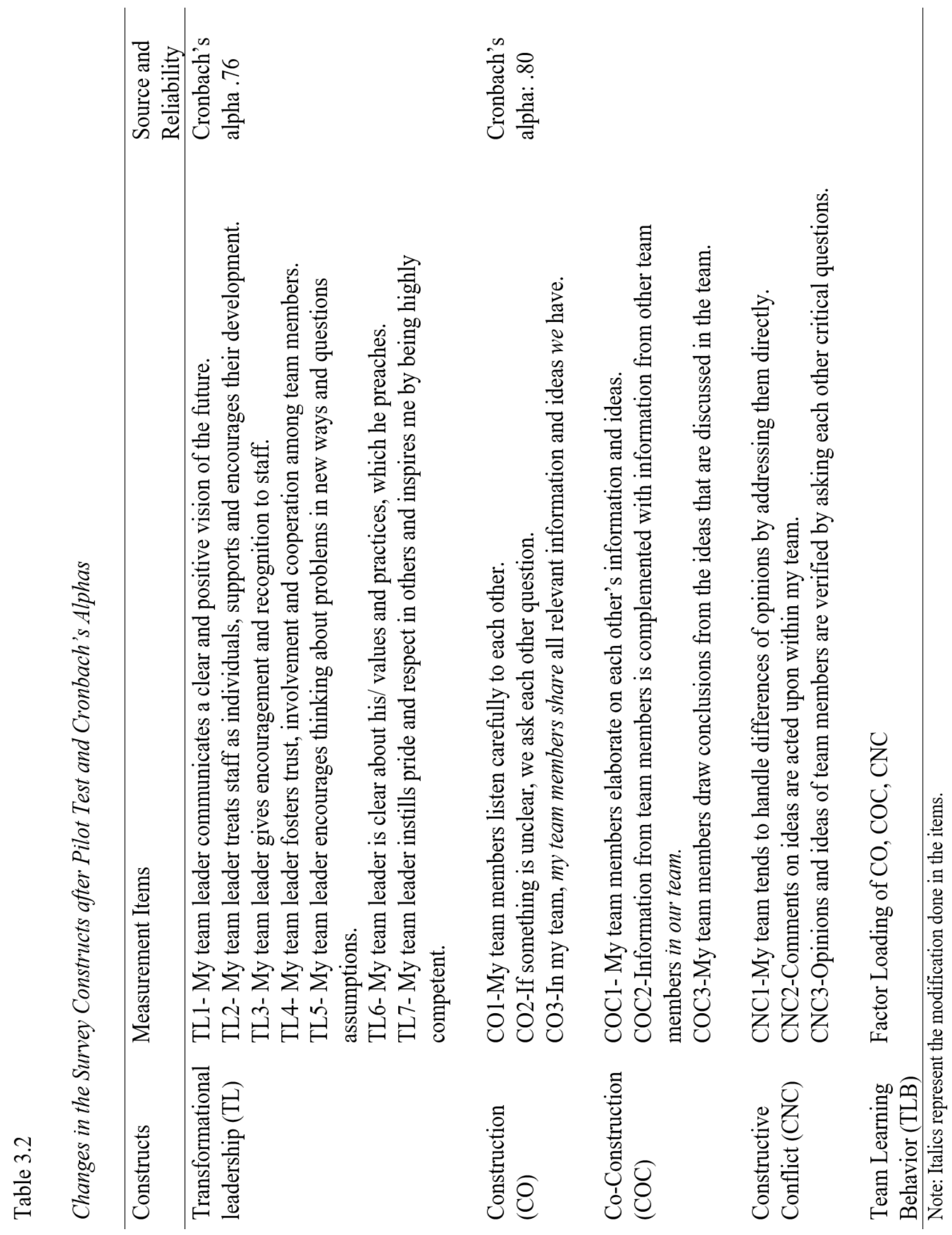




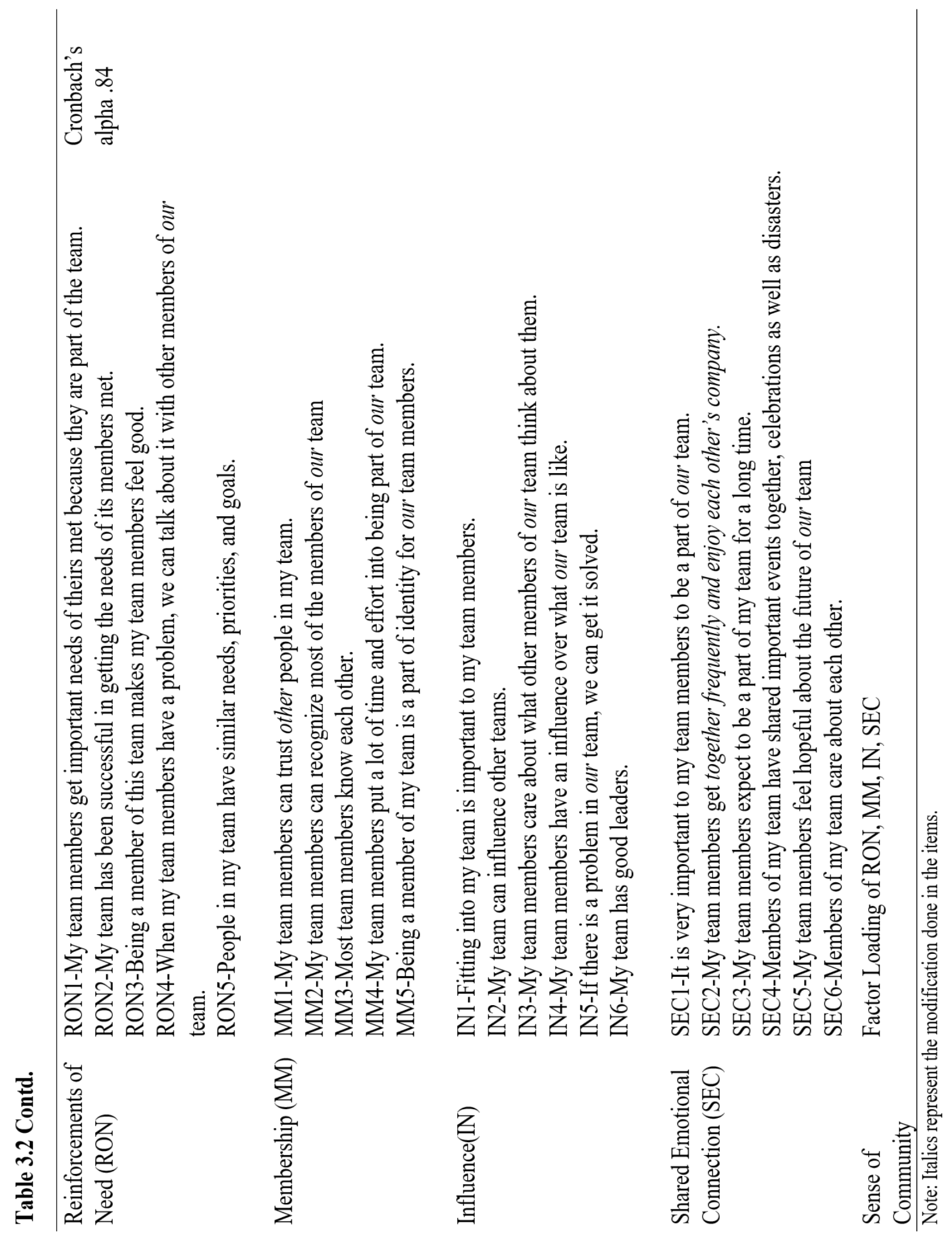




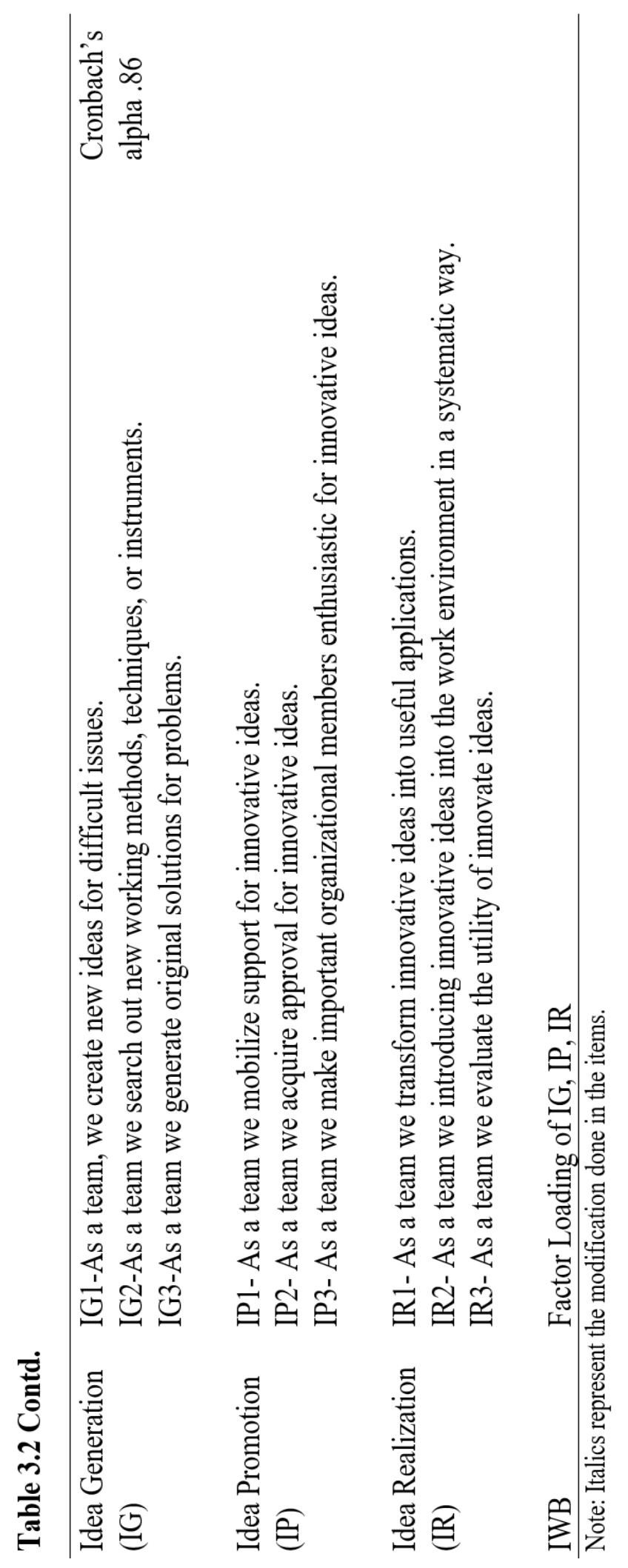




\section{Advantages of using SEM Analysis}

In SEM analysis, multiple models can be compared and checked if the alternative model's fit has statistically significant improvement in the fit with the observed data (Weston \& Gore, 2006). This element of SEM was particularly important for this study as each latent variable had more than three observed variables. If one or more of these variables did not load highly on the latent variable, a model with fewer observed variables can be analyzed and checked if the model fit improved or declined after such removal. Second, in multi-group analysis it is important to determine if the observed variables/items for each of the latent variables had similar validity for the participants of each group. This could be only done through SEM analysis by constraining the factor loading to be equal in each group and checking if the constrained model had a better fit than the unconstrained model using the chi square difference test. Third, direct and indirect effects can be calculated by running only one analysis, unlike regression where more than one model had to be analyzed.

\section{Assessing Measurement Model}

The validity of the data was determined using Confirmatory Factor Analysis (CFA). In the model evaluation phase, various goodness of fit measures such as the $p$-value associated with the Chi-squared $\left(\chi^{2}\right)$ statistic should be more than .10; the Goodness of Fit Index (GFI), Comparative Fit Index (CFI), and Tucker-Lewis Index (TLI) should be more or near .90; the Root Mean Square Error of Approximation (RMSEA) value should be less than or close to .06; and the SRMR value should be close to .08 (Hu \& Bentler, 1995). After assessing the goodness of fit through pruning and item deletion using modification indices, the next step was to test the reliability of the data, which determines the consistency of the measures (Nunnally, Bernstein, \& 
Berge, 1967). Cronbach's alpha was measured using SPSS to examine the reliability of the data and the threshold value of .70 was used (Nunnally, Bernstein, \& Berge, 1967). In the study three types of validity were addressed: content validity, convergent validity, and discriminant validity.

Content validity, which is often called face validity, is checked on the basis of items' conceptual definitions and can be evaluated by expert judges in the field (Morgan et al., 2004). In this study, during the pilot test, four academic researchers were asked to comment on the items measuring the variables, general demographic questions, and the flow of the survey. The items were slightly modified based on their comments, thus confirming content validity. The changes can be seen in Table 3.2.

Convergent validity examines whether all the items measuring a variable are correlated to each other or not. They are evaluated on the basis of significant loadings of the items on the designated construct. If the $t$ value is greater than 1.96, then the item loading is considered to be significant at 95\% confidence level (Fornell \& Larcker, 1981). In this study all the factor loadings had $t$ valued greater than 1.96 suggesting good convergent validity (Table 4.3, Table 4.6, and Table 4.7)

Discriminant validity is useful in checking if there is high correlation between items that are measuring two different constructs. For example, the items of TLB and items of SOC should not correlate highly. This validity is useful in analyzing whether or not two constructs are different. For this study, the correlations between each possible pair of constructs were checked. Correlations with a value higher than .80 between two different items are considered to have multicollinearity. In this analysis, the correlation was not found to be higher than .80. If the 
correlation is higher than .80 , the confidence interval of 2 standard errors between each pair is checked, and if it is less than 1 then it is not problematic.

\section{Assessing Structural Model}

After the evaluation of the measurement model, the structural model was evaluated to examine the hypothesis formulated in this research. The model was analyzed using the Maximum Likelihood (ML) method, as this is the most popular (Hair et al., 1998) and is used for small samples (Hoyle \& Panter, 1995). The minimum sample size for using the ML method is 100 (Hair et al., 1998). Model fit was then determined and results assessed. Path coefficients, $t$ values, and significance tests were analyzed to examine the relationship between variables as proposed in this research. The direction of path coefficients and direct and indirect effects were examined to find out more in-depth relationships between the variables. 


\section{CHAPTER IV. RESULT AND ANALYSIS}

This chapter covers the results of the data analysis conducted for this study and is divided into three parts: (a) assumption check, (b) descriptions of the study samples, and (c) result analysis and hypothesis testing.

\section{Assumption Check}

Data were inspected for missing values. No missing values were found in the 275 completed responses. Second, the presence of outliers was checked. No response was more than two standard deviations from the mean and thus no outlier was found in this study (Tabachnick \& Fidell, 2013).

Third, the match between screening questions number three and eleven was assessed to verify the study's assumption that CFPD teams were more homogenous in terms of academic background than the WTPD teams. Of the WTPD group, 73.60\% said their team was diverse in terms of academic backgrounds, while only $16.7 \%$ of the CFPD group reported that their team was academically diverse. A cross tab evaluation indicated that the Chi square value (90.41) was greater than the critical value (3.841). Thus, consistent with the research assumption of the study, it was found that WTPD teams were significantly more diverse in terms of academic background than the CFPD teams were.

Fourth, multicollinearity was checked to find high correlations between predictor variables (Hair, Black, Babin, Anderson, \& Tatham, 2006). The correlation analysis of the observed variables did not reveal any highly correlated variables. However, a VIF greater than 3 was found in four variables (MEM2, RON2, RON4, and MEM5) and was omitted for further analysis. For measuring a latent variable, there needs to be at least three observed variables. 
After removing these observed variables, there were still more than three observed variables for measuring the latent variable of SOC, therefore there was very little effect from removing these observed variables.

Fifth, normality assessments such as skewness and kurtosis for univariate normality were performed. No abnormality was found following the skewness cutoff of $1 S D$ and Kurtosis cutoff of -2 to 2 (George \& Mallery, 2010).

\section{Description of the Study Sample}

\section{Overall Demographic Descriptions}

A total of 275 complete samples were used for data analysis. Out of 275 research participants, 125 said that they worked for the WT industry, and 150 respondents said that they worked for the fashion industry. The research participants were more females $(63.64 \%)$ than males $(36.36 \%)$. The majority of the participants were Caucasians $(72.73 \%)$, followed by Hispanic (9.45\%), African American (9.09\%), Asian (6.55\%), Native American (1.09\%), and others (1.09\%). The research participants had Bachelor's Degree (53.26\%), Master's Degree (21.74\%), Associate Degree (18.48\%), High School Graduates (3.62\%), Doctoral Degree (1.81\%), and Post-Doc Degree (1.09\%). The demographic information can be seen in Table 4.1.

Most of the research participants associated themselves with Design (56.88\%), followed by Software Science and Engineering (13.41\%), others-including Management, Humanities, Business, Buying integrated with product development, Computer Science, Sales and Development, Retail and Merchandising, Retail, Sales and so on-(9.78\%), Hardware Science and Engineering (9.06\%), Informatics (7.25\%), and Health Sciences (3.62\%). The examination of their job level revealed that a majority of the research participants were in Middle 
Management (44.57\%), followed by Executive Level (19.93\%), Entry level (13.77\%), and Others $(1.81 \%)$. The research participants were spread throughout the United States, with the most in the Southeast (28.99\%), then the Northeast (22.83\%), West (20.65\%), Midwest (15.58\%), and Southwest (11.96\%). The mean age of the research participants was 35.15 years $(S D=9.84)$ and ranged from 21 to 73 years (Table 4.2).

The mean number of years of establishment of the companies for which the participants worked was 27.28 years $(S D=27.22)$, ranging from 1.00 to 159.00 years (Table 4.2). Each research participant also rated the innovation performance of their companies on a continuous scale from 1 to 100 . The mean for the innovation performance of the companies was $77.58(S D=$ 16.38) and ranged from 9 to 100.

\section{Group Demographic Comparison}

In the fashion category, most of the research participants were involved in Women's wear (44.87\%), followed by others such as all of the above, top five, a few of above, and jewelry design (25\%), Men's wear (15.38\%), Kid's wear (5.77\%), Outerwear (5.13\%), and Accessories (4.49\%). In the WTPD group, most of the research participants were involved with product development of Smart Wristbands (39.53\%), followed by Smart Clothing (31.71\%), Smart Head Gear (15.50\%), Health Monitoring Devices (9.30\%), and others such as smart shoes and all of the above $(3.88 \%)$.

In the CFPD group, the number of female employees (77.3\%) was greater than male employees (22.7\%), whereas in the WTPD group, gender distribution was almost evenly spread with a few more males $(52.8 \%)$ than females $(47.2 \%)$. The finding was consistent with the demographic characteristic of the fashion industry, which has more female employees than males 
(Dicken, 2011). The majority of the research participants in CFPD associated themselves with Design (68\%) and other disciplines such as Humanities, Retail and Merchandising, and Sales $(16 \%)$. The spread was more even in the WTPD group, the greatest number of which also associated themselves with Design (44\%), followed by Software Science and Engineering (26.4\%), and Hardware Science and Engineering (15.2\%).

The demographic information available through U.S. government websites and industry reports gives an overall analysis of whole industry rather than individual divisions. Therefore, the detailed demographic information of the population, which represented the product development part of the fashion industry and the wearable technology industry, was difficult to trace. The natures of companies involved in WT are different. Companies like Fitbit are mainly making WT products, while company like Google, Intel, and Microsoft have many other products in market other than WT products. In this case too, the demographic information of product developers in the WT sector is not known and was difficult to trace from U.S. government websites or from any industry reports. Given the lack of information about the demographic characteristics (gender, education level, functions they executed) of product developers for WT as well as CF, the cross checking of some of the parameters were done by analyzing the job postings for such roles on popular recruitment sites such as Indeed.com and Glassdoor.com.

When asked to explain in a word or two about the functions which product developers performed in their day-to-day activities, the WTPD research participants responded to doing: research and testing, functional design, designing health monitoring device, designing watches, evaluating smart wear technology, developing activity trackers, and so on. Similarly, it was 
found that functions such as design creation, product development, material specialist, software development, and research were required for the PD jobs from the recruiting websites. Most of these skill requirements from the job positing matched to the responses of the research participants.

For CFPD, research participants responded to doing product design, design through $\mathrm{CAD}$, forecasting, production management, fit analysis and pattern making, fashion merchandising, working on technical package, planning and pricing, design and custom production, and so on. Examining the job description for CFPD through job search websites, it was found that knowledge in fit and technical design, technical package creation, computer aided design, and merchandising were some of the requirements for the job. These job requirements were similar to what the research participants responded. The education level of the research participants in both groups had similar spreads. Most of the respondents had bachelor level education and higher. Similarly, from the job posting exploration, it was found that the CF and WT industry were seeking professionals who had Bachelor's degrees or higher levels of education. The majority of the research participants' companies in the CFPD group had more than 5 Million USD in gross sales, whereas in the WTPD group the majority of the research participants' companies had gross sales of less than 5 Million USD. These findings further supports the assumption that WT is an introductory stage with companies having less gross sales compared to conventional fashion, which is already an established industry with companies having evenly spread of gross sales and more sales than WTPD. Participants from WTPD and CFPD were spread throughout the United States, as product development activities for the conventional fashion industry is spread all across the country. 
Table 4.1

Demographic Information of WTPD and CFPD Groups

\begin{tabular}{|c|c|c|c|c|c|}
\hline & & \multicolumn{2}{|c|}{ WTPD $(n=125)$} & \multicolumn{2}{|c|}{ CFPD $(n=150)$} \\
\hline & & $n$ & Percent & $n$ & Percent \\
\hline \multirow[t]{6}{*}{ Ethnicity } & White & 91 & $72.8 \%$ & 109 & $72.7 \%$ \\
\hline & Hispanic/Latino & 14 & $11.2 \%$ & 12 & $8.0 \%$ \\
\hline & Black or African American & 11 & $8.8 \%$ & 14 & $9.3 \%$ \\
\hline & Native American & 2 & $1.6 \%$ & 1 & $0.7 \%$ \\
\hline & Asian/Pacific Islander & 6 & $4.8 \%$ & 12 & $8.0 \%$ \\
\hline & Others & 1 & $0.8 \%$ & 2 & $1.3 \%$ \\
\hline Highest & High School Degree & 4 & $3.2 \%$ & 6 & $4.0 \%$ \\
\hline \multirow[t]{5}{*}{ Degree } & Associate Degree & 19 & $15.2 \%$ & 32 & $21.3 \%$ \\
\hline & Bachelor's Degree & 66 & $52.8 \%$ & 81 & $54.0 \%$ \\
\hline & Master's Degree & 31 & $24.8 \%$ & 29 & $19.3 \%$ \\
\hline & Doctoral Degree & 3 & $2.4 \%$ & 2 & $1.3 \%$ \\
\hline & Post-doc & 2 & $1.6 \%$ & - & - \\
\hline \multirow{6}{*}{$\begin{array}{l}\text { Discipline } \\
\text { Association }\end{array}$} & Design & 55 & $44.0 \%$ & 102 & $68.0 \%$ \\
\hline & Hardware Science and Engineering & 19 & $15.2 \%$ & 6 & $4.0 \%$ \\
\hline & Software Science and Engineering & 33 & $26.4 \%$ & 3 & $2.0 \%$ \\
\hline & Informatics & 8 & $6.4 \%$ & 12 & $8.0 \%$ \\
\hline & Health Sciences & 7 & $5.6 \%$ & 3 & $2.0 \%$ \\
\hline & Others & 3 & $2.4 \%$ & 24 & $16.0 \%$ \\
\hline \multirow[t]{5}{*}{ Job Level } & Entry Level & 12 & $9.6 \%$ & 26 & $17.3 \%$ \\
\hline & Middle Management & 46 & $36.8 \%$ & 77 & $51.3 \%$ \\
\hline & Senior Management & 38 & $30.4 \%$ & 16 & $10.7 \%$ \\
\hline & Executive Level & 28 & $22.4 \%$ & 27 & $18.0 \%$ \\
\hline & Others & 1 & $0.8 \%$ & 4 & $2.7 \%$ \\
\hline \multirow{5}{*}{$\begin{array}{l}\text { Company } \\
\text { Location }\end{array}$} & West & 26 & $20.8 \%$ & 30 & $20.0 \%$ \\
\hline & Midwest & 17 & $13.6 \%$ & 26 & $17.3 \%$ \\
\hline & Northeast & 23 & $18.4 \%$ & 40 & $26.7 \%$ \\
\hline & Southwest & 21 & $16.8 \%$ & 12 & $8.0 \%$ \\
\hline & Southeast & 38 & $30.4 \%$ & 42 & $28.0 \%$ \\
\hline Gross Sales & Less than 1 million & 31 & $24.8 \%$ & 22 & $14.7 \%$ \\
\hline
\end{tabular}




\begin{tabular}{llrrrr}
\hline & 1 Million to 5 Million & 24 & $19.2 \%$ & 23 & $15.3 \%$ \\
5 Million to 25 Million & 18 & $14.4 \%$ & 22 & $14.7 \%$ \\
25 Million to 50 Million & 19 & $15.2 \%$ & 7 & $4.7 \%$ \\
50 Million to 100 Million & 15 & $12.0 \%$ & 20 & $13.3 \%$ \\
100 Million to 500 Million & 6 & $4.8 \%$ & 11 & $7.3 \%$ \\
Over 500 Million & 2 & $1.6 \%$ & 24 & $16 \%$ \\
Do not know & 10 & $8.0 \%$ & 21 & $14 \%$ \\
& & & & \\
Gender & 66 & $52.8 \%$ & 34 & $22.7 \%$ \\
& Male & 59 & $47.2 \%$ & 116 & $77.3 \%$ \\
\hline
\end{tabular}

Table 4.2

Group Demographic Characteristics of Participants and their Companies

\begin{tabular}{lrrrrrr}
\hline Items & & $N$ & Min. & Max. & $M$ & $S D$ \\
& Group & & & & & \\
\hline Innovation performance of & WTPD & 125 & 34 & 100 & 77.98 & 16.07 \\
companies & CFPD & 150 & 9 & 100 & 77.25 & 16.67 \\
& Overall & 275 & 9 & 100 & 77.58 & 16.38 \\
Years since establishment of & WTPD & 125 & 2 & 153 & 20.66 & 21.07 \\
companies & CFPD & 150 & 1 & 517 & 36.04 & 49.88 \\
& Overall & 275 & 1 & 517 & 27.28 & 27.22 \\
Age of the research & WTPD & 125 & 21 & 73 & 36.78 & 10.00 \\
participants & CFPD & 150 & 21 & 66 & 33.79 & 9.52 \\
& Overall & 275 & 21 & 73 & 35.15 & 9.84 \\
\hline
\end{tabular}

\section{Result Analysis and Hypothesis Testing}

This section is divided into two parts, an overall model assessment (one model consisting of data from both groups) and a multi-group model assessment (two models and their comparison). Each of these two parts is further categorized into the measurement model and structural model. In the measurement model, the factor analysis, factor loading, Chi square value, and model fit analysis of models were conducted. The models were verified using modification indices and the Chi square difference test. 


\section{Overall Model Assessment Measurement Model}

The measurement model for a model made from the combined data from WTPD and CFPD was found to be satisfactory. The measurement model did not suggest any deletion of items. The measurement model of the latent variables had a Chi square value of 1935.627; $d f=$ $1028 ; p$-value $=.0000 ; \mathrm{CFI}=.895 ; \mathrm{RMSEA}=.057$ at acceptable levels of model fit $($ Table 4.3 and Figure 4.1). The loadings for all the factors were high, and the corresponding t-values were statistically significant (Table 4.3 and Figure 4.1). These results indicate unidimensionality of the latent variables of the proposed measurement model. The overall Cronbach's alphas of the latent variables were analyzed in SPSS and were found to be satisfactory, TL (.898), TLB (.907), SOC (.959), and Innovation (.904). 
Table 4.3

Measurement Model for Overall Wearable Product Development Group ( $n=125)$

\begin{tabular}{|c|c|c|c|c|}
\hline Constructs & Items & $\begin{array}{l}\text { Standardized } \\
\text { Parameter } \\
\text { Estimate }\end{array}$ & $t$-Value & $p$-Value \\
\hline Transformational Leadership & TL1 & .659 & 13.874 & .000 \\
\hline \multirow[t]{6}{*}{ Cronbach's Alpha $=.880$} & TL2 & .786 & 19.140 & .000 \\
\hline & TL3 & .763 & 16.997 & .000 \\
\hline & TL4 & .714 & 15.269 & .000 \\
\hline & TL5 & .736 & 17.450 & .000 \\
\hline & TL6 & .769 & 20.102 & .000 \\
\hline & TL7 & .795 & 20.856 & .000 \\
\hline Sense of Community & RON1 & .729 & 19.933 & .000 \\
\hline \multirow[t]{17}{*}{ Cronbach's Alpha=.905 } & RON3 & .796 & 19.422 & .000 \\
\hline & RON5 & .770 & 16.865 & .000 \\
\hline & SEC1 & .763 & 20.753 & .000 \\
\hline & SEC2 & .696 & 15.444 & .000 \\
\hline & SEC3 & .737 & 18.689 & .000 \\
\hline & SEC4 & .678 & 14.669 & .000 \\
\hline & SEC5 & .574 & 21.741 & .000 \\
\hline & SEC6 & .772 & 20.733 & .000 \\
\hline & MEM1 & .766 & 19.061 & .000 \\
\hline & MEM3 & .725 & 11.284 & .000 \\
\hline & MEM4 & .666 & 22.353 & .000 \\
\hline & IN1 & .614 & 16.595 & .000 \\
\hline & IN2 & .715 & 14.451 & .000 \\
\hline & IN3 & .697 & 12.916 & .000 \\
\hline & IN4 & .714 & 19.056 & .000 \\
\hline & IN5 & .758 & 16.373 & .000 \\
\hline & IN6 & .730 & 19.317 & .000 \\
\hline Team Learning Behavior & $\mathrm{CO} 1$ & .738 & 19.700 & .000 \\
\hline \multirow[t]{8}{*}{ Cronbach's Alpha=.956 } & $\mathrm{CO} 2$ & .616 & 13.822 & .000 \\
\hline & $\mathrm{CO} 3$ & .749 & 19.799 & .000 \\
\hline & $\mathrm{COC} 1$ & .733 & 18.388 & .000 \\
\hline & $\mathrm{COC} 2$ & 689 & 16.632 & .000 \\
\hline & $\mathrm{COC} 3$ & .713 & 18.929 & .000 \\
\hline & $\mathrm{CNC} 1$ & .735 & 18.173 & .000 \\
\hline & $\mathrm{CNC} 2$ & .752 & 21.482 & .000 \\
\hline & $\mathrm{CNC} 3$ & .765 & 17.802 & .000 \\
\hline Innovation & IG1 & .746 & 18.324 & .000 \\
\hline \multirow[t]{4}{*}{ Cronbach's Alpha $=.899$} & $\mathrm{IG} 2$ & .748 & 18.917 & .000 \\
\hline & IG3 & .619 & 11.033 & .000 \\
\hline & IP1 & .738 & 15.739 & .000 \\
\hline & IP2 & .654 & 13.460 & .000 \\
\hline
\end{tabular}




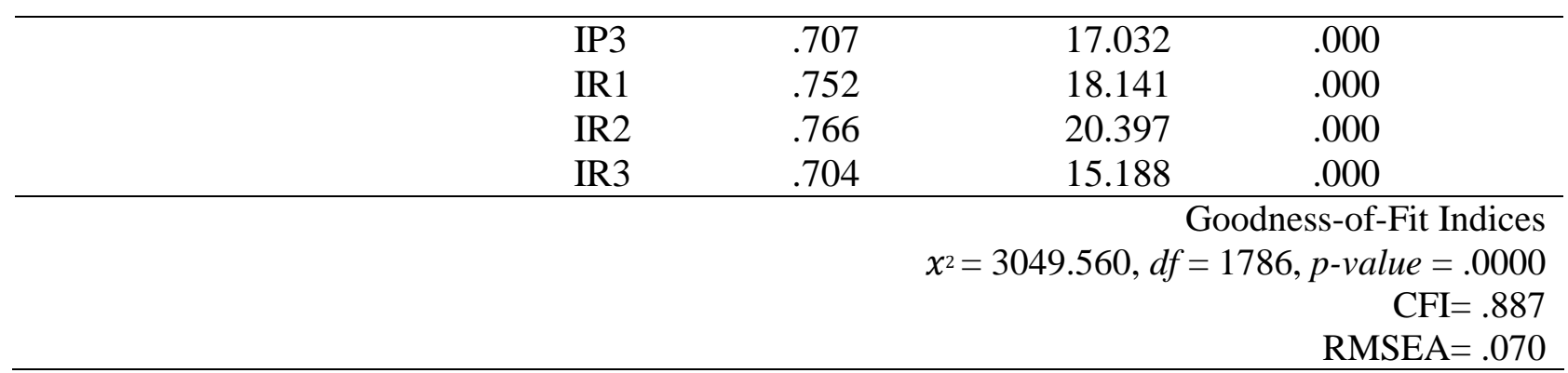

Note: Item numbers with their corresponding survey questionnaire number can be found in Appendix A. 
Figure 4.1.

Measurement Model (Confirmatory Factor Analysis)

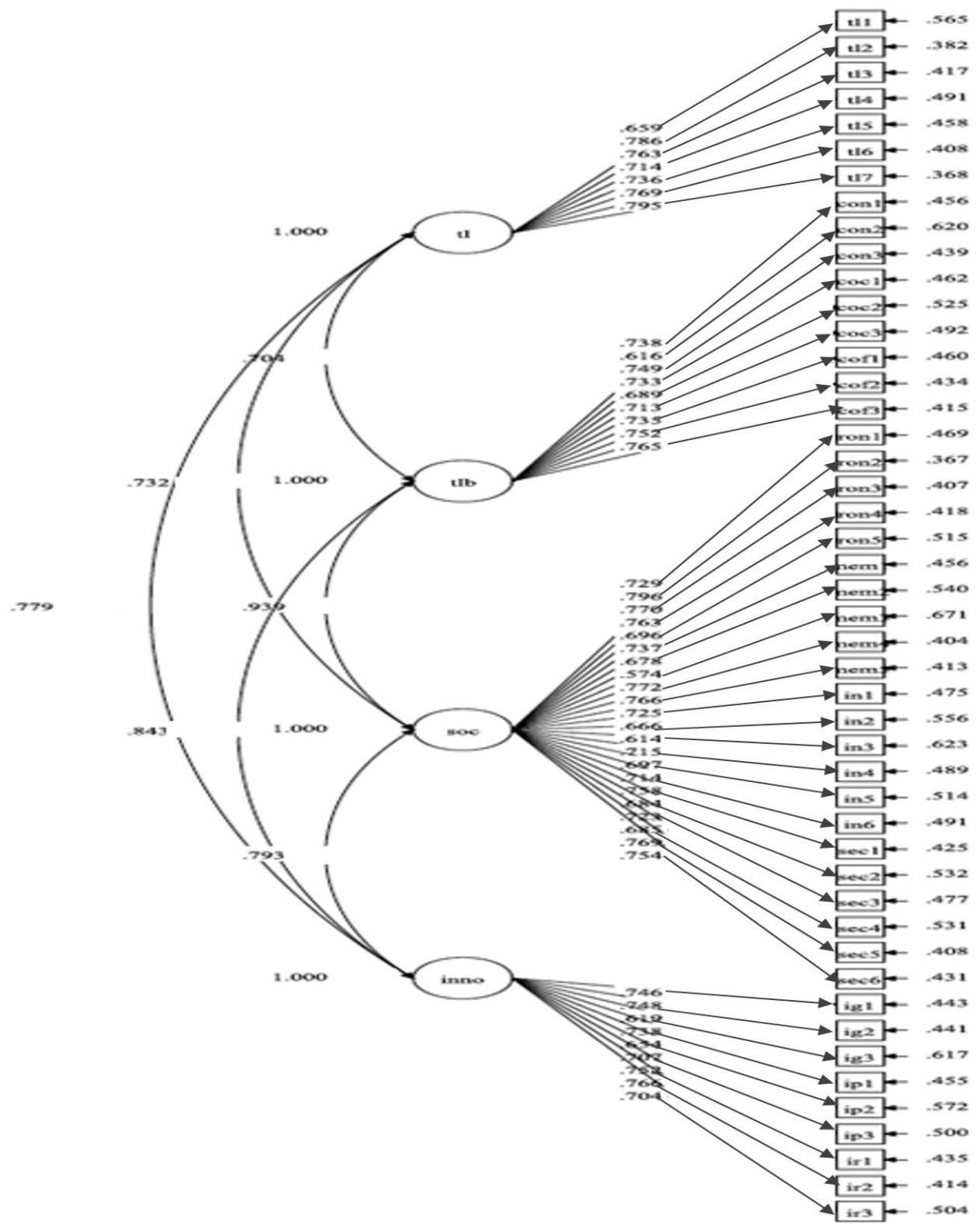

\section{Structural Model Selection and Hypothesis Testing}

The model hypothesized in the study was found to have good fitness indices, with CFI .876 and RMSEA being .054. With further analysis of the modification analysis, an additional 
path connecting TL and SOC was added. The literature review supported the additions of the path. There was a positive relationship between TL and SOC in many other studies (Bass, 1990; Bass \& Avolio, 1993; Giles et al., 2005). Thus, due to the modification indices analysis and better fitness indices of the second model with the additional path, the new model was chosen for further analysis. Analysis of Modification Indices did not suggest any other changes for the improvement of model.

The result of the standardized path estimate, t-value, and significance test for the final model is displayed in Table 4.4 and in Figure 4.2. This section further explains each one of them in detail.

\section{Hypothesis 1}

Hypothesis $1(\mathrm{H} 1)$, which stated that TL positively impacted IWB in the wearable product development teams, was found to be statistically significant in this study (standardized parameter estimate $=.412, t$-value $=5.534, p<.001$ ). This result is consistent with the previous literature, which connects transformational leadership to team outcomes such as creativity (Jaiswal \& Dhar, 2015; Lo, Tse, \& Ashkanasy, 2015), task performance (Boies, Fiset, \& Gill, 2015), and organizational innovation (Noruzy, 2013). Thus, it was confirmed that in wearable product development teams, the TL which aimed at instilling pride and respect in others and uplifting the morale for achieving higher competency (TL7), individualized consideration (TL2), clarity in expectations and idealized behavior (TL6), and encouragement and recognition of employees (TL3) was more important in creating a positive impact on innovative work behaviors such as idea generation, idea realization, and idea promotion. 
Figure 4.2.

Final Structural Model's Parameter Estimates

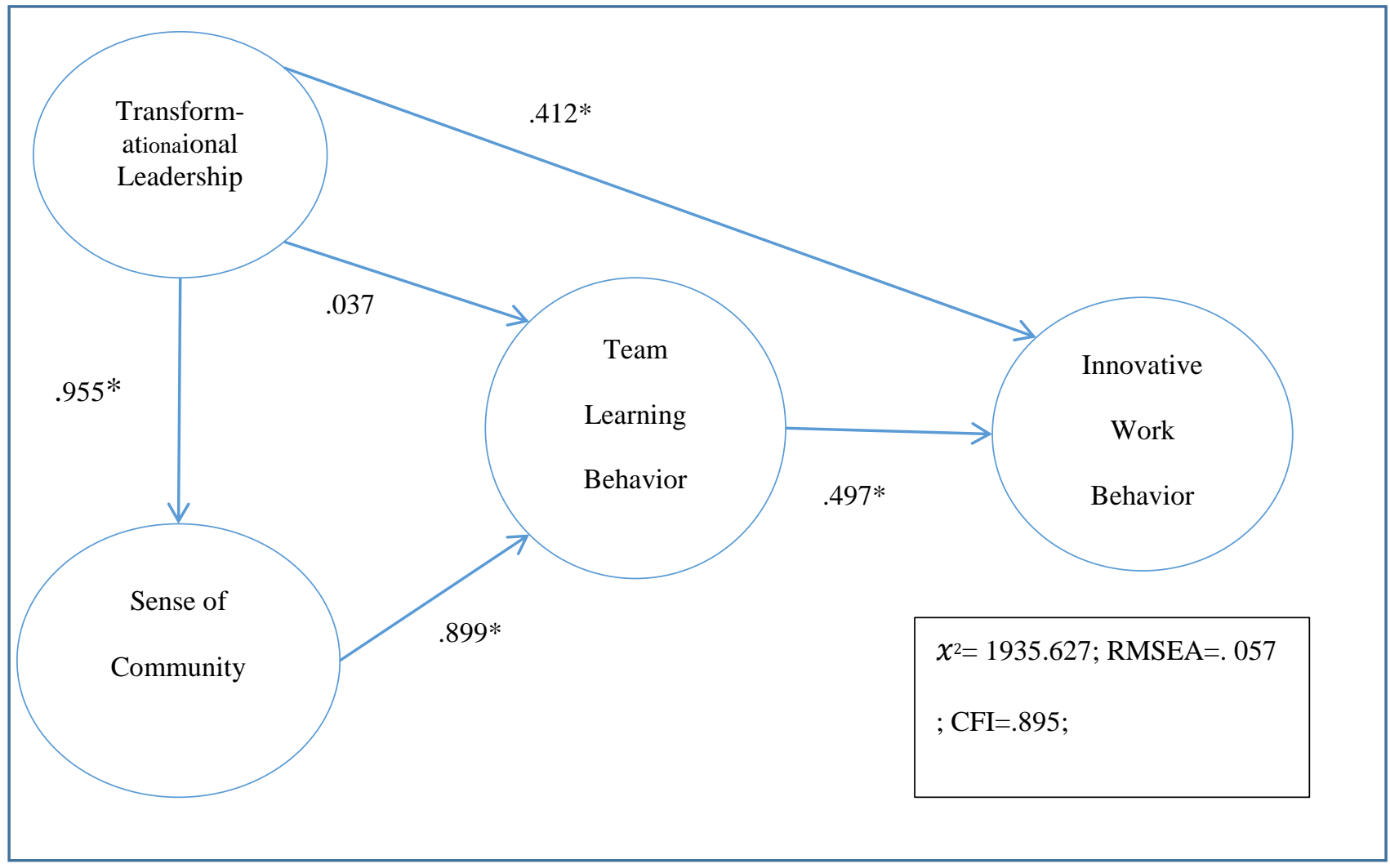

Note: All the significant relationships with $\mathrm{p}<.005$ are labeled with an asterisk.

Table 4.4

Final Structural Model's Parameter Estimates, $t$-Values, and Significance Levels $(n=275)$

\begin{tabular}{llcrc}
\hline $\begin{array}{l}\text { Paths in the Structural } \\
\text { Model }\end{array}$ & Model & $\begin{array}{c}\text { Standardized } \\
\text { Parameter Estimate }\end{array}$ & $t$-value & $\begin{array}{c}p \text { - } \\
\text { value }\end{array}$ \\
\hline TL -> IWB & Overall & .412 & 5.534 & .000 \\
TL -> TLB & Overall & - & - & .577 \\
TL -> SOC & Overall & .955 & 9.045 & .000 \\
SOC -> TLB & Overall & .899 & 10.364 & .000 \\
TLB -> IWB & Overall & .497 & 7.837 & .000 \\
\hline \multicolumn{2}{r}{} & & Goodness-of-Fit Indices \\
& & & CFI $=.895$ \\
& & & RMSEA= $=.057$ \\
\hline
\end{tabular}




\section{Hypothesis 2}

Hypothesis $2(\mathrm{H} 2)$ predicted that TL positively impacts TLB in wearable product development teams; however, it was not supported in this study with statistically insignificant results $(p=.577)$. The literature suggested that there would be a positive relationship between TL and TLB (Aga, Noorderhayen, \&Vallejo, 2016; Raes et al., 2012; Liu \& Philips, 2011). The reason for this relationship was the ability of transformational leaders to facilitate deeper communication among team members (Raes et al., 2012) and positively impact the team's knowledge sharing intentions (Liu \& Philips, 2011). With further analysis, it was found that SOC mediated the relationship between TL and TLB. TL positively impacted SOC (standardized parameter estimate $=.955, t$-value $=9.045, p<.001)$, and SOC positively impacted TLB in WPD teams (H3) with statistically significant results.

\section{Hypothesis 3}

Hypothesis $3(\mathrm{H} 3)$ stated that SOC positively impacted TLB in wearable product development teams and was found statistically significant in this study (standardized parameter estimate $=.899, t$-value $=10.364, p<.001)$. Aruştei and Leon (2013) expressed the need for more research on examining Sense of Community and personal as well as professional development in organizations. This study fills in this gap in the literature and further validated the importance of SOC in organizations, which seeks for innovative outcomes in the product development phase. Given that improving team activities through socialization could facilitate tacit knowledge conversion, SOC is found to be a critical factor for TLB (Aruştei \& Leon, 2013). Windler (2015) also found that SOC, which was achieved by sharing e-profiles of team members, enhanced the readiness to learn together and increased collaboration. Hill et al. (2014) 
explored the impact of a SOC and TLB on innovation and argued that giving voice to all members of the company is important for innovation. Empowerment through SOC was effective for developing a shared vision among the team members. Similarly, in this study, reinforcement of need for each other's skill, which comes from being connected with the team members (RON3), and knowing that other team members too have similar needs, priorities, and goals (RON5) was found to enhance sense of community, which then positively influenced TLB.

\section{Hypothesis 4}

Hypothesis 4 (H4), which stated that TLB positively impacted IWB, was found to be statistically significant in this study (standardized parameter estimate $=.497, t$-value $=7.837, p<$ .001). Similar to many other studies that showed a positive relationship between TLB and IWB (Bagher et al., 2016; Choi et al., 2016; Dingler \& Enkel, 2015), in this study the product development teams' learning behavior also positively impacted the behaviors related to innovation. Dingler and Enkel (2015) found that the sharing of knowledge through personal interactions and the development of a common language and norms triggered innovation across industry boundaries. Specifically, items measuring constructive conflict—opinions and ideas of team members were verified by asking each other critical questions (CNC3), comments of ideas are acted upon in the team (CNC2) — had highest loadings, followed by items measuring coconstruction - team members elaborated on each other's information and ideas (COC1) and team members drew conclusions from the discussions ( $\mathrm{COC} 3)$ — and construction — sharing of relevant information (CO3) and team members listening carefully to each other (CO1). For the wearable product development teams, the importance of constructive conflict was slightly more than construction and co-construction. The finding is also consistent with the study done by Choi et 
al. (2016), who found that TL and team learning had a positive impact on workers' innovative behaviors in the Korean manufacturing industry.

\section{Indirect Effects}

The indirect effects were examined using the indirect model command in MPLUS software. The direct effect, indirect effect, and total effect are shown in Table 4.5. The total effect of TL on IWB was .839 (direct effect was .412 and indirect effect was .427). The total effect of TL on TLB was .858 with only indirect effect. The total and direct effect of TL on SOC was .955 , SOC on TLB was .899, and TLB on IWB was .497.

The other relationship checked in this analysis was the direct impact of sense of community on innovative work behavior. A hypothesis explaining this relationship was not formulated because no study examined it in the literature explored for this study. When tested for the relationship, the results were not significant either. This suggests the importance of team learning behavior as it mediated the relationship between sense of community and innovative work behavior. Thus, it was found that having a sense of community alone without sharing the knowledge through construction, co-construction, and constructive conflict could not help in achieving innovative work behavior in the wearable product development teams. 
Table 4.5

Direct and Indirect Effects

\begin{tabular}{llcc}
\hline Pair & Direct Effect & Indirect Effect & Total Effect \\
\hline TL \& IWB & .412 & .427 & .839 \\
TL \& TLB & None & .858 & .858 \\
TL \& SOC & .955 & None & .955 \\
SOC \& TLB & .899 & None & .899 \\
TLB \& IWB & .497 & None & .497 \\
\hline
\end{tabular}

\section{Multi-Group Model Assessment}

To assess the group differences in the overall model, multi-group assessment was conducted. The measurement models of the WTPD group are discussed first, followed by the CFPD group. Finally, the structural models of the two groups are compared and assessed.

\section{WT Measurement Model}

The measurement model for WTPD was found to be satisfactory and did not suggest any deletion of items. The measurement model of the latent variables in the hypothesized structural model had a Chi square value of $3126.362 ; d f=1831 ; p$-value $=.0000 ; \mathrm{CFI}=.839 ; \mathrm{RMSEA}=$ .072 at acceptable levels of model fit (Table 4.6). The loadings for all the factors were high, and the corresponding t-values were statistically significant (Figure 4.3). These results indicate unidimensionality of the latent variables of the proposed structural model. 


\section{Figure 4.3}

Measurement Model for Wearable Technology Product Development Group $(n=125)$

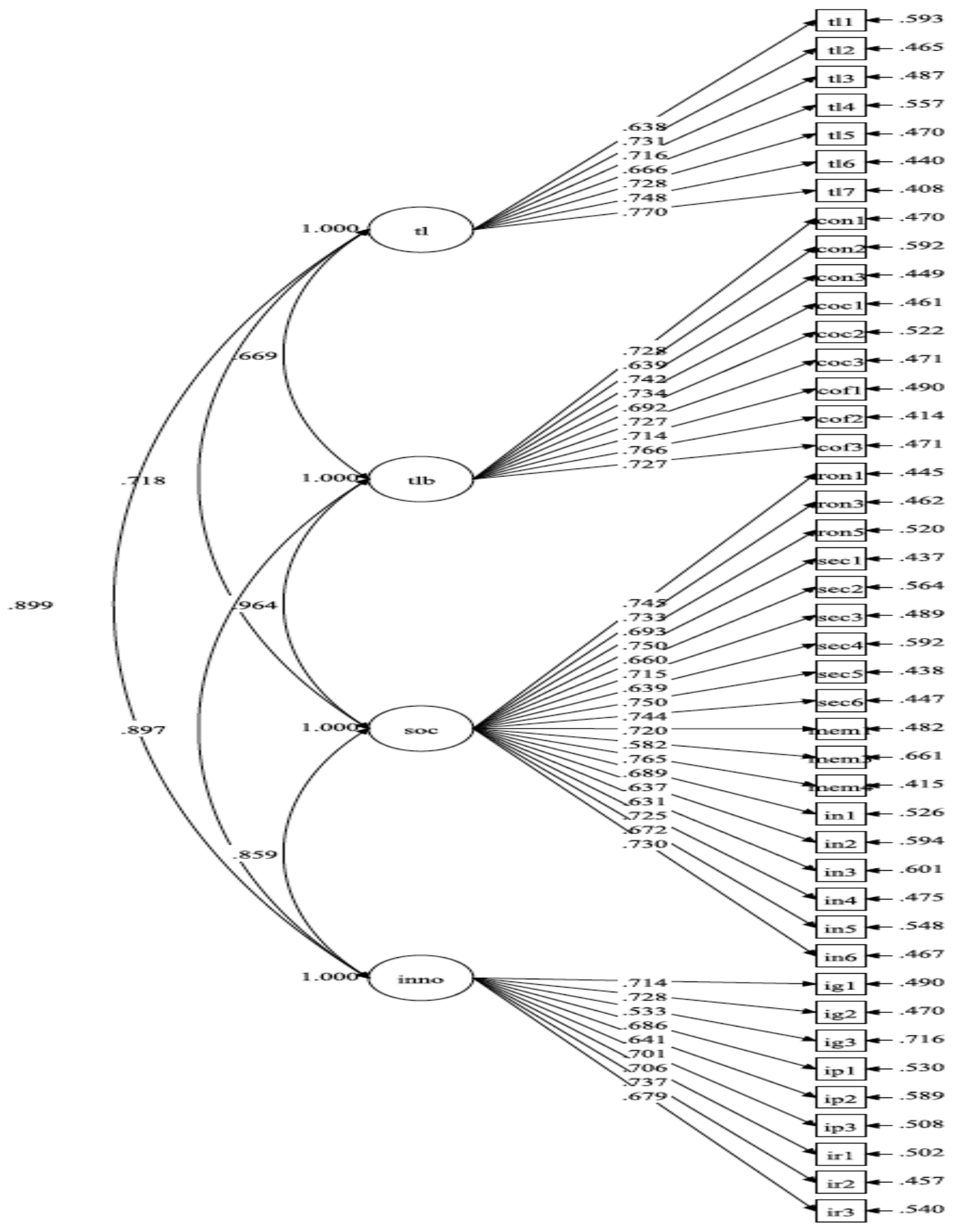


Table 4.6

Measurement Model for Wearable Technology Product Development Group ( $n=125)$

\begin{tabular}{|c|c|c|c|c|}
\hline Constructs & Items & $\begin{array}{l}\text { Standardized } \\
\text { Parameter } \\
\text { Estimate }\end{array}$ & $t$-Value & $p$-Value \\
\hline Transformational Leadership & TL1 & .638 & 13.874 & .000 \\
\hline \multirow[t]{6}{*}{ Cronbach's Alpha $=.880$} & TL2 & .731 & 19.140 & .000 \\
\hline & TL3 & .716 & 16.997 & .000 \\
\hline & TL4 & .666 & 15.269 & .000 \\
\hline & TL5 & .728 & 17.450 & .000 \\
\hline & TL6 & .748 & 20.102 & .000 \\
\hline & TL7 & .770 & 20.856 & .000 \\
\hline Sense of Community & RON1 & .745 & 19.933 & .000 \\
\hline \multirow[t]{17}{*}{ Cronbach's Alpha $=.905$} & RON3 & .733 & 19.422 & .000 \\
\hline & RON5 & .693 & 16.865 & .000 \\
\hline & SEC1 & .750 & 20.753 & .000 \\
\hline & SEC2 & .660 & 15.444 & .000 \\
\hline & SEC3 & .715 & 18.689 & .000 \\
\hline & SEC4 & .639 & 14.669 & .000 \\
\hline & SEC5 & .750 & 21.741 & .000 \\
\hline & SEC6 & .744 & 20.733 & .000 \\
\hline & MEM1 & .720 & 19.061 & .000 \\
\hline & MEM3 & .582 & 11.284 & .000 \\
\hline & MEM4 & .765 & 22.353 & .000 \\
\hline & IN1 & .689 & 16.595 & .000 \\
\hline & IN2 & .637 & 14.451 & .000 \\
\hline & IN3 & .631 & 12.916 & .000 \\
\hline & IN4 & .725 & 19.056 & .000 \\
\hline & IN5 & .672 & 16.373 & .000 \\
\hline & IN6 & .730 & 19.317 & .000 \\
\hline Team Learning Behavior & Con1 & .728 & 19.700 & .000 \\
\hline \multirow[t]{8}{*}{ Cronbach's Alpha= $=956$} & Con 2 & .639 & 13.822 & .000 \\
\hline & Con3 & .742 & 19.799 & .000 \\
\hline & Coc1 & .734 & 18.388 & .000 \\
\hline & $\operatorname{Coc} 2$ & .692 & 16.632 & .000 \\
\hline & Coc3 & .727 & 18.929 & .000 \\
\hline & Cof1 & .714 & 18.173 & .000 \\
\hline & Cof 2 & .766 & 21.482 & .000 \\
\hline & Cof3 & .727 & 17.802 & .000 \\
\hline Innovation & IG1 & .714 & 18.324 & .000 \\
\hline \multirow[t]{3}{*}{ Cronbach's Alpha $=.899$} & IG2 & .728 & 18.917 & .000 \\
\hline & IG3 & .533 & 11.033 & .000 \\
\hline & IP1 & .686 & 15.739 & .000 \\
\hline
\end{tabular}




\begin{tabular}{rrrr}
\hline IP2 & .641 & 13.460 & .000 \\
IP3 & .701 & 17.032 & .000 \\
IR1 & .706 & 18.141 & .000 \\
IR2 & .737 & 20.397 & .000 \\
IR3 & .679 & 15.188 & .000 \\
\hline & & & Goodness-of-Fit Indices \\
& & & \\
& & & CFI $=.843$ \\
& & & RMSEA $=.072$ \\
\hline
\end{tabular}

Note: Item numbers with their corresponding survey questionnaire number can be found in Appendix A.

\section{Fashion Product Development Group Measurement Model}

The measurement model for CFPD was found to be satisfactory and did not suggest any deletion of items. The measurement model of the latent variables in the hypothesized structural model had a Chi square value of $3126.362 ; d f=1831 ; p$-value $=.0000 ; \mathrm{CFI}=.839 ; \mathrm{RMSEA}=$ .072 at acceptable levels of model fit (Table 4.7). The loadings for all the factors were high, and the corresponding t-values were statistically significant (Figure 4.4). These results indicate unidimensionality of the latent variables of the proposed structural model. 
Figure 4.4

Measurement Model for Fashion Group (n=125)

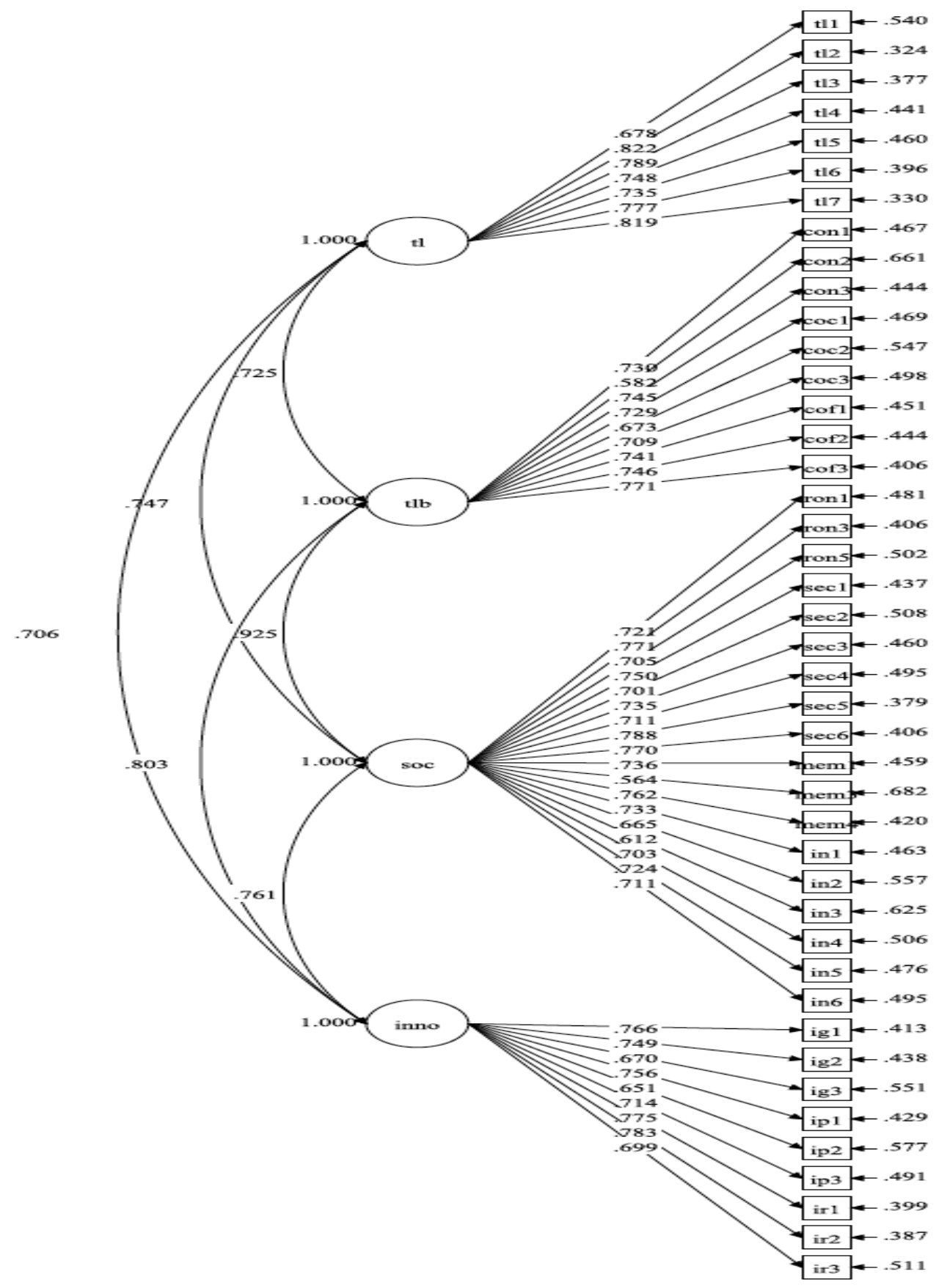


Table 4.7

Measurement Model for Fashion Product Development Group $(n=150)$

\begin{tabular}{|c|c|c|c|c|}
\hline Constructs & Items & $\begin{array}{l}\text { Standardized } \\
\text { Parameter } \\
\text { Estimate }\end{array}$ & $t$-Value & $p$-Value \\
\hline Transformational Leadership & TL1 & .678 & 15.775 & .000 \\
\hline \multirow[t]{6}{*}{ Cronbach's Alpha=.909 } & TL2 & .822 & 27.531 & .000 \\
\hline & TL3 & .789 & 24.710 & .000 \\
\hline & TL4 & .748 & 20.108 & .000 \\
\hline & TL5 & .735 & 20.183 & .000 \\
\hline & TL6 & .777 & 22.545 & .000 \\
\hline & TL7 & .819 & 28.452 & .000 \\
\hline Sense of Community & RON1 & .721 & 20.353 & .000 \\
\hline \multirow[t]{17}{*}{ Cronbach's Alpha=.904 } & RON3 & .771 & 24.457 & .000 \\
\hline & RON5 & .705 & 18.753 & .000 \\
\hline & SEC1 & .750 & 22.406 & .000 \\
\hline & SEC2 & .701 & 18.151 & .000 \\
\hline & SEC3 & .735 & 20.474 & .000 \\
\hline & SEC4 & .711 & 18.569 & .000 \\
\hline & SEC5 & .788 & 25.313 & .000 \\
\hline & SEC6 & .770 & 23.869 & .000 \\
\hline & MEM1 & .736 & 20.551 & .000 \\
\hline & MEM3 & .564 & 12.336 & .000 \\
\hline & MEM4 & .762 & 23.199 & .000 \\
\hline & IN1 & .733 & 20.808 & .000 \\
\hline & IN2 & .665 & 15.817 & .000 \\
\hline & IN3 & .612 & 14.418 & .000 \\
\hline & IN4 & .703 & 18.476 & .000 \\
\hline & IN5 & .724 & 19.459 & .000 \\
\hline & IN6 & .711 & 19.155 & .000 \\
\hline Team Learning Behavior & Con1 & .730 & 19.007 & .000 \\
\hline \multirow[t]{8}{*}{ Cronbach's Alpha $=.960$} & Con 2 & .582 & 12.489 & .000 \\
\hline & Con 3 & .745 & 21.303 & .000 \\
\hline & Coc1 & .729 & 20.539 & .000 \\
\hline & $\operatorname{Coc} 2$ & .673 & 16.126 & .000 \\
\hline & Coc3 & .709 & 18.147 & .000 \\
\hline & Cof1 & .741 & 20.276 & .000 \\
\hline & Cof 2 & .746 & 21.488 & .000 \\
\hline & Cof3 & .771 & 24.003 & .000 \\
\hline Innovation & IG1 & .766 & 21.976 & .000 \\
\hline \multirow[t]{3}{*}{ Cronbach's Alpha $=.909$} & IG2 & .749 & 20.757 & .000 \\
\hline & IG3 & 670 & 15.374 & .000 \\
\hline & IP1 & .756 & 22.055 & .000 \\
\hline
\end{tabular}




\begin{tabular}{rrrr}
\hline IP2 & .651 & 15.416 & .000 \\
IP3 & .714 & 18.603 & .000 \\
IR1 & .775 & 22.479 & .000 \\
IR2 & .783 & 22.768 & .000 \\
IR3 & .699 & 17.964 & .000 \\
\hline & & Goodness-of-Fit Indices \\
& & & \\
& & & \\
& & & CFI $=.843$ \\
& & RMSEA $=.072$ \\
\hline
\end{tabular}

Note: Item numbers with their corresponding survey questionnaire number can be found in Appendix A.

\section{Structural Model}

In the structural model, there were four main steps taken to determine any group difference in the latent means between group variables through SEM analysis (Milfont \& Fischer, 2010) (Table 4.8).

In the first step, the analysis of the model for each group was conducted separately. Only if the model fits each of the groups well can the groups be combined and analyzed for any group difference (Milfont \& Fischer, 2010). The models for each of the group were found to be satisfactory (CFPD: $\mathrm{x}^{2}=1416.352 ; d f=855$; RMSEA=.066; CFI= .871; TLI=.864; WTPD: $\mathrm{x}^{2}=$ $1552.848 ; d f=855 ; \mathrm{RMSEA}=.081 ; \mathrm{CFI}=.809 ; \mathrm{TLI}=.800)$.

Second, a model was formulated by combining the data from both the groups for multigroup analysis without constraining factor loading, error variances, or error co-variances. This model is called a configural model and had acceptable fit measurements. This proves that the factorial structure was supported for both the groups. The fit of the data was found to be satisfactory with $\mathrm{x}^{2}=3010.147 ; d f=1749 ; \mathrm{RMSEA}=.072 ; \mathrm{CFI}=.843 ; \mathrm{TLI}=.838$ (Table 4.8).

As the configural invariance model was supported in the third step the paths were constrained. This model, called metric invariance, tests if the research participants ascribe the same meaning to the variables. It was checked whether the model was significant when 
constraining the path for both the groups to be equal. In this step, the model fit was Chi square= 3054.436; $d f=1788 ; \mathrm{RMSEA}=.072 ; \mathrm{CFI}=.842 ; \mathrm{TLI}=.841$. Analyzing the difference between the models from the second and third steps, the Chi square was found to be non-significant ( $\mathrm{x}^{2}$ difference $=44.289, d f=39, p=.2582)$. With a non-significant Chi-square, any model could be chosen, as it would not result in any difference. Therefore the configural model with paths constrained was chosen (Table 4.8).

In fourth step, the factor loadings, residual variance, and residual covariance are constrained to check the invariance of intercepts (Milfont \& Fischer, 2010). This is called the scalar invariance model. In this step, the model fit with $\mathrm{x}^{2}=3126.362 ; d f=1831 ; \mathrm{RMSEA}=.072$; $\mathrm{CFI}=.839 ; \mathrm{TLI}=.841$ was adequate. Analyzing the difference between the models from the third and fourth steps, the Chi square was found to be significant $\left(\mathrm{x}^{2}\right.$ difference $=71.926, d f=43, p=$ .0029). With a significant Chi square, a complex model is chosen, therefore the last model with the paths, variance, and covariance constrained was chosen as the final model (Table 4.8). The final scalar invariance model was chosen to examine the hypotheses and the relationships between the variables in the fashion and WT groups. The results of the standardized path estimate, t-value, and significance test are displayed in Table 4.9 and in Figure 4.5. 
Table 4.8

Model Comparison to Determine Metric Invariance $(n=275)$

\begin{tabular}{|c|c|c|c|c|c|}
\hline & \multicolumn{2}{|c|}{$1^{\text {st }}$ Step } & \multirow{2}{*}{$\begin{array}{l}2^{\text {nd }} \text { Step } \\
\text { Configural } \\
\text { Model }\end{array}$} & \multirow{2}{*}{$\begin{array}{l}3^{\text {rd }} \text { Step } \\
\text { Metric } \\
\text { Invariance }\end{array}$} & \multirow{2}{*}{$\begin{array}{l}4^{\text {th }} \text { Step } \\
\text { Scalar } \\
\text { Invariance }\end{array}$} \\
\hline & $\begin{array}{l}\text { WT } \\
\text { (Step1a) }\end{array}$ & $\begin{array}{l}\text { Fashion } \\
\text { (Step1b) }\end{array}$ & & & \\
\hline Chi Square & 1552.848 & 1416.352 & 3010.147 & 3054.436 & 3126.362 \\
\hline$d f$ & 855 & 855 & 1749 & 1788 & 1831 \\
\hline$p$-Value & .000 & .000 & .000 & .000 & .000 \\
\hline CFI & .809 & .871 & .843 & .842 & .839 \\
\hline TLI & .800 & .864 & .838 & .841 & .841 \\
\hline SRMR & .060 & .054 & .058 & .069 & .081 \\
\hline \multirow[t]{3}{*}{ RMSEA } & .081 & .066 & .072 & .072 & .072 \\
\hline & \multicolumn{5}{|c|}{$\begin{array}{r}\text { Chi Square Diff }=44.289 \\
d f=39 \\
p \text {-value }=.25832 \\
\end{array}$} \\
\hline & & & & \multicolumn{2}{|c|}{$\begin{array}{r}\text { Chi Square Diff }=71.92 \\
d f=4 \\
p \text {-value }=.002\end{array}$} \\
\hline
\end{tabular}

Table 4.9

Final Structural Model's Parameter Estimates, $t$-Values, and Significance Levels $(n=275)$

\begin{tabular}{llccc}
\hline $\begin{array}{l}\text { Paths in the Structural } \\
\text { Model }\end{array}$ & Groups & $\begin{array}{c}\text { Standardized } \\
\text { Parameter Estimate }\end{array}$ & $t$-value & $\begin{array}{c}p \text { - } \\
\text { value }\end{array}$ \\
\hline TL -> IWB & CFPD & .275 & 3.064 & .003 \\
TL -> TLB & WTPD & .557 & 8.416 & .000 \\
& CFPD & - & - & .577 \\
TL -> SOC & WTPD & - & - & .679 \\
& CFPD & .748 & 17.718 & .000 \\
SOC -> TLB & WTPD & .712 & 13.451 & .000 \\
& CFPD & .863 & 14.074 & .000 \\
TLB -> IWB & WTPD & .970 & 17.455 & .000 \\
& CFPD & .602 & 7.254 & .000 \\
& WTPD & .504 & 7.591 & .000 \\
\hline & & & Goodness-of-Fit Indices \\
& & & \multicolumn{2}{c}{ RMSEA $=.072$} \\
\hline
\end{tabular}


Figure 4.5

Final Structural Model with Standardized Parameter Estimate

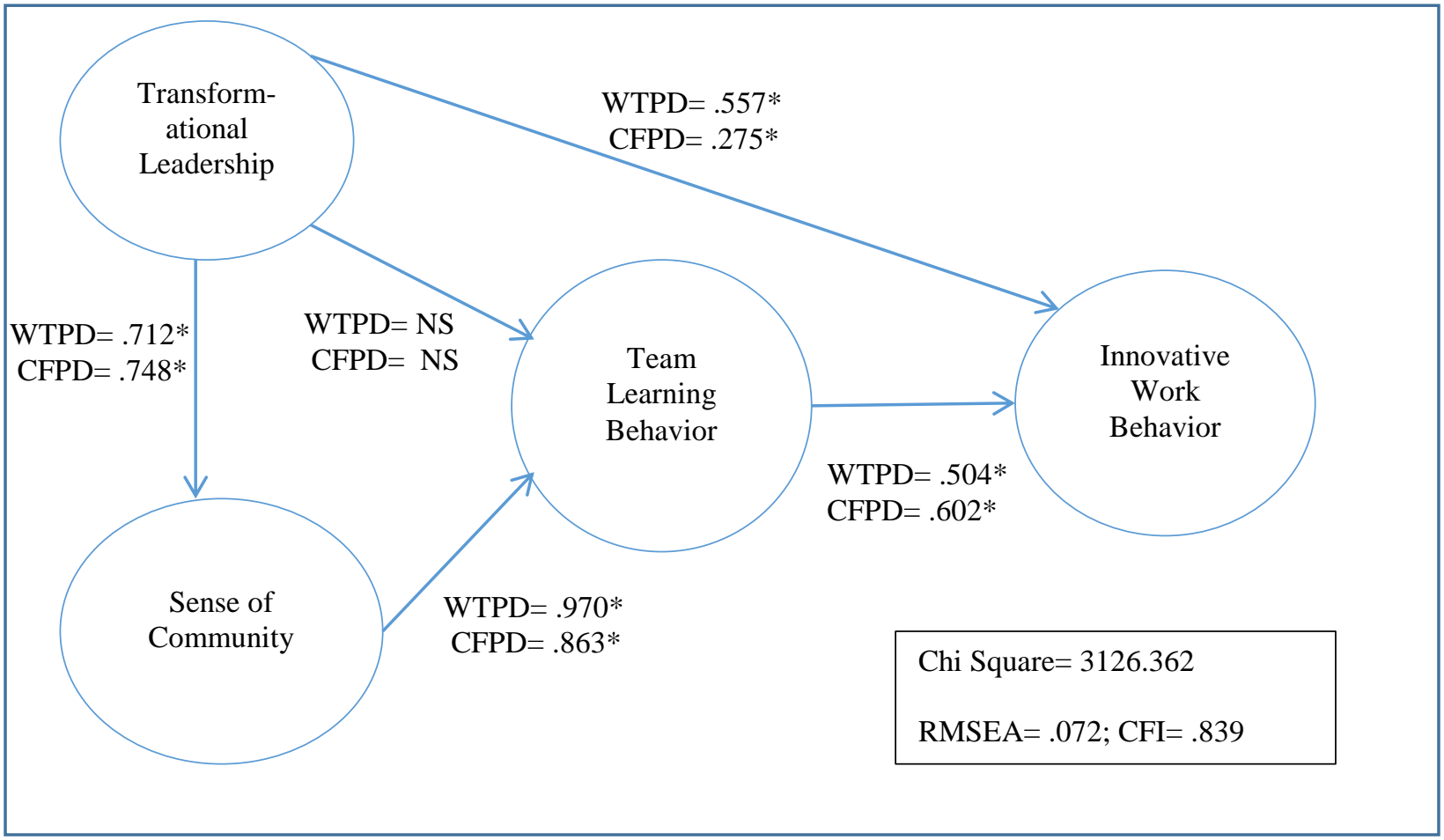

Note: All the significant relationships with $\mathrm{p}<.005$ are labeled with an asterisk.

\section{Hypothesis 1a}

According to Hypothesis 1a (H1a), TL would have a greater impact on IWB in WTPD than in CFPD, and it was found to be statistically significant. The standardized parameter for WTPD (standardized path coefficient $=.557, t$-value $=3.064, p<.001)$ was higher than that of CFPD (standardized path coefficient $=.275, t$-value $=3.064, p<.001$ ). A strong and positive effect of TL on the performances of diverse team members was also found in the studies conducted by Kearney and Diether (2009) and Wang et al. (2016). Similarly, in the context of wearable product development, the TL's impact was greater on cognitively diverse team members of WTPD than for CFPD. To inspire and motivate team members from different 
academic backgrounds, the role of the transformational leader was more impactful on innovative work behavior, while in CFPD, the impact of TL on IWB was significant but not as high as WTPD. Only for this relationship was the difference of such high magnitude. It might be argued that because WT is an emerging field, transformational leaders role in bringing out innovative outcomes from professionals with different backgrounds might be greater than the already established fashion industry where leaders are managing professionals with similar academic backgrounds.

\section{Hypothesis 2a}

According to Hypothesis 2a $(\mathrm{H} 2 \mathrm{a})$, TL would have a greater effect on TLB in WTPD than in CFPD, and this was found to be statistically not significant. There was no significant impact of TL on TLB for either of the groups. It seems that, in order to facilitate TLB, transformational leaders first need to create an environment and enhance sense of community, which then impacts TLB. This is explained in the section discussing Hypothesis 2.

\section{Hypothesis 3a}

According to Hypothesis 3a (H3a), SOC would have a greater impact on TLB in WTPD than in CFPD, and this was found to be statistically significant in this study. The standardized parameter for WTPD (standardized path coefficient $=.970, t$-value $=17.455, p<.001)$ was higher than that of CFPD (standardized path coefficient $=.863, t$-value $=14.074, p<.001$ ). Similar findings were seen in the study done by Gratton (2007), which found that for diverse teams the upper management's human resources initiatives, such as sponsoring events that give opportunities for colleagues to meet each other beyond their expected work schedules, were facilitating team learning behavior. Additionally, it was also found that the team members who 
did not share professional history faced problems in articulating their next steps (Bunniss \& Kelly, 2013). Thus the diverse team members needed extra bonding time, which is an important element of a sense of community. Meanwhile, team members belonging to similar academic backgrounds had less of a problem in understanding each other (Bunniss \& Kelly, 2013). Similarly, in this study the impact of SOC on TLB was found to be less impactful for academically homogenous CFPD compared to academically diverse WTPD. Therefore, WTPD teams need an extra emphasis on sense of community because they might not have inherited this through their educational background.

\section{Hypothesis 4a}

Hypothesis 4a stated that TLB would have a greater impact on the group's IWB within WTPD than in CFPD teams, which was not supported in this study. The standardized parameter for WT $($ standardized path coefficient $=.504, t$-value $=7.591, p<.001)$ was lower than the fashion product developers ( standardized path coefficient $=.602, t$-value $=7.254, p<.001$ ). The tension, which is brought due to the team's diversity, challenges the team members to perform better, which increases the team's performance (Roberts, 1987). This creative abrasion helps in the creation of new ideas. The lower impact of TLB on IWB for WTPD than CFPD might be due to lesser creative abrasion in the cognitively diverse team members of WT. The product developers of WT were found to be better in all the items measuring co-construction of knowledge (elaborating on each other's information, and drawing conclusions from the ideas discussed) in comparison to CFPD. Meanwhile, in comparison to CFPD, WTPD lacked in two major phases of TLB: construction (listening carefully to each other and sharing all relevant information or ideas) and constructive conflict (verification of ideas by asking critical questions 
and handling differences of opinions by addressing them directly). The team members of conventional fashion teams might have known their colleagues well in advance to understand each other and thus can handle creative abrasion through construction, co-construction of knowledge, and constructive conflict, thereby impacting IWB more strongly than in WTPD. 
Table 4.10

Summary of Hypotheses Tests

Hypothesis

Results

Hypothesis 1: Transformational leadership positively impacts innovative work Supported behavior in wearable product development teams.

Hypothesis 2: Transformational leadership positively impacts team learning Not Supported behavior in wearable product development teams.

Hypothesis 3: Sense of community positively impacts team learning behavior Supported in wearable product development teams.

Hypothesis 4: Team learning behavior positively impacts innovative work Supported behavior in wearable product development teams.

Hypothesis 1a: Transformational leadership has a greater impact on innovative Supported work behavior on heterogeneous WT product development teams than on conventional homogeneous fashion product development teams.

Hypothesis 2a: Transformational Leadership has a greater impact on team

Not-Supported learning behavior within heterogeneous wearable technology teams than in conventional homogeneous fashion product development teams.

Hypothesis 3a: Sense of community has a greater impact on team learning Supported behavior within heterogeneous wearable technology teams than in conventional homogeneous fashion product development teams. Hypothesis 4a: Team learning behavior has a greater impact on innovative Not Supported work behavior within heterogeneous wearable technology teams than in conventional homogeneous fashion product development teams. 


\section{CHAPTER V. CONCLUSIONS}

This chapter is divided into the following sections: (a) an overview of the study, (b) its contributions and implications, and (c) the study limitations and future research opportunities.

\section{Overview of the Study}

Fashion evolves as the world changes. With the current historical moment's rapid growth in technology, many researchers thinks that the industry is currently going through another major industrial revolution (Sun \& Lu, 2015; Raj \& Ha-Brookshire, 2016). The reach of tech companies is ever expanding, and as they show increased interest in fashion and wearables, they might affect the nature of fashion products. Therefore, an examination of the product developments which can cross over and merge industrial boundaries is necessary to make sure that such disruption if happens brings better products to consumers through improved organizational behavior. To examine this in the context of the fashion and the wearable technology industries, this study examined the organizational behavior of product development teams in both of these spheres. Product development groups in the two industries are at the forefront of new product development activities, requiring creative skills and creating new and handling spillovers of knowledge. The purpose of this study was therefore to examine the relationship among team learning behavior, sense of community, transformational leadership, and innovative work behavior in the wearable product development teams, that is, in both academically homogenous CFPD teams and academically diverse WTPD teams.

To examine these relationships, data were collected from product developers in both the conventional fashion and wearable technology industries using an online survey. The data collection agency Qualtrics collected 150 complete samples from the conventional fashion 
industry and 125 complete samples from the WT industry. Well-validated scales of Cronbach's alpha higher than .6 were used to measure transformational leadership, sense of community, team learning behavior, and innovative work behavior. Structural Equation Modeling was used to examine the measurement model (confirmatory factor analysis), and a structural model was used to examine the hypothesis. Factor analysis was conducted to examine the validity of the scales for both the groups, and SEM multigroup analysis was used to examine the group differences. As a result, the study had several major findings.

First, TL was found to have a significant and positive impact on IWB in wearable product development teams, and this was significantly higher in the WTPD than the CFPD teams. This finding establishes the importance of transformational leadership for innovation in the product development phase. Changes in the product development practices in an industry can happen for various reasons, and the role of leaders are important to drive the product development team in the right direction when change comes. The higher impact of TL on IWB for WTPD in comparison to CFPD makes it clear that the role of leaders is more important to bring out innovative outcomes from the product developers when the team members are cognitively diverse. The direct positive relationship between the leadership style of the managers and innovative work behavior of the team members is an important finding. Given the rapid changes in the fashion industry and consumers' growing need for functional and technologically enhanced clothing and in light of the current findings, it might be important for CFPD teams in the very near future to emphasize transformational leadership to facilitate more innovative product development outcomes. 
Second, the impact of TL on TLB was not significant for any of the groups. This is one of the most important finding of this study. It helps in understanding that transformational leaders alone cannot bring collaboration among team members. The leaders ought to make an environment that helps to create a sense of community within the team, which then positively impacts the team learning behavior for both CFPD and WTPD teams. This confirms that transformational leadership has a direct positive impact on innovative work behavior but not directly on team learning behavior. For facilitating collaboration in academically homogenous and heterogeneous team, the role of transformational leader may need to be more of a facilitator rather than a direct contributor. The impact of TL on SOC was a little higher with statistical significance for CFPD (.748) than WTPD teams (.712). This finding tells us that in CFPD, transformational leaders are slightly better at building an environment which helps reinforce needs, boosts membership feelings, builds team members' influence on each other, and enhances shared emotional connections among team members than in the emerging sector of WTPD. These characteristics of the work environment which helps in creating SOC positively impacts TLB for CFPD as well as WTPD. The impact of SOC on TLB was higher for WTPD (.970) than for CFPD (.863). The positive impact of SOC for WTPD was an important finding; therefore leaders of WTPD teams should specifically make strategies to build SOC, which would then increase TLB.

Third, collaborative behavior might or might not lead to innovative behavior, but in this study the relationship was positive and significant for both the groups. It was found that collaborative team learning behavior leads to innovative work behavior in product development teams. Therefore, construction and co-construction of knowledge, as well as constructive conflict within the teams, are highly essential for fostering idea generation, idea promotion, and idea 
realization in the product development phase. The impact of TLB on IWB was greater for CFPD (.602) than for WTPD (.504), whereas the impact of TL on IWB in WTPD almost doubled the impact in CFPD. It seems that fashion product developers are able to achieve innovative work behavior more through construction and co-construction of knowledge and constructive conflict, as they belong to similar academic backgrounds and might be able to understand each other better due to belonging to an established industry with well-formulated strategies. Meanwhile, WTPD is comparatively new and emerging and it might be still formulating strategies to increase collaboration among academically diverse team members and therefore emphasizing the abilities of transformational leaders to enhance innovative work behavior more than team learning behavior.

\section{Contributions and Implications}

This study is one of the first studies to quantitatively examine the collaboration between product developers in the emerging field of wearable technology. It provides several important contributions to social capital theory, which was used as a theoretical framework. It also provides insights for product development managers who are either working in fashion or wearable technology or would like to crossover and adapt a more hybrid domain. The findings will also benefit product developers for CF and WT. The relationship between the constructs in this study can give them a deeper understanding of organizational behavior and management strategies, which are meant for increasing their team learning behavior and innovative work behavior. Further, the study has contributions for the education sector, as the workforce for product development must be trained effectively for the rapidly growing fashion discipline. 


\section{Theoretical Contribution and Implications}

According to Hanifan (1916), social capital builds by the constant expansion of a network in a community, and this network, as well as the accumulation of social capital, enhances the satisfaction level from social needs and improves living conditions within a community substantially. In this study, it was similarly found that the structural dimension of social capital (which was achieved with the help of transformational leadership) impacts the relational dimension (which was achieved by sense of community), and both of these dimensions then positively affect the cognitive dimension of SC (which was achieved by team learning behavior). The importance of social capital and the interplay between all these dimensions to achieve innovative work behavior empirically substantiates the importance of social capital in the CFPD and WTPD domains. Thus, the results of this study establish the importance of social capital for innovation in the product development phase.

Second, according to SCT, the two types of linkages within an organization are bonding and bridging. These are enhanced with the presence of transformational leadership (Adler \& Kwon, 2002). In this study too, transformational leadership created the structural "bond" within the product development group, as the hypothesis, which predicted a positive relationship between TL and IWB (H1), was found to be significant and positive. Facilitation of cognitive development through relational bonding, especially when the group was cognitively diverse, was also revealed in this study, as TL positively and significantly impacted SOC, which in turn positively and significantly impacted TLB (H3).

Third, the positive and significant connection between the relational dimension of SCT and sense of community expands the theory and establishes its importance in the product 
development phase of CF and WT domains. The precursors of SC such as place attachment, pride for a place, and confidence in the future of the community are largely related to sense of community (Perkins et al., 1996; Perkins \& Long, 2002; Perkins et al., 2002). Participation in community activities thus results in building trust and strong bonds among the members, leading to better social capital and better-managed organizations and teams.

Fourth, the differences in the behaviors of product developers in WT and CF teams uncovered in this study also brought out new knowledge about the organizational behavior for innovation in cognitively heterogeneous and homogenous groups. The difference between the groups was greatest when the impact of TL on IWB was analyzed (H1a). In WTPD it was .557, almost double that of CFPD, which was .275. This finding hints at the importance of transformational leadership more for cognitively heterogeneous teams than for homogenous ones, which aim at innovative outcomes in the conventional fashion and WT product development.

Fifth, the impact of TL on SOC was very similar for WTPD (.712) and CFPD (.748). The finding reveals that the leadership of both kinds of teams was giving similar considerations to building a sense of community. It was also found that transformational leadership significantly and positively impacted the creation of a sense of community for the product development teams. This expands and connects two important constructs from transformational leadership and sense of community literature and informs researchers of how each contribute to innovative product development.

Sixth, the impact of sense of community on team learning behavior was slightly more in WTPD (.970) than in CFPD (.863), whereas the impact of TLB on IWB was slightly more in 
CFPD (.602) than in WTPD (.504). This suggests that for WTPD team the sense of community impacts team learning behavior stronger than for CFPD, but that the impact does not remain stronger than for CFPD when the impact of team learning behavior on innovative work behavior is accounted for. This finding is important because it informs the innovative work behavior literature that for cognitively diverse team members the effect of team learning behavior (through construction, co-construction, and constructive conflict) on innovative work behavior is not as impactful as on a cognitively similar team. These findings will help to inform researchers of the detailed relationship between the antecedents of innovative work behavior. It also gives a clear picture of the difference between the approaches to innovation taken in organizations that employ cognitively diverse and similar product development teams.

\section{Industry Contribution and Implications}

First, the importance of transformational leadership for product development was established in this study. Further, transformation leadership was also found to impact WTPD teams more than CFPD teams. Transformational leaders who encourage team members with individualized consideration, intellectual stimulation, and idealized behaviors inspired innovative work behavior among the team members. Thus, managers in the fashion and WT industries should be trained to be transformational leaders. Moreover, the type of leadership displayed not only impacted innovative work behavior but also helped in building a sense of community in the product development team. TL was approximately twice as important for WTPD (.557) teams in comparison to CFPD (.277) team, and both showed a positive significant relationship with IWB. Fashion and WT product development teams therefore need to have transformational leaders to encourage team members and push them to achieve more positive outcomes through innovative work behavior. In particular, communicating a clear and positive vision of the future to team 
members is important to inspire them to achieve their goals. Contributing to their development through recognition was also found to be a good practice for transformational leaders.

Questioning assumptions and encouraging team members to look at the problem from different angles were also found to be important in the product development context. A workshop or seminar showing these important traits and designing activities to train a leader how to foster them could be good strategies to develop transformational leadership skills.

Second, sense of community was an important element found to positively impact team learning behavior and in turn impact innovative work behavior in the product development teams. This idea of creating a community, which is nurturing and allows the free flow of information, has been championed by technology companies such as Google. Seeing its positive impact on team learning and innovative behavior during the product development phase tells the managers of these teams to give an extra effort to create an environment where a sense of belongingness, membership, and need fulfillment is achieved among the team members. The impact of a sense of community on team learning behavior was higher for WTPD teams than on CFPD teams. This suggests that the sense of community component is more important to bring those team members who are coming from diverse academic backgrounds closer. Thus, the management should create events to bring team members close together and to give them a chance of building better professional relationships with each other. Events or workshops should be designed especially to build shared emotional connections and to enhance the feeling that important needs are being met through team activities. Another way to accomplish this task can be to evaluate the employees on the basis of the positive impact they make on other team members' jobs. A regular evaluation on some of the parameters of sense of community will help 
the companies monitor this component, which has the capability to positively impact team learning behavior.

Third, the results empirically prove that team learning is one of the antecedents of innovative work behavior for product developers in the fashion and WT domains. Therefore creating teams to solve the problem together might be a better strategy in the product development phase rather than relying on the creative genius of one person. Construction and coconstruction of knowledge, as well as the constructive conflict among team members, were more impactful on IWB for CFPD (.602) than for WTPD (.504). Therefore, WTPD teams may want to look at how conventional fashion is executing its team learning behavior and take ideas from them to improve their impact on innovative work behavior through team learning behavior rather than achieving it mainly through transformational leadership. The product developers are also informed that constructive conflicts are good for the developing teams. Therefore, team members should be encouraged to voice their thoughts, even if they are contradictory.

Fourth, for the first time it was found that WTPD teams were cognitively more diverse than CFPD teams. The demographic characteristics revealed from this study are also very important findings. In the WTPD teams, the genders were more evenly spread with a slightly larger proportion of males (52.8\%), and majority of the research participants associated themselves with design (44\%), followed by software science and engineering (26.4\%), hardware science and engineering (15.2\%). Whereas in the CFPD group, the number of female employees $(77.3 \%)$ was much greater than male $(22.7 \%)$, and majority of the research participants associated themselves with design (68\%) and 'other' (16\%) discipline. The majority of the research participant's companies in the CFPD group had more than 5 Million USD in gross sales, 
which further hints at the fact that it is a more mature industry. Meanwhile, in the WTPD group the majority of the research participants had less than 5 Million USD in gross sales, revealing that this domain is emerging and not as strong financially in comparison to the conventional fashion industry. This information can help researchers and managers in developing appropriate organizational behavior strategies in lieu of the current demographic information as revealed from this study. The cognitive diversity of the WTPD teams suggests that if conventional fashion product development teams want to develop products with a balance of fashion and function, they would need to train or hire workforce from unconventional areas such as software or hardware science and engineering.

Fifth, for product developers in these industries, the findings can give clues on how to achieve innovative work behavior. For PD teams, realization of the fact that construction and coconstruction of knowledge, as well as having constructive conflict in the team, are important ways to achieve innovative work behavior can lead them to share more knowledge to their team members. Moreover, handling difference of opinions by addressing them directly and making sure that comments by team members on ideas are acted upon in the team can especially help in

achieving TLB. Product developers may need to be encouraged not to shy away from asking and handling critical questions. These are important elements of TLB that, if exercised, can positively impact innovative work behavior.

\section{Academic Contribution and Implications}

First, the study showed that transformational leadership is essential for WTPD. Thus, academic programs, which produce the workforce of this industry, should include modules on TL and train students how to function under and eventually become transformational leaders. 
Having a sense of community in the workplace was also found to be important. Therefore it is important to expand the comfort zone, to reach out and broaden the networks to understand those people who are from different academic backgrounds and with different tacit knowledge. This could be achieved in colleges and universities by taking part in events or projects from different disciplines. Professors are encouraged to plan such interdisciplinary events and projects where cognitively diverse team members participate in product development activities. This exposure will help them to understand people with different academic backgrounds and would eventually help in collaboration or team learning behavior.

Second, even though the impact of TL was not as strong for CFPD teams as it was for WTPD, it was still significant. TL skills therefore remain important for fashion product development teams, and product development students should be exposed to these skills in college. Team learning behavior had a high impact on innovative work behavior for CFPD, therefore the chance to execute group projects in a product development class can help in facilitating and training future professionals for collaboration, as it was found to significantly impact innovative work behavior.

Third, the advent of WT has the potential to change the way fashion product development is being taught in universities. The formation of advanced wearable technology laboratories in many colleges worldwide is currently underway. Correspondingly, the study finding further substantiates the need for close collaboration from sciences such as electronics and engineering. Increased collaboration at the university level among product developers from not only fashion but other disciplines such as engineering and technology can further help in understanding and building team learning behavior among cognitively diverse team members. More hybrid product 
development courses can help in preparing the workforce of the CFPD as well as WTPD teams. The increased collaboration between hard and soft sciences departments at the university can help in achieving these objectives.

Fourth, the soft skills that are necessary for product development in both PD teams were transformational leadership and collaborative skills. Therefore, at the college level students should be trained to hone these skills through group activities, especially in an interdisciplinary environment. Class activities or projects should be aimed at exposing students to skills related to transformational leadership. Role-playing by fashion designers, electronics engineers, software engineers, and health care personnel can especially help in exposing students and bringing the knowledge of these important areas to the product development process. Product development teams are known to research their target users and then develop the products according to their research. Adding technology in their product development process will add a step of bringing knowledge from other discipline to their workspace and would require more effort by students and extra guidance from the professors.

Fifth, with the increasing cognitive diversity in WTPD and CFPD teams, the need for good communication and empathy for each other can be important for the success of the teams. This is also supported by other studies, which emphasized the need for soft skills such as teamwork, leadership, and communication (Frazier \& Cheek, 2016) as important factors for success in jobs in the fashion industry. Similarly, as per the results of the study, building a sense of community among the cognitively diverse team members is very important for team learning and innovative work behavior. Therefore, empathy and respect for members of different academic backgrounds is an important factor for the success of CFPD and WTPD team. 


\section{Study Limitations and Future Research Opportunities}

Like any other study that explores social and organizational phenomena, this study too has a few limitations. These can be broadly categorized as the limitations related to the scope of the study, methodological limitations, and the biasedness due to the self-reported data from the research participants.

First, the CFI of the overall group model was .895 and the scalar invariant model was .84 , which is close to but lower than the cutoff value of .90 . Therefore, the results of this study should be interpreted in light of the lower CFI level. However, the other parameter RMSEA's cutoff value was found to be good for both the models.

Second, the study was designed to examine the perceived behaviors of team members during the product development phase of the fashion and the wearable technology domains. Therefore, all the generalizations of the study should be made in the context of product development activities. Apart from looking at the product development activities, other areas such as marketing and supply chain issues can be further studied to help inform fashion companies that would like to venture into the wearable technology industry and vice versa. If there is an increased inclination of wearing smart clothing among consumers, such research can help the industries develop strategies to facilitate collaboration among professionals for accelerated innovation.

Third, wearable technology was defined as those gadgets which could be worn over the human body and which have some type of technological functionality. Therefore, this study did not take into account wearable technology products that did not serve any technological functions apart from common weather protection and aesthetics. For example, a wearable shirt, 
which is made up 3D printed plates but does not have any technological functionality is not considered wearable technology product for this study. This study explored the product development of the two extreme ends of the wearable technology continuum, of which one end was conventional fashion and the other were technologically enhanced fashion products. Future research is recommended to examine the product development of those items, which lie inbetween the ends of the fashion technology continuum. This would further facilitate our understanding of the convergence of wearable technology and conventional fashion product development and would help eventually to close the gap between these product development activities to facilitate more innovative products with a balanced fashion and functionality component.

Fourth, the literature suggested that the empirical examination of the product development phase of the WT industry has not been extensively explored. Also, this sector is currently in the growth stage in its lifecycle, with most of the products in the "on the rise" section of the Gartner Hype Cycle (McIntyre \& Reinhart, 2016). Therefore, the population parameters for accessing the overall characteristics of the product developers of this particular industry were difficult to assess and generalize. A future study is recommended to examine the characteristics of the employees working in the WT industry, which could help in creating strategies for the current and upcoming workforce.

The high reliability of the scales used in this study shows that the constructs examined in the study had similar meaning in both the industries. The model fit was also adequate for both groups. However, as the industry matures and a greater number of research participants in the WT field become available, analyzing the relationships with more participants and a more 
mature industry will help in uncovering more knowledge. A longitudinal study can help in deciphering the growth and challenges of product development in the WT and fashion industries.

The online survey technique is not very helpful in diminishing the biasedness of the research participants. Some of the factors that can attribute to their biasedness are selective memory (that is, remembering only a few instances), attributions (linking the failures to external factors and success to the internal factors), and exaggeration (reporting instances with more significant emphasis than in reality). Having good clarifying prompts and clear questions can diminish the biasedness. However, it cannot be fully eliminated. Future research on social network analysis, which examines communication patterns by analyzing email exchanges between product developers, can help in eliminating some of these constraints and further expand the knowledge on collaboration for innovation in these cognitively diverse teams. Also, caution should be taken in generalizing the findings, as the participants were not randomly recruited. The research participants were recruited through Qualtrics, and only those who were in the data collection agency's panels were able to take the survey. However, reaching out to professionals who were specifically working in the product development activities for WT (a niche area) and CF would have been very difficult without using the help of a data collection agency. 


\section{REFERENCES}

Adler, P.S. \& Kwon, S.W. (2002). Social capital: prospects for a new concept. Academy of Management Review, 27(1), 17-40.

Aga, D., Noorderhaven, N., \& Vallejo, B. (2016). Transformational leadership and project success: The mediating role of team-building. International Journal of Project Management, 34806-818.

Akçomak, I. S., \& Ter Weel, B. (2009). Social capital, innovation and growth: Evidence from Europe. European Economic Review, 53(5), 544-567.

Akturan, A., \& Çekmecelioğlu, H. G. (2016). The Effects of Knowledge Sharing and Organizational Citizenship Behaviors on Creative Behaviors in Educational Institutions. Procedia - Social And Behavioral Sciences, 235(12th International Strategic Management Conference, ISMC 2016, 28-30 October 2016, Antalya, Turkey), 342-350.

Amabile, T. M. (1988). A model of creativity and innovation in organizations. Research in Organizational Behavior, 10, 123-167.

Amabile, T. M. (1996). Creativity in Context. Boulder, CO: Westview Press.

Amabile, T. M. (1983). The social psychology of creativity: A componential conceptualization. Journal of Personality and Social Psychology, 45, 357-376.

Ariyatum, B., Ray, H., \& David, H. (2005). The future design direction of smart clothing development. Journal of the Textile Institute, 96(4), 199-210. 
Arthur, R. (2016). The future of fashion: 10 wearable tech brands you need To know. Forbes. Retrieved from http://www.forbes.com/sites/rachelarthur/2016/06/30/the-future-offashion-10-wearable-tech-brands-you-need-to-know/\#664f69f04852

Aruştei (Lungu), C. C., \& Leon, R. D. (2013). Organizational citizenship behavior - an instrument for sharing tacit knowledge. International Journal of Management Science \& Technology Information, (9), 70-81.

Aubé, C., Rousseau, V., \& Tremblay, S. (2015). Perceived shared understanding in teams: The motivational effect of being 'on the same page'. British Journal of Psychology, 106(3), 468-486. .

Avolio, B. J., Waldman, D. A., \& Einstein, W. O. (1988). Transformational leadership in a management game simulation. Group \& Organizational Studies, 13, 59-80.

Bagher, A. N., Masoume, M. M., \& Soltani, M. (2016). Effect of transformational leadership and knowledge management processes on organizational innovation in Ardabil University of Medical Sciences. International Journal of Management, Accounting \& Economics, 3(11), 672-698.

Bai, Y., Lin, L., \& Li, P. P. (2016). How to enable employee creativity in a team context: A cross-level mediating process of transformational leadership. Journal of Business Research, 69(1), 3240-3250.

Baker, M. (1994). A model for negotiation in teaching-learning dialogues. Journal of Artificial Intelligence in Education, 5(2), 199-254. 
Bandura, A. (1986). Social Foundations of Thought and Action: A Social Cognitive Theory. Englewood Cliffs, N.J.: Prentice-Hall.

Barfield, W., \& Caudell, T. (2001). Basic concepts in wearable computers and augmented reality. Fundamentals of Wearable Computers and Augmented Reality. Mahwa, NJ: Lawrence Erlbaum Associates.

Bass, B. M. (1985 a). Leadership and Performance Beyond Expectations. New York, NY: Free Press.

Bass, B. M. (1985b). Leadership: Good, better, best. Organizational Dynamics, 13(3), $26-40$.

Bass, B. M. (1990). From transactional to transformational leadership: Learning to share the vision. Organizational dynamics, 18(3), 19-31.

Bass, B. M., \& Avolio, B. J. (1990). Transformational leadership development, Manual for the Multifactor Leadership Questionnaire. Palo Alto, CA: Consulting Psychologists Press.

Bass, B. M., \& Avolio, B. J. (1993). Transformational leadership and organizational culture. Public administration quarterly, 112-121.

Beckman, P. J., Barnwell, D., Horn, E., Hanson, M. J., Gutierrez, S., \& Lieber, J. (1998). Communities, families, and inclusion. Early Childhood Research Quarterly, 13, 125-150.

Beers, P. J., Kirschner, P. A., Boshuizen, H. P. A., \& Gijselaers, W. (2007). ICT-support for grounding in the classroom. Instructional Science, 35, 535-556.

Beloff, L. (2010). Wearable artefacts as research vehicles. Technoetic Arts: A Journal of Speculative Research, 8(1), 47-53. 
Berhnhofen, D.M. \& Opie, A. (1997). Thinking teams thinking clients: issues of discourse and representation in the work of health care teams. Sociology of Health and Illness, 19(3), $259-280$

Bhasin, K. (2015, November 4). Michael Kors CEO Vows to End Retail Rollout. Bloomberg. Retrieved from https://www.businessoffashion.com/articles/news-analysis/michael-kors$\underline{\text { too-many-stores }}$

Bittner, E. C., \& Leimeister, J. M. (2014). Creating shared understanding in heterogeneous Work groups: Why it matters and how to achieve It. Journal of Management Information Systems, 31(1), 111-144.

Blanco, T., Casas, R., Asensio, Á., Manchado-Pérez, E., \& López-Pérez, J. (2015). From the islands of knowledge to a shared understanding: interdisciplinarity and technology literacy for innovation in smart electronic product design. International Journal of Technology and Design Education, 1-34.

Boies, K., Fiset, J., \& Gill, H. (2015). Communication and trust are key: Unlocking the relationship between leadership and team performance and creativity. The Leadership Quarterly, 26 (2015), 1080-1094.

Bolino, M. (1999). Citizenship and impression management: good soldiers or good actors? Academy of Management Review 24(1), 82-98.

Bolkan, S., \& Goodboy, A. K. (2010). Transformational leadership in the classroom: The development and validation of the student intellectual stimulation scale. Communication Reports, 23(2), 91-105. 
Boon, A., Raes, E., Kyndt, E., \& Dochy, F. (2013). Team learning beliefs and behaviors in response teams. European Journal of Training and Development, 37(4), 357-379.

Bottomley, P., Mostafa, A. S., Gould-Williams, J. S., \& León-Cázares, F. (2016). The impact of transformational leadership on organizational citizenship behaviours: The contingent role of public service motivation. British Journal of Management, 27(2), 390-405.

Boujut, J. (2003). User-defined annotations: artefacts for co-ordination and shared understanding in design teams. Journal of Engineering Design, 14(4), 409-419.

Bourdieu, P. (2011). The forms of capital.(1986). Cultural theory: An anthology, 81-93.

Bruffee, K.A. (1993). Collaborative learning: Higher education, interdependence, and the authority of knowledge. Baltimore: John Hopkins University.

Burt, R. S. (2000). The network structure of social capital. Research in Organizational Behavior, $345-423$.

Burns, J. M. (1978). Leadership. New York, NY: Harper \& Row.

Bunniss S, \& Kelly DR. (2013). Flux, questions, exclusion and compassion: collective learning in secondary care. Medical Education, 47(12), 1197-208.

Bycio, P., Hackett, R. D., \& Allen, J. S. (1995). Further assessments of Bass's (1985) conceptualization of transactional and transformational leadership. Journal of applied psychology, 80(4), 468. 
Caillier, J. G. (2016). Linking transformational leadership to self-efficacy, extra-role behaviors, and turnover intentions in public agencies: The mediating role of goal clarity. Administration \& Society, 48(7), 883-906.

Campbell, D. T. (1960). Blind variation and selective retention in creative thought as in other knowledge processes. Psychological Review, 67, 380-400.

Carless, S.A., Wearing, J. \& Mann, L. (2000). A short measure of transformational leadership. Journal of Business and Psychology, 14 (3), 389-405.

Carter, D.R., Dechurch, L.A., Braun, M.T., \& Contractor, N.S. (2015). Social network approaches to leadership: an integrative conceptual review. Journal of Applied Psychology, 100(3), 597-622

Chang, W., Liao, S., Lo, W., \& Lee, Y. (2015). Organizational commitment, knowledge sharing and organizational citizenship behavior: The case of the Taiwanese semiconductor industry. Knowledge Management Research and Practice, 13(3), 299-310.

Chavis, D. M. et al. (1986). Sense of community through Brunswick's lens: A first look. Journal of Community Psychology, 14(1), 24-40.

Chavis, D.M., Lee, K.S., \& Acosta J.D. (2008). The Sense of Community (SCI) Revised: The Reliability andValidity of the SCI-2. Paper presented at the 2nd International Community Psychology Conference, Lisboa, Portugal.

Chavis, D. M. \& Wandersman A. (1990). Sense of community in the urban environment, A catalyst for participation and community development. American Journal of Community Psychology, 18, 55-81. 
Chipuer, H. M., \& Pretty, G.M. (1999). A review of the sense of community index: Current uses, factor structure, reliability, and further development. Journal of Community Psychology, $27(6), 659-679$.

Choi , S. B., Kim , K., Ullah, S. M. E., Kang, S.W (2016). How transformational leadership facilitates innovative behavior of Korean workers: Examining mediating and moderating processes. Personnel Review, 45 (3), 459 - 479

Chun, J. U., Cho, K., \& Sosik, J. J. (2016). A multilevel study of group-focused and individualfocused transformational leadership, social exchange relationships, and performance in teams. Journal of Organizational Behavior, 37(3), 374-396.

Collin K, Paloniemi S, Mecklin J. (2010). Promoting interprofessional teamwork and learning the case of a surgical operating theatre. Journal of Educational Work, 23, 43-63.

Coleman, J. S. (1988). Social capital in the creation of human capital. American journal of sociology, 94, S95-S120.

Cook, S. D. N., \& Brown, J. S. (1999). Bridging epistemologies: The generative dance between organizational knowledge and organizational knowing. Organization Science, 10, 381 400.

Cott, C. (1997). We decide, you carry it out: a social network analysis of multidisciplinary longterm care teams. Social Science and Medicine, 45(9), 1411-1421.

Cronin, M. A., \& Weingart, L. R. 2007. Representational gaps, information processing, and conflict in functionally diverse teams. Academy of Management Review, 32, 761-773. 
Cross, N. (2011). Design thinking: Understanding how designers think and work. Louvigny: Berg

Dakhli, M., \& De Clercq, D. (2004). Human capital, social capital, and innovation: a multicountry study. Entrepreneurship \& regional development, 16(2), 107-128.

Davenport, T. H. \& Prusak, A. (1998). Working Knowledge: How Organization Manages What They Know. Boston, MA: Harvard Business School Press.

De Dreu, C. K. W., \& Weingart, L. R. (2003). Task versus relationship conflict, team performance, and team member satisfaction: A meta-analysis. Journal of Applied Psychology, 88(4), 741-749.

de Oliveira Rodrigues, A., \& Ferreira, M. C. (2015). The Impact of Transactional and Transformational Leadership Style on Organizational Citizenship Behaviors. PsicoUSF, 20(3), 493-504.

Dede, C. (1996). The evolution of distance education: Emerging Technologies and distributed learning. American Journal of Distance Education, 10(2), 4-36.

Deinert, A., Homan, A. C., Boer, D., Voelpel, S. C., \& Gutermann, D. (2015). Transformational leadership sub-dimensions and their link to leaders' personality and performance. The Leadership Quarterly, 261095-1120.

Den Hartog, D.N. \& Belschak, F.D. (2012). When does transformational leadership enhance employee proactive behavior? The role of autonomy and role breadth self-efficacy. Journal of Applied Psychology, 97(1), 194-202. 
Deshpande, N.; de Vries, B. \& van Leeuwen, J. P. (2005). Building and supporting shared understanding in collaborative problem-solving. In E. Banissi, M. Sarfraz, J.C. R oberts, B. L often, A. Ursyn, R.A. Burkhard, A. L ee, and G. Andrienko (eds.), Proceedings of the Ninth International Conference on Information Visualisation. Los Alamitos, CA: IEEE Computer Society, pp. 737-744.

Dicken, P. (2011). Global Shift, Sixth Edition: Mapping the Changing Contours of the World Economy. New York: Gilford Press.

Dillenbourg, P., Baker, M., Blaye, A., \& O’Malley, C. (1996). The evolution of research on collaborative learning. In E. Spada \& P. Reiman (Eds.), Learning in Humans and Machine: Towards an interdisciplinary learning science (pp. 189-211). Oxford: Elsevier.

Dillman, D. A., Smyth, J. D., \& Christian, L. M. (2014). Internet, phone, mail, and mixed-mode surveys: the tailored design method. Hoboken, NJ: John Wiley \& Sons, Lawrence Erlbaum.

Dingler, A., \& Enkel, E. (2016). Socialization and innovation: Insights from collaboration across industry boundaries. Technological Forecasting \& Social Change, 10950-60.

Doig, S. (2014, August 29). Ralph Lauren's polo tech shirt. The Telegraph. Retrieved from http://www.telegraph.co.uk/luxury/technology/43641/ralph-laurens-polo-tech-shirt.html

Drach-Zahavy, A., \& Somech, A. (2001, Jun.). Understanding team innovation: The role of team processes and structures. Group Dynamics: Theory, Research, and Practice, 5(2), 111123. 
Drucker, P. F. (1985). Innovation and Entrepreneurship: Practice and Principles. London, UK: Heinemann.

Erdem Aydin, I., \& Gumus, S. (2016). Sense of classroom community and team development process in online learning. Turkish Online Journal Of Distance Education, 17(1), 60-77.

Feather, J. (2003). Theoretical perspectives on the information society. In S. Hornby \& Z. Clarke (Eds.), Challenge and Change in the Information Society (pp. 3-17). London, UK: Facet Publishing.

Fischer, G. (2000). Symmetry of ignorance, social creativity, and meta-design. KnowledgeBased Systems, 13 (7), 527-537.

Ford, C. M. (1996). A theory of individual creative action in multiple social domains. Academy of Management Review, 21, 1112-1142.

Frazier, B., \& Cheek, W. (2016). An industry view of competencies for entry-level merchandising jobs: Application of the ITAA Meta-Goals. Clothing and Textiles Research Journal, 34(2), 79-93.

Fried, V. H., \& Hisrich, R. D. 1994. Toward a model of venture capital investment decision making. Financial Management, 23, 28-37.

Frost, P. J., \& Egri, C. P. 1991. The political process of innovation. Research in Organizational Behavior, 13, 229-295.

Fruchter, R. (2001). Dimensions of teamwork education. International Journal of Engineering Education, 17(4/5), 426-430. 
Gent, E. (2014). Fashion focus could give UK lead in wearable technology. Engineering and Technology, 9(7), 19.

Gepperth, J. (2012). Smart things: Wearables \& clothing. Advances in Media Technology, 3, 4148.

George, J. M., \& Zhou, J. (2001). When Openness to Experience and Conscientiousness Are Related to Creative Behavior: An Interactional Approach. Journal of Applied Pyschology, 86, 513- 524.

Gratton, L., \& Erickson, T. J. (2007). 8 Ways to build collaborative teams. Harvard Business Review, 85(11), 100-109.

George, D., \& Mallery, P. (2010). SPSS for Windows step by step. A simple study guide and reference (10. Bask1).

Giles, C., Johnson, L. A. U. R. I., Brooks, S., \& Jacobson, S. L. (2005). Building bridges, building community: Transformational leadership in a challenging urban context. Journal of School Leadership, 15(5), 519.

Granovetter, M. S. (1973). The strength of weak ties. American Journal of Sociology, 13601380.

Griffiths, L. (1997). Accomplishing teamwork: teamwork and categorization in two community mental health teams. Sociological Review, 45(1), 59-78.

Hair, J. F., Black, W. C., Babin, B. J., Anderson, R. E., \& Tatham, R. L. (2006). SEM: confirmatory factor analysis. Multivariate data analysis. Pearson Prentice Hall, Upper Saddle River, $770-842$. 
Hanifan, L. J. (1916). The rural school community center. The Annals of the American Academy of Political and Social Science, 67(1), 130-138.

Hayward,J., Chansin, G., \& Zervos, H.(2016). Wearable Technology 2016-2026. Retrieved from http://www.idtechex.com/research/reports/wearable-technology-2016-2026$\underline{000483 . a s p}$

Hater, J. J., \& Bass, B. M. (1988). Superiors' evaluations and subordinates' perceptions of transformational and transactional leadership. Journal of Applied Psychology, 73, 695702.

He, J., Butler, E., \& King, W. R. (2007). Team Cognition: Development and Evolution in Software Project Teams. Journal of Management Information Systems, 24(2), 261-292.

Heavey, C., Mowday, R.T., Kelly, A. and Roche, F. (2009). Reconceptualizing executive environmental scanning and search: implications for international leadership research and practice. Advances in Global Leadership, 5(5), 65-92.

Hill, C. (2015). Wearables-the future of biometric technology?. Biometric Technology Today, 2015(8), 5-9.

Hill, L. A., Lineback, K., Truelove, E., \& Brandeau, G. (2014). Collective Genius : The Art and Practice of Leading Innovation. Boston, Massachusetts : Harvard Business Review Press, [2014].

Hoeft, R. M., Jentsch, F., Smith-Jentsch, K., \& Bowers, C. (2005). Exploring the role of shared mental models for implicit coordination in teams. Proceedings of the Human Factors and Ergonomic Society 49th Annual Meeting, 49 (20), 1863-1867. 
Homan, A. C., van Knippenberg, D., Van Kleef, G. A., \& De Dreu, C. K. W. (2007). Bridging faultlines by valuing diversity: Diversity beliefs, information elaboration, and performance in diverse work groups. Journal of Applied Psychology, 92(5), 1189-1199.

House, R. J. (1976). A 1976 theory of charismatic leadership. In J. G. Hunt \& L. L. Larson (Eds.), Leadership: The cutting edge (pp. 189-207). Carbondale, IL: Southern Illinois University Press.

Howell, J. M., \& Higgins, C. A. 1990. Champions of technological innovation. Administrative Science Quarterly, 35, 317-341.

Hsiao, H. C., Chang, J. C., Tu, Y. L., \& Chen, S. C. (2011). The impact of self-efficacy on innovative work behavior for teachers. International Journal of Social Science and Humanity, 1(1), 31 .

Hsieh, Y. (2006). Culture and shared understanding in distributed requirements engineering. Paper presented at the International Conference on Global Software Engineering, Florianopolis, Brazil.

Humphrey, A. (2012). Transformational leadership and organizational citizenship behaviors: The role of organizational identification. The Psychologist-Manager Journal, 15(4), 247-268.

Horwitz, S. K., \& Horwitz, I. B. (2007). The effects of team diversity on team outcomes: A meta-analytic review of team demography. Journal of management, 33(6), 987-1015.

Irvine, R. (1985). Power and conflict in primary medical care: a case study of the micro-politics of health centre practice. Unpublished PhD thesis. University of Edinburgh. 
Isa, R. M, Abdullah, N. L., \& Senik, Z. C. (2010). Social capital dimension for tacit knowledge sharing: Exploring the Indicators. Jurnal Pengurusan, 30 (2010), 75-91.

Jaccard, J., \& Jacoby, J. (2010). Theory construction and model-building skills: A practical guide for social scientists. Guilford Press.

Jaiswal, N. K., \& Dhar, R. L. (2015). Transformational leadership, innovation climate, creative self-efficacy and employee creativity: A multilevel study. International Journal of Hospitality Management, 5130-41.

Janssen, O. (2000). Job demands, perceptions of effort-reward fairness and innovative work behavior. Journal of Occupational and Organizational Psychology, 73(3), 287-302.

Janssen, O. (2001). Fairness perceptions as a moderator in the curvilinear relationships between job demands, and job performance and job satisfaction. Academy of Management Journal, 44, 1039-1050.

Janssen, O. (2003). Innovative behavior and job involvement at the price of conflict and less satisfactory relations with co-workers. Journal of Occupational \& Organizational Psychology, 76(3), 347-364.

Johnson, T. E., Lee, Y., Lee, M., O’Connor, D. L., Khalil, M., \& Huang, X. (2007). Measuring sharedness of team-related knowledge: Design and validation of a shared mental model instrument. Human Resource Development International, 10, 437-454.

Jung, D. I. (2001). Transformational and transactional leadership and their effects on creativity in groups. Creativity Research Journal, 13, 185 - 197. 
Kanter, R. M. (1988). When a thousand flowers bloom: Structural, collective, and social conditions for innovation in organization. Research in Organizational Behavior, 10, 169211.

Karpova, E., Jacobs, B., Lee, J., \& Andrew, A. (2011). Preparing students for careers in the global apparel industry: Experiential learning in a virtual multinational team-based collaborative project. Clothing and Textiles Research Journal, 29(4), 298-313.

Kazmi, S. Z., Naarananoja, M., \& Wartsila, J. K. (2016). Integrating Strategic Thinking and Transformational Leadership for NPD Idea Support Process. Procedia - Social And Behavioral Sciences, 229(5th International Conference on Leadership, Technology, Innovation and Business Management 2015, ICLTIBM 2015, 10-12 December 2015, Istanbul, Turkey), 387-397.

Kearney, E., \& Gebert, D. (2009). Managing diversity and enhancing team outcomes: The promise of transformational leadership. Journal of Applied Psychology, 94(1), 77-89.

Keller, R. T. (1992). Transformational leadership and the performance of research and development project groups. Journal of Management, 18, 489-501.

Keller, R.T. (2001). Cross-functional project groups in research and new product development: diversity, communications, job stress, and outcomes. Academy of Management Journal, $44,547-555$.

Kleinsmann, M., \& Valkenburg, R. (2008). Barriers and enablers for creating shared understanding in co-design projects. Design Studies, 29(4), 369-386. 
Klimoski, R., \& Mohammed, S. (1994). Team mental model: Construct or metaphor? Journal of Management, 20, 403-437.

Krishnan, V., \& Ulrich, K. T. (2001). Product development decisions: A review of the literature. Management science, 47(1), 1-21.

Lamkin, P.,(February 17 $\left.7^{\text {th }}, 2016\right)$. Wearable Tech Market to Be Worth $\$ 34$ Billion By 2020. Retreived from. http://www.forbes.com/sites/paullamkin/2016/02/17/wearable-techmarket-to-be-worth-34-billion-by-2020/\#131c7c283fe3

Langan-Fox, J.; Anglim, J.; \& Wilson, J.R. (2004). Mental models, team mental models, and performance: Process, development, and future directions. Human Factors and Ergonomics in Manufacturing, 14 (4), 331-352.

Langan-Fox, J.; Anglim, J.; \& Wilson, J.R. (2004). Mental models, team mental models, and performance: Process, development, and future directions. Human Factors and Ergonomics in Manufacturing, 14(4)), 331-352.

Lave, J., \& Wenger, E. (1991). Situated Learning: Legitimate Peripheral Participation. Cambridge, UK : Cambridge University Press.

Leonard, D. \& Sensiper, S. (1998). The role of tacit knowledge in-group innovation. California Management Review, 40(3), 112-132.

Li, V., Mitchell, R., \& Boyle, B. (2016). The Divergent Effects of Transformational Leadership on Individual and Team Innovation. Group and Organization Management, 41(1), 66-97. 
Lian, L. K., \& Tui, L. G. (2012). Leadership styles and organizational citizenship behavior: The mediating effect of subordinates competence and downward influence tactics. Journal of Applied Business and Economics, 13(2), 59-96.

Liao, S., Fei, W., \& Chen, C. (2007). Knowledge sharing, absorptive capacity, and innovation capability: An empirical study of Taiwan's knowledge-intensive industries. Journal of Information Science, 33(3), 340-359.

Lisa, E (2016). Google's diversity efforts still have a long way to go. Time. Retrieved from http://time.com/4391031/google-diversity-statistics-2016/

Lo, M. L., Tse, H. H., \& Ashkanasy, N. M. (2015). A multilevel model of transformational leadership, affect, and creative process behavior in work teams. The Leadership Quarterly, 26(Special Issue: Leadership and Emotions), 543-556.

Malhotra N. K., Dash S. (2011). Marketing Research: An Applied Orientation (Paperback). London: Pearson Publishing.

Mann, S. (1998). Wearable computing as means for personal empowerment. Keynote address presented at the First International Conference on Wearable Computing at Fairfax, VA.

Marin-Garcia, A. J., \& Zarate-Martinez, E. (2007). A theoretical review of knowledge management and teamworking in the organisations. International Journal of Management Science and Engineering Management, 2(4), 278-288.

Martin, V.A., Hatzakis, T., Lycett, M., \& Macredie, R. (2005). Cultivating knowledge sharing through the relationship management maturity model. The Learning Organization, 12 (4), $340-354$. 
Marzano, S., Green, J., vanHeerden, C., \& Mama, J. (2000). New Nomads: An Exploration of Wearable Electronics by Philips. Rotterdam: 010 Publishers

Mayfield, J., \& Mayfield, M. (2012). The Relationship Between Leader Motivating Language and Self-Efficacy: A Partial Least Squares Model Analysis. Journal of Business Communication, 49(4), 357-376.

McCann, J. (1999). Establishing the requirement for the design development performance sportswear. Retrieved from ProQuest Digital Dissertations

McCloughen, A., Gillies, D., \& O'Brien, L. (2011). Collaboration between mental health consumers and nurses: Shared understandings, dissimilar experiences. International Journal of Mental Health Nursing, 20(1), 47-55.

McCole, D. (2015). Seasonal employees: The link between sense of community and retention. Journal of Travel Research, 54(2), 193-205.

McCole, D., Jacobs, J., Lindley, B., \& McAvoy, L. (2012). The Relationship Between Seasonal Employee Retention and Sense of Community: The Case of Summer Camp Employment. Journal of Park \& Recreation Administration, 30(2), 85-101.

McCarthy, M., Pretty, G. \& Catalano, V. (1990) Psychological sense of community and burnout. Journal of Community Psychology, 18, 21 1-216.

McFadyen, M. A., \& Cannella, A. A. (2004). Social capital and knowledge creation: Diminishing returns of the number and strength of exchange relationships. Academy of management Journal, 47(5), 735-746.

McIntyre, A. \& Reinhart, M. (2016).Hype cycle for wearable devices, 2016. Gartner. 
McMillan, D. W. \& Chavis, D. M. (1986). Sense of community: A definition and theory. Journal of Community Psychology, 14(1), 6-23.

McMurtry, A., Rohse, S., \& Kilgour, K. N. (2016). Socio-material perspectives on interprofessional team and collaborative learning. Medical Education, 50(2), 169-180.

Mednick, S. A. 1962. The associative basis of the creative process. Psychological Review, 69, 220-232.

Milfont, T. L., \& Fischer, R. (2010). Testing measurement invariance across groups: Applications in crosscultural research. International Journal of psychological research, 3(1).

Milliken F. and Martins L. (1996) Searching for common threads: Understanding the multiple effects of diversity in organizational groups. Academy of Management Review 21(2): 402-433.

Morgan, N.A., Kaleka, A., \& Katsikeas, C.S. (2004). Antecedents of export venture performance: A theoretical model and empirical assessment. Journal of Marketing, 68(1), 90-108.

Moon, K. (2017). The effects of diversity and transformational leadership climate on organizational citizenship behavior in the U.S. Federal Government: An organizationallevel longitudinal study. Public Performance \& Management Review, 40(2), 361-381.

Moore, D. R. (2011). Technology literacy: The extension of cognition. International Journal of Technology and Design Education, 21(2), 185-193. 
Mueller, J. S., \& Kamdar, D. 2011. Why seeking help from teammates is a blessing and a curse: A theory of help seeking and individual creativity in team contexts. Journal of Applied Psychology, 96, 263-276.

Mulder, I., \& Swaak, J. (2002). Assessing group learning and shared understanding in technology mediated interaction. Educational Technology \& Society, 5 (1), 35-47.

Mulder, I., Swaak, J., \& Kessels, J. (2004). In Search of Reflective Behavior and Shared Understanding in Ad Hoc Expert Teams. Cyberpsychology \& Behavior, 7(2), 141-154.

Mumford, M. D., Connelly, S., \& Gaddis, B. (2003). How creative leaders think: Experimental findings and cases. The Leadership Quarterly, 14, 411-432.

Nahapiet, J. \& Ghoshal, S. (1998). Social capital, intellectual capital and the organizational advantage. Academy of Management Review, 23(2), 242-266.

Nissen, H. A., Evald, M. R., \& Clarke, A. H. (2014). Knowledge sharing in heterogeneous teams through collaboration and cooperation: Exemplified through Public-Private-Innovation partnerships. Industrial Marketing Management, 43(Special Issue on Innovation in Networks - Per Freytag and Louise Young), 473-482.

Nonaka, I, \& Takeuchi, H. (1995) The Knowledge-creating Company: How Japanese Companies Create the Dynamics of Innovation. Oxford University Press, New York.

Norman, D. A. (2005). Emotional design: Why we love (or hate) everyday things. New York: Basic Books.

Noruzy, A., Dalfard, V., Azhdari, B., Nazari-Shirkouhi, S., \& Rezazadeh, A. (2013). Relations between transformational leadership, organizational learning, knowledge management, 
organizational innovation, and organizational performance: an empirical investigation of manufacturing firms. International Journal of Advanced Manufacturing Technology, 64(5-8), 1073-1085.

Nunnally, J. C., Bernstein, I. H., \& Berge, J. M. T. (1967). Psychometric Theory. New York: McGrawHill.

Omar, Z., Zainal, A., Omar, F., \& Khairudin, R. (2009). The influence of leadership behavior on organizational citizenship behavior in self-managed work teams in Malaysia. South African Journal of Human Resource Management, 7(1), 1-11.

Parker, S. K., Bindl, U. K., \& Strauss, K. (2010). Making things happen: A model of proactive motivation. Journal of Management, 36, 827-856.

Pascual, R.G. (1999). Tools for capturing and training shared understanding in teams. Paper presented at the International Conference on Human Interfaces in Control Rooms, Cockpits and Command Centers, Bath, UK, June 21-23.

Pau, G., Segre Reinach, S., Im, M., Tolic, I., Tse, R., \& Marfia, G. (2015, June). Mobile sensing and beyond in the information age: An experimental perspective. In Proceedings of the 2015 Workshop on Pervasive Wireless Healthcare (pp. 3-6). ACM.

Perkins, D. D. (1990). Participation and the social environment of residential blocks. American Journal of Community Psychology, 18. 83-116.

Perkins, D. D., Brown, B. B., \& Taylor, R. B. (1996). The ecology of empowerment: Predicting participation in community organizations. Journal of Social Issues, 52, 85-110. 
Perkins, D. D., Hughey, J., \& Speer, P. W (2002). Community psychology perspective on social capital theory and community development practice. Journal of the Community Development Society, 33(1), 33-52

Perkins, D.D., \& Long, D.A. (2002). Neighborhood sense of community and social capital: A multi-level analysis. In A. Fisher, C. Sonn, \& B. Bishop (Eds.), Psychological Sense of Community: Research, Applications, and Implications (pp. 291-318). New York, NY: Plenum.

Perry-Smith, J. E., \& Mannucci, P. V. 2015. Social networks, creativity, and entrepreneurship. In C. E. Shalley, M. A. Hitt, \& J. Zhou (Eds.) The Oxford handbook of creativity, innovation, and entrepreneurship: 205-224. New York, NY: Oxford University Press.

Poupyrev, I., Gong, N. W., Fukuhara, S., Karagozler, M. E., Schwesig, C., \& Robinson, K. E. (2016, May). Project Jacquard: Interactive Digital Textiles at Scale. In Proceedings of the 2016 CHI Conference on Human Factors in Computing Systems (pp. 4216-4227). ACM.

Preacher, K. J., \& Coffman, D. L. (2006, May). Computing Power and Minimum Sample Size for RMSEA [Computer software]. Available from http://quantpsy.org/.

Pretty, G. (1990) Relating psychological sense of community to social climate characteristics. Journal of Community Psychology, 18, 16-65.

Pretty, G. H., Andrews \& Collet, C. (1994) Exploring adolescents' sense of community and its relationship to loneliness. Journal of Community Psychology, 22, 346-358.

Pretty, G. \& McCarthy, M. (1991) Exploring psychological sense of community among women and men in the work place. Journal of Community Psychology, 19, 351-261. 
Putnam, R. D. (2000). Bowling alone: America's declining social capital. In Culture and politics (pp. 223-234). Palgrave Macmillan US.

Raes, E., Decuyper, S., Lismont, B., Van den Bossche, P., Kyndt, E., Demeyere, S., \& Dochy, F. (2013). Facilitating team learning through transformational leadership. Instructional Science, 41(2), 287-305.

Raj, D., \& Ha-Brookshire, J. (2015a). Exploration of Knowledge Creation Processes and Work Environments in the Wearable Technology Industry. Proceedings of International Textiles and Apparel Association, November 2015, Santa Fe, USA.

Raj, D., \& Ha-Brookshire, J. (2015b). The Needs for Interdisciplinary Collaborations for Preparing Future Fashion Technocrats. Proceedings of International Textiles and Apparel Association, November 2015, Santa Fe, USA

Raj, D., \& Ha-Brookshire, J. (2016). Holding Hands for Walking or Pushing to Fly? Advisors' Leadership Styles to Train Future Faculty. Proceedings of International Textiles and Apparel Association, November 2016, Vancouver, British Columbia, Canada.

Raj, D. \& Morris, K. (2016). Disruptive Potential of 3D printing for Clothing and Textile Sector Proceedings of International Textiles and Apparel Association, November 2016, Vancouver, British Columbia, Canada

Ramamoorthy, N., Flood, P. C., Slattery, T., \& Sardessai, R. (2005). Determinants of Innovative Work Behavior: Development and Test of an Integrated Model. Creativity \& Innovation Management, 14(2), 142-150. 
Roberts, E.B. (1987). Introduction: managing technological innovation research for generalizations. In Roberts, E.B. (ed.), Generating Technological Innovation. Oxford, UK: Oxford University Press.

Sapsed, J., Bessant, J., Partington, D., Tranfield, D., \& Young, M. (2002). Teamworking and knowledge management: A review of converging themes. International Journal of Management Reviews, 4(1), 71-85.

Scott, S. G., \& Bruce, R. A. (1994). Determinants of innovative behavior: A path model of individual innovation in the workplace. Academy of Management Journal, 37(3), 580607.

Scott, S. G., \& Bruce, R. A. (1998). Following the leader in R\&D: the joint effect of subordinate problem-solving style and leader-member relations on innovative behavior. Engineering Management, IEEE Transactions on, 45(1), 3-10.

Seymour, S. (2008). Fashionable Technology: The intersection of Design, Fashion, Science, and Technology. New York, NY: Springer.

Shamir, B., House, R. J., \& Arthur, M. B. (1993). The motivational effects of charismatic leadership: A self-concept based theory. Organization Science, 4(4), 577-594.

Sher, P. J. \& Lee, V. C. (2004). Information technology as a facilitator for enhancing dynamic capabilities through knowledge management. Information \& Management, 41(8), 933945. 
Shin, S. J., Kim, T., Lee, J., \& Bian, L. (2012). Cognitive team diversity and individual team member creativity: A cross-level interaction. Academy of Management Journal, 55(1), 197-212.

Shin, S. J., \& Zhou, J. (2007). When is educational specialization heterogeneity related to creativity in research and development teams? Transformational leadership as a moderator. Journal of applied Psychology, 92(6), 1709.

Smart, P.R.; Mott, D.; Sycara, K.; Braines, D.; Strub, M.; and Shadbolt, N.R. (2009). Shared understanding within military coalitions: A definition and review of research challenges. Paper presented at Knowledge Systems for Coalition Operations, Southampton, UK, March 31-April 1.

Snow, C. P. 1993. The Two Cultures. New York, NY: Cambridge University Press.

Somech, A., \& Drach-Zahavy, A. (2013). Translating team creativity to innovation implementation: The role of team composition and climate for innovation. Journal of Management, 39(3), 684-708.

Sosik, J. M., Kahai, S. S., \& Avolio, B. J. (1998). Transformational leadership and dimensions of creativity: motivating idea generation in computer mediated groups. Creativity Research Journal, 11, $111-122$.

Stickdorn, M., \& Schneider, J. (2011). This is service design thinking: Basics, tools, cases. London, UK: Wiley. 
Sultan, N. (2015). Reflective thoughts on the potential and challenges of wearable technology for healthcare provision and medical education. International Journal of Information Management, 35(5), 521-526.

Sun, L. \& Lu, S. (2015). The 3D printing era: A conceptual model for the textile and apparel industry. Proceeding from International Textile and Apparel Association Conference, Santa Fe, New Mexico.

Torrance, E. P. 1988. The nature of creativity a s manifest in its testing. In R. J. Steinberg (Ed.), The Nature of Creativity: Contemporary Psychological Views: 43-75. New York, NY: Cambridge University Press.

Tortora, P. G. (2015). Dress, Fashion and Technology: From Prehistory to the Present. Bloomsbury Publishing.

Tsai, W., \& Ghoshal, S. (1998). Social Capital and Value Creation: The Role of Intrafirm Networks. The Academy of Management Journal, 464-476.

Tuominen, T., \& Toivonen, M. (2011). Studying innovation and change activities in KIBS through the lens of innovative behavior. International Journal of Innovation Management, 15(02), 393-422.

Weston, R., \& Gore Jr, P. A. (2006). A brief guide to structural equation modeling. The counseling psychologist, 34(5), 719-751

Van der Vegt, G. S., \& Janssen, O. (2003). Joint Impact of Interdependence and Group Diversity on Innovation. Journal of Management, 29729-751. 
Van de Ven, A. H. 1986. Central problems in the management of innovation. Management Science, 32, 590-607.

van Knippenberg, D., De Dreu, C. K. W., \& Homan, A. C. (2004). Work group diversity and group performance: An integrative model and research agenda. Journal of Applied Psychology, 89(6), 1008-1022.

Visschers-Pleijerrs, A.J.S.F., Dolmans, D. H. J.M, Wolfhagen, I. H. A. P \& Van der Vleuten, C.P.M. (2004). Exploration of a method to analyze group interactions in problem-based learning. Medical Teacher, 26(5), 471-478.

Vreede, G.J., de; Briggs, R.O., and Massey, A.P. (2009). Collaboration engineering: Foundations and opportunities: Editorial to the special issue on the Journal of the Association for Information Systems. Journal of the Association for Information Systems, 10, Special Issue, 121-137.

Wallis, J., Killerby, P., \& Dollery, B. (2003). Social economics and social capital. University of New England, School of Economic Studies.

Wang, X., Kim, T., \& Lee, D. (2016). Cognitive diversity and team creativity: Effects of team intrinsic motivation and transformational leadership. Journal of Business Research, 693231-3239.

Wang, J., \& Wang, X. (2012). Structural equation modeling: Applications using Mplus. John Wiley \& Sons. 
Webb, N. M., \& Palincsar, A. S. (1996). Group processes in the classroom. In D. C. Berliner \& R. C. Calfee (Eds.), Handbook of Educational Psychology. New York: Simon \& Schuster Macmillan.

Weber, M. (1947). Max Weber: The Theory of Social and Economic Organization. New York, NY: Free Press.

Webber, S. S., \& Donahue, L. M. (2001). Impact of highly and less job-related diversity on work group cohesion and performance: A meta-analysis. Journal of management, 27(2), 141162.

Wellman, B. (1999). The network community: An introduction to network in the global village. In Wellman, B. (Ed.) Networks in the Global Village. Boulder, CO: Westview Press.

Wenger, E., (1998) Communities of Practice: Learning, Meaning and Identity. New York: Cambridge University Press.

West, M. A., \& Farr, J. L. (1990). Innovation and Creativity at Work. Oxford, UK: John Wiley.

Williams, K., and O'Reilly, C. 1998. Demography and diversity in organizations: A review of 40 years of research. In B. M. Staw and R. Sutton (Eds.), Research in Organizational Behavior (vol. 21, pp. 77-140). Greenwich, Conn.: JAI Press.

Windeler, J. B., Maruping, L. M., Robert, L. P., \& Riemenschneider, C. K. (2015). E-profiles, Conflict, and Shared Understanding in Distributed Teams. Journal of The Association for Information Systems, 16(7), 608-645. 
Wu, C., \& Wang, Z. (2015). How transformational leadership shapes team proactivity: The mediating role of positive affective tone and the moderating role of team task variety. Group Dynamics: Theory, Research, And Practice, 19(3), 137-151.

Xenikou, A., \& Simosi, M. (2006). Organizational culture and transformational leadership as predictors of business unit performance. Journal of Managerial Psychology, 21 (6), 566 579

Xiang, C., Lu, Y., \& Gupta, S. (2013). Knowledge sharing in information system development teams: examining the impact of shared mental model from a social capital theory perspective. Behaviour \& Information Technology, 32(10), 1024-1040.

Yetisen, A., \& Gibney, E. (2015). Q\&A: The nanomaterials designer. Nature, 526. Weinberg, B. D., Milne, G. R., Andonova, Y. G., \& Hajjat, F. M. (2015). Internet of Things: Convenience vs. privacy and secrecy. Business Horizons, 58(6), 615-624.

Yuan, F. \& Woodman, R. W. (2010). Innovative behavior in the workplace: The role of performance and image outcome. Academy of Management Journal, 53(2), 323.

Zwarenstein, M., \& Bryant, W. (2000). Interventions to promote collaboration between nurses and doctors. The Cochrane Library. 


\section{APPENDIX A.}

Survey Instrument

Questionnaire

\section{Consent to Act as a Human Participant}

Project Title: Innovation in Fashion and Wearable Technology Product Development Team Exempt IRB Application Number: 2008084 Project Director: Deepika Raj and Dr. Jung HaBrookshire

Description and Explanation of Procedures: The purpose of this quantitative research is to examine leadership behaviors of team leaders and collaboration between team members for innovation in the product development phase. Structural equation modeling will be used to find out the antecedents of innovative work behavior. To address this goal, surveys will be conducted which should take less than 10 minutes. Your participation in this research is totally voluntary.

Confidentiality: Data will be saved confidentially. Any electronic files will be saved with numeric codes, with no personal identifiers. Throughout the procedures, if you feel uncomfortable with any questions or experiences, you may stop participation at any time. Finally, only the researcher will have access to the data and the aggregated data will be analyzed and shared for publication. The data will be kept for seven years after the study has been completed.

Risks and Discomforts: It is anticipated that there are NO physical, psychological or sociological risks involved in participating in this study. 
Benefits to Soceity: The results of this study will benefit society and industry by providing the specific knowledge about leadership, team learning, and sense of community that helps innovation in companies. The result will also help in finding out the leadership styles which helps increase collaboration in the homogeneous and heterogeneous team members during the product development phase. The study will also help in examining the ways team members interact in work environment. This knowledge would help in training and educating the employees of the fashion industry for innovation.

Consent: You are free to refuse to participate or to withdraw your consent to participate in this research at any time without penalty or prejudice; your participation is entirely voluntary. Your privacy will be protected because you will not be identified by name or any other type of identifier in the disseminated result of this study. If you have any questions concerning your rights as a participant, you may contact Campus Institutional Review Board at 573-882-9585. If you have any questions regarding the research itself, you may contact me by e-mail at drc4c@mail.missouri.edu or my advisor Dr. Jung Ha-Brookshire at habrookshirej@missouri.edu.

Thank you in advance for your assistance and time. Please keep this consent form with you for future references.

If you agree with the informed consent form and you are above 18 years of age, please click on the next button to fill the survey. 


\section{Part 1: Screening Questions}

Q1. Are you 18 years old or above?
a. Yes
b. No

Q2. Do you work in the United States?
c. Yes
d. No

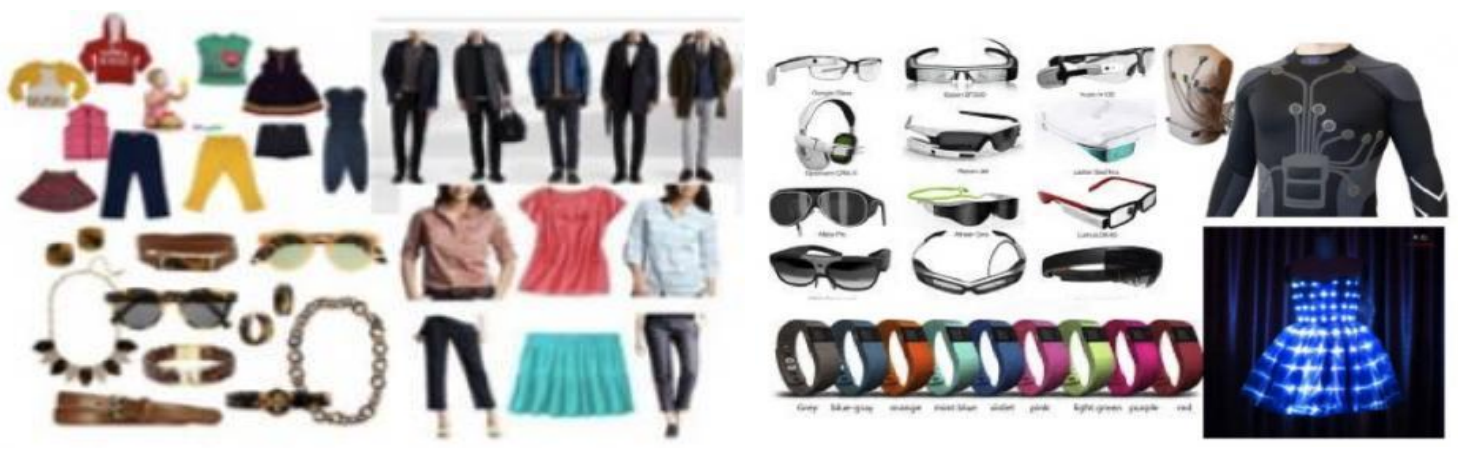

Conventional Fashion Industry's Product

Wearable Technology Industry's Product

Conventional Fashion Industry: Industry that produces apparel or accessories those are worn on the body and do not have any electronic or communication function.

Wearable Technology Industry: Industry that produces those apparel or accessories that are worn on the body and have some electronic or communication functions.

Q3. Considering the above definitions and pictures, which of the following industry do you belong to?

O Conventional Fashion Industry

O Wearable Technology Industry

Do not belong to either of these

Q4. Are you full time employees of either wearable technology or fashion industry?

$\mathrm{O}$ Yes

O No 
Q5. Have you worked for more than a year for either wearable technology or fashion industry?

O Yes

O No

Q6. Is your company located in the United States of America?

O Yes

O No

Product development involves the creation of products with new or different characteristics that offer new or additional benefits to the customer. It might also involve modification of an existing product or its presentation, or formulation of an entirely new product that satisfies a newly defined customer want or market niche.

Q7 Considering the above definition of product development, does your work involve in any areas related to product development?

$\mathrm{O}$ Yes

O No

Q8. What is the broader category of the product your team developed?

O Kid's Wear

O Women's Wear

O Men's Wear

O Active Wear

O Outer Wear

O Denim

O Accessories

O Footwear

O Intimates

O Swim Wear

O Knit Wear

Others

Q9. What is the broader category of the product your team developed?

O Smart Wristband

O Smart HeadGears

O Smart Clothing

O Health Monitoring Devices

Others 
Q10. Explain in a word or two the functions which you perform in your current position. For example, product research, product design, functional design, forecasting, and so on.

Q11. How diverse are your team members in terms of their academic disciplines and professional experience? Is it less diverse as option A or more diverse as Option B?

O Option A

\section{Fashion Designer.}

Fashion Forecaster

Fashion Merchandiser

Consumer Researcher

Pattern Master

Quality Analyst

Textile Expert

Sourcer

Option B

Electronics Engineer"

Gesture Control Expert

Material Science Expert

Health Informatics Expert

Product Designer

Big Data Analyst

App Developer

Coder 
Think about your most recent team experience at your current company and answer all the questions in the coming sections based on the experience you have had or are having in that particular team.

\section{Transformational Leadership Behavior}

Q12. Please rate the leadership behavior of your team leader in terms of how frequently he or she engage in the behavior described below.

\begin{tabular}{|c|c|c|c|c|c|}
\hline & $\begin{array}{c}\mathrm{NeV} \\
\mathrm{er}\end{array}$ & Rarely & $\begin{array}{l}\text { Some } \\
\text { times }\end{array}$ & $\begin{array}{c}\text { Very } \\
\text { Ofte } \\
n\end{array}$ & $\begin{array}{l}\text { Alway } \\
\text { s }\end{array}$ \\
\hline $\begin{array}{l}\text { My team leader communicates a clear and positive } \\
\text { vision of the future. }\end{array}$ & 0 & 0 & 0 & 0 & 0 \\
\hline $\begin{array}{l}\text { My team leader treats staff as individuals, supports } \\
\text { and encourages their development }\end{array}$ & 0 & 0 & 0 & 0 & 0 \\
\hline $\begin{array}{l}\text { My team leader gives encouragement and recognition } \\
\text { to staff }\end{array}$ & 0 & 0 & 0 & 0 & 0 \\
\hline $\begin{array}{l}\text { My team leader fosters trust, involvement and } \\
\text { cooperation among team members. }\end{array}$ & 0 & 0 & 0 & 0 & 0 \\
\hline $\begin{array}{l}\text { My team leader encourages thinking about problems } \\
\text { in new ways and questions assumptions }\end{array}$ & 0 & 0 & 0 & 0 & 0 \\
\hline $\begin{array}{l}\text { My team leader is clear about his/values and practices } \\
\text { which s/he preaches }\end{array}$ & 0 & 0 & 0 & 0 & 0 \\
\hline $\begin{array}{l}\text { My team leader instills pride and respect in others and } \\
\text { inspires me by being highly competent. }\end{array}$ & 0 & 0 & 0 & 0 & 0 \\
\hline
\end{tabular}




\section{Team Learning Behavior}

Q13. Please rate your team member's team learning in terms of how frequently he or she engages in the behavior described below.

\begin{tabular}{|c|c|c|c|c|c|}
\hline & $\begin{array}{l}\text { Strongl } \\
\text { y } \\
\text { Disagre } \\
\text { e }\end{array}$ & $\begin{array}{l}\text { Mostly } \\
\text { Disagre } \\
\quad \mathrm{e}\end{array}$ & $\begin{array}{l}\text { Moderate } \\
\text { ly Agree }\end{array}$ & $\begin{array}{l}\text { Mostl } \\
\text { y } \\
\text { Agre } \\
\text { e }\end{array}$ & $\begin{array}{l}\text { Strong } \\
\text { ly } \\
\text { Agree }\end{array}$ \\
\hline $\begin{array}{l}\text { My team members listens carefully to each } \\
\text { other. }\end{array}$ & 0 & 0 & 0 & 0 & 0 \\
\hline $\begin{array}{l}\text { If something is unclear, we ask questions to } \\
\text { each other. }\end{array}$ & 0 & 0 & 0 & 0 & 0 \\
\hline $\begin{array}{l}\text { In my team, my team members share all } \\
\text { relevant information and ideas that we have. }\end{array}$ & 0 & 0 & 0 & 0 & 0 \\
\hline $\begin{array}{l}\text { My team members elaborate on each other's } \\
\text { information and ideas. }\end{array}$ & 0 & 0 & 0 & 0 & 0 \\
\hline $\begin{array}{l}\text { Information from team members is } \\
\text { complemented with information from other } \\
\text { team members in our team. }\end{array}$ & 0 & 0 & 0 & 0 & 0 \\
\hline $\begin{array}{l}\text { My team members draw conclusions from } \\
\text { the ideas that are discussed in the team. }\end{array}$ & 0 & 0 & 0 & 0 & 0 \\
\hline $\begin{array}{l}\text { My team tends to handle differences of } \\
\text { opinions by addressing them directly. }\end{array}$ & 0 & 0 & 0 & 0 & 0 \\
\hline $\begin{array}{l}\text { Comments on ideas are acted upon within } \\
\text { my team. }\end{array}$ & 0 & 0 & 0 & 0 & 0 \\
\hline $\begin{array}{l}\text { Opinions and ideas of team members are } \\
\text { verified by asking each other critical } \\
\text { questions. }\end{array}$ & 0 & 0 & 0 & 0 & 0 \\
\hline
\end{tabular}




\section{Sense of Community}

Q14. Please rate your sense of community feeling towards your team based on the statements described below.

\begin{tabular}{|c|c|c|c|c|c|}
\hline & $\begin{array}{l}\text { Strongly } \\
\text { Disagree }\end{array}$ & $\begin{array}{l}\text { Mostly } \\
\text { Disagree }\end{array}$ & $\begin{array}{l}\text { Moderately } \\
\text { Agree }\end{array}$ & $\begin{array}{l}\text { Mostly } \\
\text { Agree }\end{array}$ & $\begin{array}{l}\text { Strongly } \\
\text { Agree }\end{array}$ \\
\hline $\begin{array}{l}\text { My team members get important needs } \\
\text { of theirs met because they are part of a } \\
\text { team }\end{array}$ & 0 & 0 & 0 & 0 & 0 \\
\hline $\begin{array}{l}\text { My team has been successful in getting } \\
\text { the needs of its members met. }\end{array}$ & 0 & 0 & O & O & 0 \\
\hline $\begin{array}{l}\text { Being a member of this team makes my } \\
\text { team members feel good. }\end{array}$ & $\bigcirc$ & $\bigcirc$ & O & O & 0 \\
\hline $\begin{array}{l}\text { When my team members have a } \\
\text { problem, they talk about it with the } \\
\text { members of our team. }\end{array}$ & O & $\bigcirc$ & O & O & 0 \\
\hline $\begin{array}{l}\text { People in my team have similar needs, } \\
\text { priorities, and goals. }\end{array}$ & O & O & O & O & O \\
\hline $\begin{array}{l}\text { My team members trust other people in } \\
\text { our team. }\end{array}$ & 0 & O & O & O & O \\
\hline $\begin{array}{l}\text { My team members can recognize most } \\
\text { of the members of our team }\end{array}$ & 0 & $\mathrm{O}$ & O & O & O \\
\hline Most team members know me. & $\mathrm{O}$ & $\mathrm{O}$ & $\bigcirc$ & O & O \\
\hline $\begin{array}{l}\text { My team members put a lot of time and } \\
\text { effort into being part of our team. }\end{array}$ & O & 0 & ○ & 0 & 0 \\
\hline $\begin{array}{l}\text { Being a member of our team is a part of } \\
\text { the identity of team members. }\end{array}$ & 0 & 0 & 0 & 0 & 0 \\
\hline $\begin{array}{l}\text { Fitting into my team is important to my } \\
\text { team members. }\end{array}$ & 0 & O & 0 & O & 0 \\
\hline My team can influence other teams. & O & $\mathrm{O}$ & O & O & O \\
\hline $\begin{array}{l}\text { My team members care about what } \\
\text { other members of our team think of } \\
\text { them. }\end{array}$ & O & O & O & O & O \\
\hline $\begin{array}{l}\text { My team members have an influence } \\
\text { over what our team is like. }\end{array}$ & 0 & $\mathrm{O}$ & O & O & O \\
\hline $\begin{array}{l}\text { If there is a problem in my team, we can } \\
\text { get it solved. }\end{array}$ & 0 & $\mathrm{O}$ & 0 & O & O \\
\hline My team has good leaders. & O & O & O & O & O \\
\hline $\begin{array}{l}\text { It is very important to my team } \\
\text { members to be a part of our team. }\end{array}$ & 0 & $\mathrm{O}$ & O & 0 & O \\
\hline
\end{tabular}




\begin{tabular}{|c|c|c|c|c|c|}
\hline $\begin{array}{l}\text { My team members get together very } \\
\text { frequently and enjoy each other's } \\
\text { company. }\end{array}$ & 0 & 0 & 0 & 0 & 0 \\
\hline $\begin{array}{l}\text { My team members expect to be a part of } \\
\text { our team for a long time. }\end{array}$ & 0 & 0 & 0 & 0 & 0 \\
\hline $\begin{array}{l}\text { Members of my team have shared } \\
\text { important events together, celebrations } \\
\text { as well as disasters. }\end{array}$ & 0 & 0 & 0 & 0 & 0 \\
\hline $\begin{array}{l}\text { My team members feel hopeful about } \\
\text { the future of our team }\end{array}$ & 0 & 0 & 0 & 0 & 0 \\
\hline $\begin{array}{l}\text { Members of my team care about each } \\
\text { other. }\end{array}$ & 0 & 0 & 0 & 0 & 0 \\
\hline
\end{tabular}

\section{Innovative Work Behavior}


Q15. Please rate your team's innovative behavior based on the statements below

\begin{tabular}{|c|c|c|c|c|c|}
\hline & Never & Rarely & Sometimes & $\begin{array}{l}\text { Very } \\
\text { Often }\end{array}$ & Always \\
\hline $\begin{array}{l}\text { As a team, we create new ideas for } \\
\text { improvements. }\end{array}$ & 0 & 0 & 0 & 0 & 0 \\
\hline $\begin{array}{l}\text { As a team, we search out new working } \\
\text { methods, techniques, or instruments. }\end{array}$ & 0 & 0 & 0 & 0 & 0 \\
\hline $\begin{array}{l}\text { As a team, we generate original solutions } \\
\text { to problems. }\end{array}$ & 0 & 0 & 0 & 0 & 0 \\
\hline $\begin{array}{l}\text { As a team, we mobilize support for } \\
\text { innovative ideas. }\end{array}$ & 0 & 0 & 0 & 0 & 0 \\
\hline $\begin{array}{l}\text { As a team, we acquire approval for } \\
\text { innovative ideas. }\end{array}$ & 0 & 0 & 0 & 0 & 0 \\
\hline $\begin{array}{l}\text { As a team, we make important } \\
\text { organizational members enthusiastic for } \\
\text { innovative ideas. }\end{array}$ & 0 & 0 & 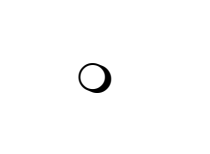 & 0 & 0 \\
\hline $\begin{array}{l}\text { As a team, we transform innovative ideas } \\
\text { into useful applications }\end{array}$ & 0 & 0 & 0 & 0 & 0 \\
\hline $\begin{array}{l}\text { As a team, we introduce innovative ideas } \\
\text { into the work environment in a } \\
\text { systematic way. }\end{array}$ & 0 & 0 & 0 & 0 & 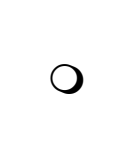 \\
\hline $\begin{array}{l}\text { As a team, we evaluate the utility of } \\
\text { innovate ideas. }\end{array}$ & 0 & 0 & 0 & 0 & 0 \\
\hline
\end{tabular}

\section{General Information}


Q16. What is the product your team develops in your current company?

Q 17. Highest degree attained (check one):

O Less than High School Level

O High School Degree

O Associate Degree

O Bachelors Degree

O Masters Degree

O Doctoral Degree

O Post-Doc

O Other

Q18. To which discipline do you associate with?

O Design

O Hardware Science and Engineering

O Software Science and Engineering

O Informatics

O Health Sciences

Others

Q19. Which of the following closely matches your job level?

O Entry Level

O Middle Management

O Senior Management

O Executive Level

O Other

Q20. Where is you current company located?

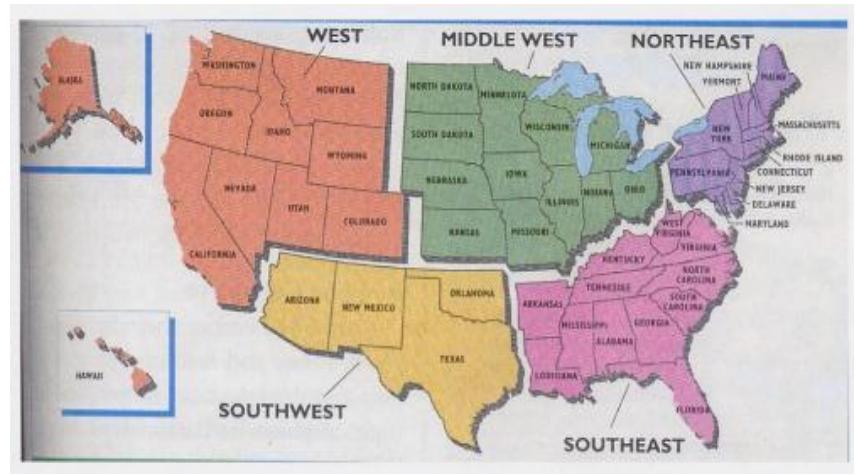

O West

O Mid-West

O North East 
South West

O South East

Q21. How many members are/were there in your product development team?

Less than or equal to 5

More than 5 and less than or equal to 10

more than 10 and less than or equal to 15

More than 15 and less than or equal to 20

More than 20 and less than or equal to 25

more than 25 and less than or equal to 30

more than 30 and less than or equal to 50

O more than 50

Q22. What is your firm's or division's annual gross sales figure in USD (\$)? (Please CHECK only ONE response)

Less than 1 million

More than 1 million and less than 5 million

O More than 5 million and less than 25 million

O More than 25 million and less than 50 million

O More than 50 million and less than 100 million

O More than 100 million and less than 500 million

over 500 million

Do not know

Q23 In what year was the company you work for founded?

Q24. How would you rate the innovation performance of your company in the last three years? Please point the slider to the appropriate number on a scale of 1 to 100 with 0 being unsuccessful and 100 being highly successful.

Successful Innovation

\section{Demographics}

Q 25. What is your age?

Q 26. What is your gender or to which gender you associate with?
O Male
F Female
Other 
Q 27. Please specify your ethnicity.

O White

O Hispanic or Latino

O Black or African American

O Native American or American Indian

O Asian / Pacific Islander

O Other

The researcher would be happy to share with you a detailed executive summary of the aggregate results of the study, including relevant and applicable information that may help you with practical business problems, at no cost. If you wish to receive a copy of the study results, please provide your name and detailed address in the space below.

a Name

口 Email 


\section{APPENDIX B.}

March 16, 2017

\section{Study's Institutional Review Board Approval}

Principal Investigator: Deepika Raj

Your Exempt Application to project entitled Innovation in Fashion and Wearable Technology Product Development Team was reviewed and approved by the MU Institutional Review Board according tothe terms and conditions described below:

IRB Project Number 2008084

IRB Review Number 224648

Funding Source Center for the Digital Globe

Initial Application Approval Date March 16, 2017

IRB Expiration Date March 16, 2018

Level of Review Exempt

Project Status Active - Open to Enrollment

Exempt Categories 45 CFR 46.101b(2)

Risk Level Minimal Risk

Internal Funding Internal Grant (ex. Research council, etc)

The principal investigator (PI) is responsible for all aspects and conduct of this study. The PI must comply with the following conditions of the approval:

1. No subjects may be involved in any study procedure prior to the IRB approval date or after the expiration date.

2. All unanticipated problems and deviations must be reported to the IRB within 5 business days. 3. All changes must be IRB approved prior to implementation unless they are intended to reduce immediate risk.

4. All recruitment materials and methods must be approved by the IRB prior to being used.

5. The Annual Exempt Form must be submitted to the IRB for review and approval at least 30 days prior to the project expiration date. If the study is complete, the Completion/Withdrawal Form may be submitted in lieu of the Annual Exempt Form

6. Maintain all research records for a period of seven years from the project completion date.

7. Utilize all approved research documents located within the attached files section of eCompliance. These documents are highlighted green.

If you are offering subject payments and would like more information about research participant payments, please click here to view the MU Business Policy and Procedure:

http://bppm.missouri.edu/chapter2/2_250.html

If you have any questions, please contact the IRB at 573-882-3181 or irb@missouri.edu.

Thank you,

MU Institutional Review Board 


\section{APPENDIX C.}

\section{Mplus Outputs}

SEM Result for WT Group from Mplus (Step 1a for multi group analysis)

INPUT READING TERMINATED NORMALLY

WT group

SUMMARY OF ANALYSIS

Number of groups

1

Number of observations

125

Number of dependent variables

Number of independent variables

Number of continuous latent variables

Observed dependent variables

Estimator

Information matrix

Maximum number of iterations

Convergence criterion

Maximum number of steepest descent iterations

ML

OBSERVED

1000

$0.500 \mathrm{D}-04$

Input data file(s)

WT.dat

Input data format FREE

THE MODEL ESTIMATION TERMINATED NORMALLY

\section{MODEL FIT INFORMATION}

Number of Free Parameters

134

Loglikelihood

$\begin{array}{ll}\text { H0 Value } & -4951.935 \\ \text { H1 Value } & -4175.511\end{array}$

Information Criteria 
Akaike (AIC) $\quad 10171.870$

Bayesian (BIC) $\quad 10550.864$

Sample-Size Adjusted BIC 10127.132

$(\mathrm{n} *=(\mathrm{n}+2) / 24)$

Chi-Square Test of Model Fit

Value

1552.848

Degrees of Freedom

855

P-Value

0.0000

RMSEA (Root Mean Square Error Of Approximation)

$\begin{array}{lr}\text { Estimate } & 0.081 \\ \text { 90 Percent C.I. } & 0.0740 .087\end{array}$

Probability RMSEA $<=.05 \quad 0.000$

CFI/TLI

CFI $\quad 0.809$

TLI $\quad 0.799$

Chi-Square Test of Model Fit for the Baseline Model

$\begin{array}{lr}\text { Value } & 4564.710 \\ \text { Degrees of Freedom } & 903 \\ \text { P-Value } & 0.0000\end{array}$

SRMR (Standardized Root Mean Square Residual)

Value $\quad 0.060$ 
MODEL RESULTS

Two-Tailed

Estimate S.E. Est./S.E. P-Value

TL BY

$\begin{array}{lllll}\text { TL1 } & 1.000 & 0.000 & 999.000 & 999.000 \\ \text { TL2 } & 1.352 & 0.209 & 6.480 & 0.000 \\ \text { TL3 } & 1.512 & 0.220 & 6.863 & 0.000 \\ \text { TL4 } & 1.166 & 0.186 & 6.268 & 0.000 \\ \text { TL5 } & 1.449 & 0.214 & 6.766 & 0.000 \\ \text { TL6 } & 1.282 & 0.193 & 6.661 & 0.000 \\ \text { TL7 } & 1.473 & 0.212 & 6.938 & 0.000\end{array}$

TLB BY

$\begin{array}{lllll}\text { CON1 } & 1.000 & 0.000 & 999.000 & 999.000 \\ \text { CON2 } & 0.875 & 0.135 & 6.490 & 0.000 \\ \text { CON3 } & 1.183 & 0.152 & 7.805 & 0.000 \\ \text { COC1 } & 1.270 & 0.160 & 7.933 & 0.000 \\ \text { COC2 } & 0.931 & 0.131 & 7.113 & 0.000 \\ \text { COC3 } & 1.139 & 0.154 & 7.412 & 0.000 \\ \text { COF1 } & 1.100 & 0.148 & 7.452 & 0.000 \\ \text { COF2 } & 1.179 & 0.147 & 7.997 & 0.000 \\ \text { COF3 } & 1.343 & 0.163 & 8.225 & 0.000\end{array}$

SOC BY

$\begin{array}{lcccc}\text { RON1 } & 1.000 & 0.000 & 999.000 & 999.000 \\ \text { RON3 } & 0.985 & 0.111 & 8.881 & 0.000 \\ \text { RON5 } & 0.880 & 0.108 & 8.186 & 0.000 \\ \text { SEC1 } & 0.942 & 0.105 & 8.973 & 0.000 \\ \text { SEC2 } & 0.996 & 0.129 & 7.697 & 0.000 \\ \text { SEC3 } & 0.901 & 0.110 & 8.179 & 0.000\end{array}$




$\begin{array}{lcccc}\text { SEC4 } & 0.929 & 0.123 & 7.548 & 0.000 \\ \text { SEC5 } & 0.880 & 0.104 & 8.452 & 0.000 \\ \text { SEC6 } & 0.921 & 0.105 & 8.790 & 0.000 \\ \text { MEM1 } & 0.857 & 0.104 & 8.199 & 0.000 \\ \text { MEM3 } & 0.746 & 0.102 & 7.329 & 0.000 \\ \text { MEM4 } & 0.917 & 0.101 & 9.070 & 0.000 \\ \text { IN1 } & 0.950 & 0.114 & 8.347 & 0.000 \\ \text { IN2 } & 0.826 & 0.115 & 7.207 & 0.000 \\ \text { IN3 } & 0.922 & 0.114 & 8.110 & 0.000 \\ \text { IN4 } & 0.793 & 0.096 & 8.291 & 0.000 \\ \text { IN5 } & 0.830 & 0.110 & 7.578 & 0.000 \\ \text { IN6 } & 0.852 & 0.100 & 8.510 & 0.000\end{array}$

$\begin{array}{ccccc}\text { INNO } & \text { BY } & & & \\ \text { IG1 } & 1.000 & 0.000 & 999.000 & 999.000 \\ \text { IG2 } & 1.094 & 0.142 & 7.711 & 0.000 \\ \text { IG3 } & 0.997 & 0.162 & 6.155 & 0.000 \\ \text { IP1 } & 1.355 & 0.173 & 7.833 & 0.000 \\ \text { IP2 } & 1.097 & 0.151 & 7.284 & 0.000 \\ \text { IP3 } & 1.051 & 0.141 & 7.437 & 0.000 \\ \text { IR1 } & 1.005 & 0.139 & 7.220 & 0.000 \\ \text { IR2 } & 1.008 & 0.135 & 7.461 & 0.000 \\ \text { IR3 } & 1.096 & 0.143 & 7.638 & 0.000\end{array}$

$\begin{array}{cccccc}\text { TLB } & \text { ON } & & & & \\ \text { TL } & & -0.004 & 0.084 & -0.045 & 0.964 \\ \text { SOC } & & 0.776 & 0.110 & 7.037 & 0.000 \\ & & & & & \\ \text { INNO } & \text { ON } & & & & \\ \text { TLB } & & 0.477 & 0.090 & 5.328 & 0.000 \\ \text { TL } & & 0.625 & 0.118 & 5.317 & 0.000\end{array}$




\begin{tabular}{|c|c|c|c|c|}
\hline SOC ON & & & & \\
\hline $\mathrm{TL}$ & 1.030 & 0.179 & 5.746 & 0.000 \\
\hline Intercepts & & & & \\
\hline TL1 & 4.256 & 0.064 & 66.600 & 0.000 \\
\hline TL2 & 4.200 & 0.076 & 55.340 & 0.000 \\
\hline TL3 & 4.112 & 0.079 & 52.342 & 0.000 \\
\hline TL4 & 4.216 & 0.069 & 60.785 & 0.000 \\
\hline TL5 & 4.200 & 0.077 & 54.735 & 0.000 \\
\hline TL6 & 4.208 & 0.070 & 60.103 & 0.000 \\
\hline TL7 & 4.296 & 0.074 & 57.890 & 0.000 \\
\hline CON1 & 4.144 & 0.069 & 60.459 & 0.000 \\
\hline CON2 & 4.328 & 0.067 & 64.870 & 0.000 \\
\hline CON3 & 4.280 & 0.074 & 57.961 & 0.000 \\
\hline $\mathrm{COC} 1$ & 4.264 & 0.078 & 54.891 & 0.000 \\
\hline COC2 & 4.304 & 0.064 & 67.016 & 0.000 \\
\hline COC3 & 4.176 & 0.075 & 55.605 & 0.000 \\
\hline $\mathrm{COF} 1$ & 4.136 & 0.072 & 57.555 & 0.000 \\
\hline COF2 & 4.272 & 0.071 & 60.174 & 0.000 \\
\hline COF3 & 4.168 & 0.079 & 52.771 & 0.000 \\
\hline RON1 & 4.168 & 0.076 & 55.080 & 0.000 \\
\hline RON3 & 4.232 & 0.075 & 56.305 & 0.000 \\
\hline RON5 & 4.200 & 0.072 & 57.977 & 0.000 \\
\hline MEM1 & 4.248 & 0.070 & 60.391 & 0.000 \\
\hline MEM3 & 4.472 & 0.067 & 66.270 & 0.000 \\
\hline MEM4 & 4.240 & 0.069 & 61.281 & 0.000 \\
\hline IN1 & 4.224 & 0.077 & 55.129 & 0.000 \\
\hline IN2 & 4.128 & 0.076 & 54.406 & 0.000 \\
\hline IN3 & 4.192 & 0.076 & 54.812 & 0.000 \\
\hline IN4 & 4.304 & 0.064 & 67.016 & 0.000 \\
\hline IN5 & 4.320 & 0.073 & 59.201 & 0.000 \\
\hline IN6 & 4.392 & 0.068 & 64.794 & 0.000 \\
\hline
\end{tabular}




$\begin{array}{lcccc}\text { SEC1 } & 4.344 & 0.072 & 60.630 & 0.000 \\ \text { SEC2 } & 4.088 & 0.086 & 47.439 & 0.000 \\ \text { SEC3 } & 4.232 & 0.074 & 56.953 & 0.000 \\ \text { SEC4 } & 4.120 & 0.082 & 50.211 & 0.000 \\ \text { SEC5 } & 4.328 & 0.070 & 61.433 & 0.000 \\ \text { SEC6 } & 4.256 & 0.071 & 59.551 & 0.000 \\ \text { IG1 } & 4.240 & 0.063 & 66.880 & 0.000 \\ \text { IG2 } & 4.152 & 0.067 & 61.983 & 0.000 \\ \text { IG3 } & 4.192 & 0.076 & 54.812 & 0.000 \\ \text { IP1 } & 4.208 & 0.081 & 51.931 & 0.000 \\ \text { IP2 } & 4.232 & 0.072 & 59.044 & 0.000 \\ \text { IP3 } & 4.264 & 0.067 & 63.575 & 0.000 \\ \text { IR1 } & 4.240 & 0.066 & 63.897 & 0.000 \\ \text { IR2 } & 4.216 & 0.065 & 65.282 & 0.000 \\ \text { IR3 } & 4.296 & 0.068 & 63.265 & 0.000\end{array}$

Variances

$\begin{array}{lllll}\text { TL } & 0.195 & 0.053 & 3.683 & 0.000\end{array}$

Residual Variances

$\begin{array}{lllll}\text { TL1 } & 0.315 & 0.043 & 7.391 & 0.000 \\ \text { TL2 } & 0.363 & 0.051 & 7.080 & 0.000 \\ \text { TL3 } & 0.325 & 0.048 & 6.804 & 0.000 \\ \text { TL4 } & 0.336 & 0.046 & 7.273 & 0.000 \\ \text { TL5 } & 0.326 & 0.048 & 6.867 & 0.000 \\ \text { TL6 } & 0.292 & 0.042 & 7.025 & 0.000 \\ \text { TL7 } & 0.265 & 0.040 & 6.624 & 0.000 \\ \text { CON1 } & 0.314 & 0.042 & 7.500 & 0.000 \\ \text { CON2 } & 0.347 & 0.046 & 7.605 & 0.000 \\ \text { CON3 } & 0.299 & 0.041 & 7.309 & 0.000 \\ \text { COC1 } & 0.314 & 0.044 & 7.156 & 0.000 \\ \text { COC2 } & 0.278 & 0.037 & 7.491 & 0.000\end{array}$




$\begin{array}{lcccc}\text { COC3 } & 0.350 & 0.047 & 7.442 & 0.000 \\ \text { COF1 } & 0.315 & 0.043 & 7.403 & 0.000 \\ \text { COF2 } & 0.250 & 0.035 & 7.202 & 0.000 \\ \text { COF3 } & 0.287 & 0.040 & 7.111 & 0.000 \\ \text { RON1 } & 0.303 & 0.041 & 7.440 & 0.000 \\ \text { RON3 } & 0.305 & 0.041 & 7.439 & 0.000 \\ \text { RON5 } & 0.336 & 0.044 & 7.580 & 0.000 \\ \text { MEM1 } & 0.315 & 0.042 & 7.580 & 0.000 \\ \text { MEM3 } & 0.339 & 0.044 & 7.671 & 0.000 \\ \text { MEM4 } & 0.251 & 0.034 & 7.437 & 0.000 \\ \text { IN1 } & 0.361 & 0.048 & 7.523 & 0.000 \\ \text { IN2 } & 0.438 & 0.057 & 7.671 & 0.000 \\ \text { IN3 } & 0.380 & 0.050 & 7.595 & 0.000 \\ \text { IN4 } & 0.256 & 0.034 & 7.557 & 0.000 \\ \text { IN5 } & 0.381 & 0.050 & 7.646 & 0.000 \\ \text { IN6 } & 0.274 & 0.036 & 7.533 & 0.000 \\ \text { SEC1 } & 0.276 & 0.037 & 7.460 & 0.000 \\ \text { SEC2 } & 0.518 & 0.068 & 7.622 & 0.000 \\ \text { SEC3 } & 0.355 & 0.047 & 7.580 & 0.000 \\ \text { SEC4 } & 0.485 & 0.063 & 7.647 & 0.000 \\ \text { SEC5 } & 0.301 & 0.040 & 7.534 & 0.000 \\ \text { SEC6 } & 0.288 & 0.038 & 7.487 & 0.000 \\ \text { IG1 } & 0.256 & 0.035 & 7.423 & 0.000 \\ \text { IG2 } & 0.266 & 0.036 & 7.337 & 0.000 \\ \text { IG3 } & 0.486 & 0.064 & 7.633 & 0.000 \\ \text { IP1 } & 0.369 & 0.051 & 7.234 & 0.000 \\ \text { IP2 } & 0.346 & 0.046 & 7.437 & 0.000 \\ \text { IP3 } & 0.290 & 0.039 & 7.425 & 0.000 \\ \text { IR } & 0.302 & 0.040 & 7.487 & 0.000 \\ \text { IN } & 0.271 & 0.036 & 7.441 & 0.000 \\ \text { IN } 30.281 & 0.038 & 7.289 & 0.000 \\ \text { IN } 3 & 0.010 & 2.669 & 0.008\end{array}$




$\begin{array}{lcccc}\text { SOC } & 0.206 & 0.045 & 4.583 & 0.000 \\ \text { INNO } & 0.015 & 0.008 & 1.885 & 0.059\end{array}$

SEM result for Scalar Invariance from Mplus (Step 4)

Number of groups

Number of observations

Group WT

Group FASHION

Total sample size

Number of dependent variables

Number of independent variables

Number of continuous latent variables

Variables with special functions

Grouping variable DIS
Estimator

Information matrix

Maximum number of iterations

Convergence criterion

Maximum number of steepest descent iterations
2

125

150

275

$$
\begin{array}{r}
\text { OBSERVED } \\
1000 \\
0.500 \mathrm{D}-04
\end{array}
$$

Input data file(s)

finalfull.dat

Input data format FREE 
THE MODEL ESTIMATION TERMINATED NORMALLY

MODEL FIT INFORMATION

Number of Free Parameters

147

Loglikelihood

$\begin{array}{ll}\text { H0 Value } & -11505.063 \\ \text { H1 Value } & -9941.882\end{array}$

Information Criteria

$\begin{array}{lc}\text { Akaike (AIC) } & 23304.126 \\ \text { Bayesian (BIC) } & 23835.792 \\ \text { Sample-Size Adjusted BIC } & 23369.683 \\ \left(\mathrm{n}^{*}=(\mathrm{n}+2) / 24\right) & \end{array}$

Chi-Square Test of Model Fit

$\begin{array}{lc}\text { Value } & 3126.362 \\ \text { Degrees of Freedom } & 1831 \\ \text { P-Value } & 0.0000\end{array}$

Chi-Square Contribution From Each Group

WT 1648.070

FASHION $\quad 1478.292$ 
RMSEA (Root Mean Square Error Of Approximation)

$\begin{array}{lrr}\text { Estimate } & 0.072 & \\ \text { 90 Percent C.I. } & 0.067 & 0.076 \\ \text { Probability RMSEA }<=.05 & 0.000\end{array}$

CFI/TLI

CFI $\quad 0.839$

TLI $\quad 0.841$

Chi-Square Test of Model Fit for the Baseline Model

$\begin{array}{lc}\text { Value } & 9833.155 \\ \text { Degrees of Freedom } & 1806 \\ \text { P-Value } & 0.0000\end{array}$

SRMR (Standardized Root Mean Square Residual)

Value $\quad 0.081$

MODEL RESULTS

Two-Tailed

Estimate S.E. Est./S.E. P-Value

\section{Group WT}

TL BY

$\begin{array}{lllll}\text { TL1 } & 1.000 & 0.000 & 999.000 & 999.000\end{array}$ 


$\begin{array}{lllll}\text { TL2 } & 1.360 & 0.119 & 11.398 & 0.000 \\ \text { TL3 } & 1.303 & 0.117 & 11.117 & 0.000 \\ \text { TL4 } & 1.119 & 0.106 & 10.545 & 0.000 \\ \text { TL5 } & 1.300 & 0.121 & 10.702 & 0.000 \\ \text { TL6 } & 1.311 & 0.116 & 11.325 & 0.000 \\ \text { TL7 } & 1.339 & 0.116 & 11.554 & 0.000\end{array}$

$\begin{array}{lllll}\text { TLB BY } & & & & \\ \text { CON1 } & 1.000 & 0.000 & 999.000 & 999.000 \\ \text { CON2 } & 0.824 & 0.081 & 10.186 & 0.000 \\ \text { CON3 } & 1.011 & 0.081 & 12.514 & 0.000 \\ \text { COC1 } & 1.020 & 0.083 & 12.276 & 0.000 \\ \text { COC2 } & 0.860 & 0.075 & 11.502 & 0.000 \\ \text { COC3 } & 1.043 & 0.086 & 12.069 & 0.000 \\ \text { COF1 } & 0.963 & 0.078 & 12.356 & 0.000 \\ \text { COF2 } & 0.995 & 0.079 & 12.622 & 0.000 \\ \text { COF3 } & 1.003 & 0.079 & 12.705 & 0.000\end{array}$

$\begin{array}{lcccc}\text { SOC BY } & & & & \\ \text { RON1 } & 1.000 & 0.000 & 999.000 & 999.000 \\ \text { RON3 } & 0.976 & 0.077 & 12.754 & 0.000 \\ \text { RON5 } & 0.915 & 0.078 & 11.735 & 0.000 \\ \text { SEC1 } & 0.977 & 0.077 & 12.621 & 0.000 \\ \text { SEC2 } & 1.037 & 0.090 & 11.491 & 0.000 \\ \text { SEC3 } & 0.992 & 0.081 & 12.216 & 0.000 \\ \text { SEC4 } & 0.947 & 0.084 & 11.321 & 0.000 \\ \text { SEC5 } & 1.010 & 0.078 & 13.030 & 0.000 \\ \text { SEC6 } & 0.977 & 0.076 & 12.793 & 0.000 \\ \text { MEM1 } & 0.952 & 0.078 & 12.262 & 0.000 \\ \text { MEM3 } & 0.666 & 0.071 & 9.323 & 0.000 \\ \text { MEM4 } & 0.977 & 0.076 & 12.878 & 0.000 \\ \text { IN1 } & 0.933 & 0.078 & 11.988 & 0.000\end{array}$




$\begin{array}{lllll}\text { IN2 } & 0.902 & 0.082 & 10.966 & 0.000 \\ \text { IN3 } & 0.809 & 0.079 & 10.179 & 0.000 \\ \text { IN4 } & 0.879 & 0.073 & 12.046 & 0.000 \\ \text { IN5 } & 0.914 & 0.078 & 11.769 & 0.000 \\ \text { IN6 } & 0.918 & 0.076 & 12.128 & 0.000\end{array}$

\begin{tabular}{|c|c|c|c|c|}
\hline INNO & BY & & & \\
\hline IG1 & 1.000 & 0.000 & 999.000 & 999.000 \\
\hline IG2 & 1.075 & 0.084 & 12.793 & 0.000 \\
\hline IG3 & 0.877 & 0.085 & 10.289 & 0.000 \\
\hline IP1 & 1.151 & 0.093 & 12.428 & 0.000 \\
\hline IP2 & 0.953 & 0.088 & 10.821 & 0.000 \\
\hline IP3 & 1.030 & 0.085 & 12.090 & 0.000 \\
\hline IR1 & 1.052 & 0.082 & 12.766 & 0.000 \\
\hline IR2 & 1.121 & 0.085 & 13.115 & 0.000 \\
\hline IR3 & 0.963 & 0.082 & 11.760 & 0.000 \\
\hline
\end{tabular}

$\begin{array}{lrrrr}\text { TLB } & \text { ON } & & & \\ \text { TL } & -0.016 & 0.093 & -0.168 & 0.867 \\ \text { SOC } & 0.952 & 0.102 & 9.324 & 0.000\end{array}$

INNO ON

$\begin{array}{lllll}\text { TLB } & 0.431 & 0.067 & 6.450 & 0.000\end{array}$

$\begin{array}{lllll}\text { TL } & 0.612 & 0.092 & 6.649 & 0.000\end{array}$

SOC ON

$\begin{array}{lllll}\text { TL } & 0.932 & 0.128 & 7.263 & 0.000\end{array}$

Means

$\begin{array}{lllll}\text { TL } & 0.000 & 0.000 & 999.000 & 999.000\end{array}$

Intercepts 


\begin{tabular}{|c|c|c|c|c|}
\hline TL1 & 4.198 & 0.056 & 75.234 & 0.000 \\
\hline TL2 & 4.198 & 0.068 & 61.668 & 0.000 \\
\hline TL3 & 4.196 & 0.066 & 63.365 & 0.000 \\
\hline TL4 & 4.254 & 0.059 & 71.840 & 0.000 \\
\hline TL5 & 4.178 & 0.068 & 61.569 & 0.000 \\
\hline TL6 & 4.175 & 0.066 & 63.064 & 0.000 \\
\hline TL7 & 4.281 & 0.066 & 64.893 & 0.000 \\
\hline CON1 & 4.126 & 0.066 & 62.130 & 0.000 \\
\hline CON2 & 4.294 & 0.062 & 69.042 & 0.000 \\
\hline CON3 & 4.280 & 0.066 & 64.369 & 0.000 \\
\hline $\mathrm{COC} 1$ & 4.233 & 0.068 & 62.246 & 0.000 \\
\hline $\mathrm{COC} 2$ & 4.280 & 0.060 & 71.730 & 0.000 \\
\hline $\mathrm{COC} 3$ & 4.127 & 0.070 & 58.888 & 0.000 \\
\hline COF1 & 4.161 & 0.064 & 65.343 & 0.000 \\
\hline $\mathrm{COF} 2$ & 4.274 & 0.065 & 65.950 & 0.000 \\
\hline COF3 & 4.260 & 0.065 & 65.292 & 0.000 \\
\hline RON1 & 4.166 & 0.067 & 61.970 & 0.000 \\
\hline RON3 & 4.255 & 0.064 & 66.417 & 0.000 \\
\hline RON5 & 4.133 & 0.063 & 65.463 & 0.000 \\
\hline MEM1 & 4.227 & 0.064 & 66.149 & 0.000 \\
\hline MEM3 & 4.521 & 0.054 & 83.460 & 0.000 \\
\hline MEM4 & 4.276 & 0.064 & 67.195 & 0.000 \\
\hline IN1 & 4.244 & 0.064 & 66.714 & 0.000 \\
\hline IN2 & 4.187 & 0.065 & 64.225 & 0.000 \\
\hline IN3 & 4.180 & 0.062 & 67.776 & 0.000 \\
\hline IN4 & 4.269 & 0.060 & 71.432 & 0.000 \\
\hline IN5 & 4.301 & 0.063 & 68.288 & 0.000 \\
\hline IN6 & 4.359 & 0.062 & 70.111 & 0.000 \\
\hline SEC1 & 4.287 & 0.064 & 66.492 & 0.000 \\
\hline SEC2 & 4.121 & 0.073 & 56.723 & 0.000 \\
\hline SEC3 & 4.227 & 0.067 & 63.327 & 0.000 \\
\hline SEC4 & 4.190 & 0.067 & 62.627 & 0.000 \\
\hline
\end{tabular}




$\begin{array}{lcccc}\text { SEC5 } & 4.290 & 0.065 & 65.581 & 0.000 \\ \text { SEC6 } & 4.302 & 0.064 & 67.384 & 0.000 \\ \text { IG1 } & 4.259 & 0.057 & 75.301 & 0.000 \\ \text { IG2 } & 4.184 & 0.061 & 68.694 & 0.000 \\ \text { IG3 } & 4.234 & 0.057 & 74.119 & 0.000 \\ \text { IP1 } & 4.241 & 0.066 & 64.174 & 0.000 \\ \text { IP2 } & 4.225 & 0.060 & 70.612 & 0.000 \\ \text { IP3 } & 4.208 & 0.060 & 69.782 & 0.000 \\ \text { IR1 } & 4.244 & 0.060 & 71.175 & 0.000 \\ \text { IR2 } & 4.154 & 0.062 & 66.556 & 0.000 \\ \text { IR3 } & 4.309 & 0.057 & 75.126 & 0.000 \\ \text { TLB } & 0.000 & 0.000 & 999.000 & 999.000 \\ \text { SOC } & 0.000 & 0.000 & 999.000 & 999.000 \\ \text { INNO } & 0.000 & 0.000 & 999.000 & 999.000\end{array}$

Variances

$\begin{array}{lllll}\text { TL } & 0.218 & 0.043 & 5.073 & 0.000\end{array}$

Residual Variances

$\begin{array}{lllll}\text { TL1 } & 0.337 & 0.031 & 10.852 & 0.000 \\ \text { TL2 } & 0.318 & 0.032 & 10.008 & 0.000 \\ \text { TL3 } & 0.330 & 0.032 & 10.196 & 0.000 \\ \text { TL4 } & 0.317 & 0.030 & 10.584 & 0.000 \\ \text { TL5 } & 0.391 & 0.037 & 10.448 & 0.000 \\ \text { TL6 } & 0.315 & 0.031 & 10.115 & 0.000 \\ \text { TL7 } & 0.270 & 0.027 & 9.818 & 0.000 \\ \text { CON1 } & 0.357 & 0.033 & 10.839 & 0.000 \\ \text { CON2 } & 0.475 & 0.042 & 11.261 & 0.000 \\ \text { CON3 } & 0.343 & 0.032 & 10.792 & 0.000 \\ \text { COC1 } & 0.381 & 0.035 & 10.837 & 0.000 \\ \text { COC2 } & 0.344 & 0.031 & 11.048 & 0.000 \\ \text { COC3 } & 0.418 & 0.039 & 10.832 & 0.000\end{array}$




$\begin{array}{lcccc}\text { COF1 } & 0.324 & 0.030 & 10.786 & 0.000 \\ \text { COF2 } & 0.311 & 0.029 & 10.696 & 0.000 \\ \text { COF3 } & 0.316 & 0.029 & 10.706 & 0.000 \\ \text { RON1 } & 0.387 & 0.035 & 11.156 & 0.000 \\ \text { RON3 } & 0.315 & 0.028 & 11.050 & 0.000 \\ \text { RON5 } & 0.379 & 0.034 & 11.244 & 0.000 \\ \text { MEM1 } & 0.347 & 0.031 & 11.154 & 0.000 \\ \text { MEM3 } & 0.424 & 0.037 & 11.493 & 0.000 \\ \text { MEM4 } & 0.298 & 0.027 & 11.016 & 0.000 \\ \text { IN1 } & 0.368 & 0.033 & 11.184 & 0.000 \\ \text { IN2 } & 0.470 & 0.041 & 11.337 & 0.000 \\ \text { IN3 } & 0.483 & 0.042 & 11.429 & 0.000 \\ \text { IN4 } & 0.320 & 0.029 & 11.188 & 0.000 \\ \text { IN5 } & 0.374 & 0.033 & 11.239 & 0.000 \\ \text { IN6 } & 0.341 & 0.031 & 11.179 & 0.000 \\ \text { SEC1 } & 0.326 & 0.029 & 11.072 & 0.000 \\ \text { SEC2 } & 0.531 & 0.047 & 11.278 & 0.000 \\ \text { SEC3 } & 0.383 & 0.034 & 11.159 & 0.000 \\ \text { SEC4 } & 0.463 & 0.041 & 11.302 & 0.000 \\ \text { SEC5 } & 0.304 & 0.028 & 10.996 & 0.000 \\ \text { SEC6 } & 0.305 & 0.028 & 11.035 & 0.000 \\ \text { IG1 } & 0.250 & 0.023 & 10.655 & 0.000 \\ \text { IG2 } & 0.293 & 0.028 & 10.619 & 0.000 \\ \text { IG3 } & 0.404 & 0.036 & 11.219 & 0.000 \\ \text { IP1 } & 0.365 & 0.034 & 10.722 & 0.000 \\ \text { IP2 } & 0.404 & 0.036 & 11.076 & 0.000 \\ \text { IP3 } & 0.327 & 0.030 & 10.824 & 0.000 \\ \text { IR1 } & 0.279 & 0.026 & 10.663 & 0.000 \\ \text { IR2 } & 0.278 & 0.027 & 10.464 & 0.000 \\ \text { IR3 } & 0.317 & 0.029 & 10.882 & 0.000 \\ \text { ILC } & 0.028 & 0.011 & 2.412 & 0.016 \\ \text { Re } 3 & 0.036 & 5.123 & 0.000\end{array}$


$\begin{array}{lllll}\text { INNO } & 0.015 & 0.008 & 1.788 & 0.074\end{array}$

\section{Group FASHION}

TL BY

$\begin{array}{lllll}\text { TL1 } & 1.000 & 0.000 & 999.000 & 999.000\end{array}$

$\begin{array}{lllll}\text { TL2 } & 1.360 & 0.119 & 11.398 & 0.000\end{array}$

$\begin{array}{lllll}\text { TL3 } & 1.303 & 0.117 & 11.117 & 0.000\end{array}$

$\begin{array}{lllll}\text { TL4 } & 1.119 & 0.106 & 10.545 & 0.000\end{array}$

$\begin{array}{lllll}\text { TL5 } & 1.300 & 0.121 & 10.702 & 0.000\end{array}$

$\begin{array}{lllll}\text { TL6 } & 1.311 & 0.116 & 11.325 & 0.000\end{array}$

$\begin{array}{lllll}\text { TL7 } & 1.339 & 0.116 & 11.554 & 0.000\end{array}$

TLB BY

$\begin{array}{lllll}\text { CON1 } & 1.000 & 0.000 & 999.000 & 999.000 \\ \text { CON2 } & 0.824 & 0.081 & 10.186 & 0.000 \\ \text { CON3 } & 1.011 & 0.081 & 12.514 & 0.000 \\ \text { COC1 } & 1.020 & 0.083 & 12.276 & 0.000 \\ \text { COC2 } & 0.860 & 0.075 & 11.502 & 0.000 \\ \text { COC3 } & 1.043 & 0.086 & 12.069 & 0.000 \\ \text { COF1 } & 0.963 & 0.078 & 12.356 & 0.000 \\ \text { COF2 } & 0.995 & 0.079 & 12.622 & 0.000 \\ \text { COF3 } & 1.003 & 0.079 & 12.705 & 0.000\end{array}$

SOC BY

$\begin{array}{lcccc}\text { RON1 } & 1.000 & 0.000 & 999.000 & 999.000 \\ \text { RON3 } & 0.976 & 0.077 & 12.754 & 0.000 \\ \text { RON5 } & 0.915 & 0.078 & 11.735 & 0.000 \\ \text { SEC1 } & 0.977 & 0.077 & 12.621 & 0.000 \\ \text { SEC2 } & 1.037 & 0.090 & 11.491 & 0.000 \\ \text { SEC3 } & 0.992 & 0.081 & 12.216 & 0.000 \\ \text { SEC4 } & 0.947 & 0.084 & 11.321 & 0.000\end{array}$




$\begin{array}{lcccc}\text { SEC5 } & 1.010 & 0.078 & 13.030 & 0.000 \\ \text { SEC6 } & 0.977 & 0.076 & 12.793 & 0.000 \\ \text { MEM1 } & 0.952 & 0.078 & 12.262 & 0.000 \\ \text { MEM3 } & 0.666 & 0.071 & 9.323 & 0.000 \\ \text { MEM4 } & 0.977 & 0.076 & 12.878 & 0.000 \\ \text { IN1 } & 0.933 & 0.078 & 11.988 & 0.000 \\ \text { IN2 } & 0.902 & 0.082 & 10.966 & 0.000 \\ \text { IN3 } & 0.809 & 0.079 & 10.179 & 0.000 \\ \text { IN4 } & 0.879 & 0.073 & 12.046 & 0.000 \\ \text { IN5 } & 0.914 & 0.078 & 11.769 & 0.000 \\ \text { IN6 } & 0.918 & 0.076 & 12.128 & 0.000\end{array}$

\begin{tabular}{|c|c|c|c|c|}
\hline INNO & $\mathrm{BY}$ & & & \\
\hline IG1 & 1.000 & 0.000 & 999.000 & 999.000 \\
\hline IG2 & 1.075 & 0.084 & 12.793 & 0.000 \\
\hline IG3 & 0.877 & 0.085 & 10.289 & 0.000 \\
\hline IP1 & 1.151 & 0.093 & 12.428 & 0.000 \\
\hline IP2 & 0.953 & 0.088 & 10.821 & 0.000 \\
\hline IP3 & 1.030 & 0.085 & 12.090 & 0.000 \\
\hline IR1 & 1.052 & 0.082 & 12.766 & 0.000 \\
\hline IR2 & 1.121 & 0.085 & 13.115 & 0.000 \\
\hline IR3 & 0.963 & 0.082 & 11.760 & 0.000 \\
\hline
\end{tabular}

$\begin{array}{cccccc}\text { TLB } & \text { ON } & & & & \\ \text { TL } & & 0.093 & 0.090 & 1.028 & 0.304 \\ \text { SOC } & & 0.834 & 0.096 & 8.688 & 0.000 \\ & & & & & \\ \text { INNO } & \text { ON } & & & & \\ \text { TLB } & & 0.527 & 0.088 & 5.991 & 0.000 \\ \text { TL } & & 0.294 & 0.100 & 2.937 & 0.003\end{array}$

SOC ON 

TL
0.946
0.116
8.169
0.000

Means

TL

$\begin{array}{llll}-0.076 & 0.065 & -1.170 & 0.242\end{array}$

Intercepts

$\begin{array}{lcccc}\text { TL1 } & 4.198 & 0.056 & 75.234 & 0.000 \\ \text { TL2 } & 4.198 & 0.068 & 61.668 & 0.000 \\ \text { TL3 } & 4.196 & 0.066 & 63.365 & 0.000 \\ \text { TL4 } & 4.254 & 0.059 & 71.840 & 0.000 \\ \text { TL5 } & 4.178 & 0.068 & 61.569 & 0.000 \\ \text { TL6 } & 4.175 & 0.066 & 63.064 & 0.000 \\ \text { TL7 } & 4.281 & 0.066 & 64.893 & 0.000 \\ \text { CON1 } & 4.126 & 0.066 & 62.130 & 0.000 \\ \text { CON2 } & 4.294 & 0.062 & 69.042 & 0.000 \\ \text { CON3 } & 4.280 & 0.066 & 64.369 & 0.000 \\ \text { COC1 } & 4.233 & 0.068 & 62.246 & 0.000 \\ \text { COC2 } & 4.280 & 0.060 & 71.730 & 0.000 \\ \text { COC3 } & 4.127 & 0.070 & 58.888 & 0.000 \\ \text { COF1 } & 4.161 & 0.064 & 65.343 & 0.000 \\ \text { COF2 } & 4.274 & 0.065 & 65.950 & 0.000 \\ \text { COF3 } & 4.260 & 0.065 & 65.292 & 0.000 \\ \text { RON1 } & 4.166 & 0.067 & 61.970 & 0.000 \\ \text { RON3 } & 4.255 & 0.064 & 66.417 & 0.000 \\ \text { RON5 } & 4.133 & 0.063 & 65.463 & 0.000 \\ \text { MEM1 } & 4.227 & 0.064 & 66.149 & 0.000 \\ \text { MEM3 } & 4.521 & 0.054 & 83.460 & 0.000 \\ \text { MEM4 } & 4.276 & 0.064 & 67.195 & 0.000 \\ \text { IN1 } & 4.244 & 0.064 & 66.714 & 0.000 \\ \text { IN2 } & 4.187 & 0.065 & 64.225 & 0.000 \\ \text { IN3 } & 4.180 & 0.062 & 67.776 & 0.000 \\ \text { IN4 } & 4.269 & 0.060 & 71.432 & 0.000\end{array}$




$\begin{array}{lcccc}\text { IN5 } & 4.301 & 0.063 & 68.288 & 0.000 \\ \text { IN6 } & 4.359 & 0.062 & 70.111 & 0.000 \\ \text { SEC1 } & 4.287 & 0.064 & 66.492 & 0.000 \\ \text { SEC2 } & 4.121 & 0.073 & 56.723 & 0.000 \\ \text { SEC3 } & 4.227 & 0.067 & 63.327 & 0.000 \\ \text { SEC4 } & 4.190 & 0.067 & 62.627 & 0.000 \\ \text { SEC5 } & 4.290 & 0.065 & 65.581 & 0.000 \\ \text { SEC6 } & 4.302 & 0.064 & 67.384 & 0.000 \\ \text { IG1 } & 4.259 & 0.057 & 75.301 & 0.000 \\ \text { IG2 } & 4.184 & 0.061 & 68.694 & 0.000 \\ \text { IG3 } & 4.234 & 0.057 & 74.119 & 0.000 \\ \text { IP1 } & 4.241 & 0.066 & 64.174 & 0.000 \\ \text { IP2 } & 4.225 & 0.060 & 70.612 & 0.000 \\ \text { IP3 } & 4.208 & 0.060 & 69.782 & 0.000 \\ \text { IR1 } & 4.244 & 0.060 & 71.175 & 0.000 \\ \text { IR2 } & 4.154 & 0.062 & 66.556 & 0.000 \\ \text { IR3 } & 4.309 & 0.057 & 75.126 & 0.000 \\ \text { TLB } & -0.083 & 0.040 & -2.065 & 0.039 \\ \text { SOC } & -0.071 & 0.061 & -1.171 & 0.241 \\ \text { INNO } & -0.082 & 0.043 & -1.918 & 0.055\end{array}$

Variances

$\begin{array}{lllll}\text { TL } & 0.306 & 0.057 & 5.362 & 0.000\end{array}$

Residual Variances

$\begin{array}{lllll}\text { TL1 } & 0.337 & 0.031 & 10.852 & 0.000 \\ \text { TL2 } & 0.318 & 0.032 & 10.008 & 0.000 \\ \text { TL3 } & 0.330 & 0.032 & 10.196 & 0.000 \\ \text { TL4 } & 0.317 & 0.030 & 10.584 & 0.000 \\ \text { TL5 } & 0.391 & 0.037 & 10.448 & 0.000 \\ \text { TL6 } & 0.315 & 0.031 & 10.115 & 0.000 \\ \text { TL7 } & 0.270 & 0.027 & 9.818 & 0.000\end{array}$




\begin{tabular}{|c|c|c|c|c|}
\hline CON1 & 0.357 & 0.033 & 10.839 & 0.000 \\
\hline CON2 & 0.475 & 0.042 & 11.261 & 0.000 \\
\hline CON3 & 0.343 & 0.032 & 10.792 & 0.000 \\
\hline $\mathrm{COC} 1$ & 0.381 & 0.035 & 10.837 & 0.000 \\
\hline $\mathrm{COC} 2$ & 0.344 & 0.031 & 11.048 & 0.000 \\
\hline COC3 & 0.418 & 0.039 & 10.832 & 0.000 \\
\hline $\mathrm{COF} 1$ & 0.324 & 0.030 & 10.786 & 0.000 \\
\hline $\mathrm{COF} 2$ & 0.311 & 0.029 & 10.696 & 0.000 \\
\hline $\mathrm{COF} 3$ & 0.316 & 0.029 & 10.706 & 0.000 \\
\hline RON1 & 0.387 & 0.035 & 11.156 & 0.000 \\
\hline RON3 & 0.315 & 0.028 & 11.050 & 0.000 \\
\hline RON5 & 0.379 & 0.034 & 11.244 & 0.000 \\
\hline MEM1 & 0.347 & 0.031 & 11.154 & 0.000 \\
\hline MEM3 & 0.424 & 0.037 & 11.493 & 0.000 \\
\hline MEM4 & 0.298 & 0.027 & 11.016 & 0.000 \\
\hline IN1 & 0.368 & 0.033 & 11.184 & 0.000 \\
\hline IN2 & 0.470 & 0.041 & 11.337 & 0.000 \\
\hline IN3 & 0.483 & 0.042 & 11.429 & 0.000 \\
\hline IN4 & 0.320 & 0.029 & 11.188 & 0.000 \\
\hline IN5 & 0.374 & 0.033 & 11.239 & 0.000 \\
\hline IN6 & 0.341 & 0.031 & 11.179 & 0.000 \\
\hline SEC1 & 0.326 & 0.029 & 11.072 & 0.000 \\
\hline SEC2 & 0.531 & 0.047 & 11.278 & 0.000 \\
\hline SEC3 & 0.383 & 0.034 & 11.159 & 0.000 \\
\hline SEC4 & 0.463 & 0.041 & 11.302 & 0.000 \\
\hline SEC5 & 0.304 & 0.028 & 10.996 & 0.000 \\
\hline SEC6 & 0.305 & 0.028 & 11.035 & 0.000 \\
\hline IG1 & 0.250 & 0.023 & 10.655 & 0.000 \\
\hline IG2 & 0.293 & 0.028 & 10.619 & 0.000 \\
\hline IG3 & 0.404 & 0.036 & 11.219 & 0.000 \\
\hline IP1 & 0.365 & 0.034 & 10.722 & 0.000 \\
\hline IP2 & 0.404 & 0.036 & 11.076 & 0.000 \\
\hline
\end{tabular}




$\begin{array}{lcccc}\text { IP3 } & 0.327 & 0.030 & 10.824 & 0.000 \\ \text { IR1 } & 0.279 & 0.026 & 10.663 & 0.000 \\ \text { IR2 } & 0.278 & 0.027 & 10.464 & 0.000 \\ \text { IR3 } & 0.317 & 0.029 & 10.882 & 0.000 \\ \text { TLB } & 0.070 & 0.016 & 4.269 & 0.000 \\ \text { SOC } & 0.216 & 0.039 & 5.554 & 0.000 \\ \text { INNO } & 0.113 & 0.022 & 5.207 & 0.000\end{array}$




\section{Vita}

Deepika Raj was born in the Silk City of India, Bhagalpur, Bihar. She attended primary and secondary education through Mount Assisi School, Bhagalpur. She then pursued her undergraduate education at National Institute of Fashion Technology, Kolkata. Her undergraduate degree was in apparel product development and information technology. After her undergraduate she worked as a Quality Analyst at Shahi Exports, Faridabad. Working in high pace fashion manufacturing industry made her interested in conducting industry based research. To accomplish this, she joined the master's program at Illinois State University and $\mathrm{PhD}$ program at University of Missouri. During her time at Mizzou, she presented the findings of nine research projects in various international conferences and published two research papers in international journals. She also got prestigious Lectra Innovation research award at the International Textile and Apparel Association conference held at Santa Fe, New Mexico. She served as a Lab Kit Coordinator and Vice-President for Graduate Student Association of Textile and Apparel Management. Her research was featured in Science daily, and in more than seven news outlets. She has accepted the position of User Experience Researcher for Microsoft products through Steyer Content, a consulting company. 